BNL-43813

Informal Report

\title{
STUDIES ON ELECTRICAL CABLE INSULATION \\ FOR NUCLEAR APPLICATIONS
}

\author{
B.S. LEE \\ P. BLACKBURN* \\ P. SOO \\ D.R. MACKENZIE
}

DECEMBER 1989

INFORMAL REPORT

DEPARTMENT OF NUCLEAR ENERGY

BROOKHAVEN NATIONAL LABORATORY

ASSOCIATED UNIVERSITIES, INC. UPTON, LONG ISLAND, NEW YORK 11973

Under Contract No. DE-ACO2-76CH00016 with the UNITED STATES DEPARTMENT OF ENERGY

*Science Teacher at Beloit Jr.-Sr. High School, Beloit, KS. 


\section{DISCLAIMER}

This report was prepared as an account of work sponsored by an agency of the United States Government. Neither the United States Government nor any agency thereof, nor any of their employees, not any of their contractors, subcontractors, or their employees, makes any warranty, express or implied, or assumes any legal liability or responsibility for the accuracy, completeness, or usefulness of any information, apparatus, product, or process disclosed, or represents that its use would not infringe privately owned rights. Reference herein to any specific commercial product, process, or service by trade name, trademark, manufacturer, or otherwise, does not necessarily constitute or imply its endorsement, recommendation, or favoring by the United States Government or any agency, contractor, or subcontractor thereof. The views and opinions of authors expressed herein do not necessarily state or reflect those of the United States Government or any agency, contractor or subcontractor thereof.

Printed in the United States of America Available from

National Technical Information Service

U.S. Department of Commerce

5285 Port Royal Road

Springfield, VA 22161

NTIS price codes:

Printed Copy: A06; Microfiche Copy: A01 


\section{ABSTRACT}

Two new polyethylene cable insulations have been formulated for nuclear applications, and have been tested under gamma radiation. Both insulations are based on low density polyethylene, one with $\mathrm{PbO}$ and the other with $\mathrm{Sb}_{2} \mathrm{O}_{3}$ as additives. The test results show that the concept of using inorganic antioxidants to retard radiation initiated oxidation is viable, and $\mathrm{PbO}$ is more effective than $\mathrm{Sb}_{2} \mathrm{O}_{3}$ in slowing down radiation initiated oxidation (RIO). Also, radiation degradation data for polyethylene and polyvinyl chloride at $60^{\circ} \mathrm{C}$ have been generated, which will be used to understand radiation initiated oxidation process on these materials combined with the $25^{\circ} \mathrm{C}$ data that will be generated in the future. 
ABSTRACT................................

CONTENTS. ...................

LIST OF FIGURES ..................... . . . . . vii

LIST OF TABLES. ......................... Xi

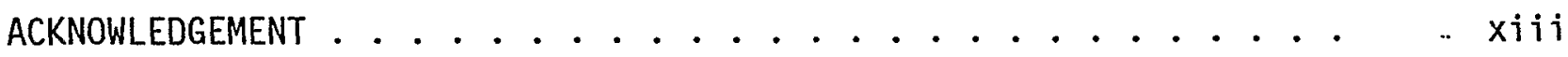

1. INTRODUCTION. ..................... 1

2. CURRENT UNDERSTANDING OF RIO. ................. 3

3. GAMMA IRRADIATION FACILITY AT BNL ................ 7

4. RIO STUDY ON PE AND PVC AT ELEVATED TEMPERATURES. . . . . . . 9

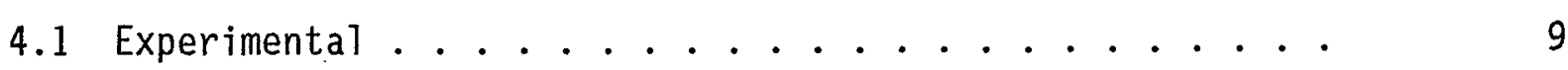

4.1.1 Sample Preparation ............. . . . 9

4.1.2 Description of the Heater. ......... 9

4.1 .3 Irradiation. . . . . . . . . . . . . . 9

4.1.4 Mechanical Testing ............ 9

4.2 Results and Discussion............... 11

4.3 Summary and Recommendations. . . . . . . . . . . 11

5. DEVELOPMENT OF A RADIATION RESISTANT POLYMER INSULATION . . . . 13

5.1 Development Strategy ............... 13

5.2 Choice of Polymer. ................ 13

5.3 Choice of Additives. ............... 15

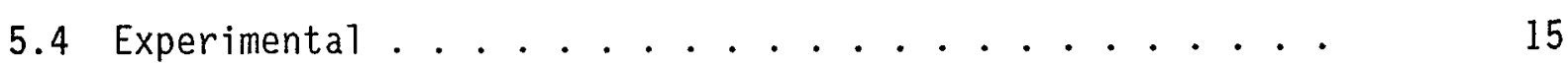

5.4.1 Sample Preparation................. 15

5.4.2 Mechanical Testing ............. 15 
CONTENTS (CONT.)

PAGE

5.5 Results....................... 15

5.6 Discussion ........................... 16

5.6.1 The Effects of Additives.......... 16

5.6.2 Dose Rate Effects. . . . . . . . . . . 49

5.7 Conclusions and Recommendations. . . ......... 49

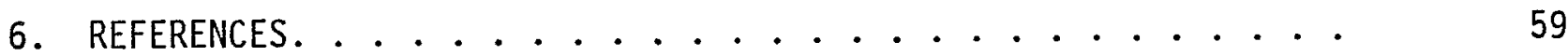

APPENDIX..................... A-1 


\section{LIST OF FIGURES}

PAGE

Figure 4.1 Samples used for RI0 study at $60^{\circ} \mathrm{C}$.

Left: CLPE, right: PVC. .......... 10

Figure 4.2 Elongation for CLPE and PVC as a function of

total dose..............

Figure 5.1 Standard sample used for radiation resistant

polymer insulation development study . . . . . .

Figure 5.2 Elongation as a function of total dose for

samples $A$ and $Z$. Dose rate: $1.1 \times 10^{6} \mathrm{rad} /$ hour. .

Figure 5.3 Elongation as a function of total dose for samples $B$ and $Z$. Dose rate: $1.1 \times 10^{6} \mathrm{rad} /$ hour. .

Figure 5.4 Elongation as a function of total dose for samples $C$ and $Z$. Dose rate: $1.1 \times 10^{6} \mathrm{rad} /$ hour. .

Figure 5.5 Elongation as a function of total dose for samples $D$ and $Z$. Dose rate: $1.1 \times 10^{6} \mathrm{rad} /$ hour. . .

Figure 5.6 Elongation as a function of total dose for samples $E$ and $Z$. Dose rate: $1.1 \times 10^{6} \mathrm{rad} /$ hour. . .

Figure 5.7 Elongation as a function of total dose for samples $F$ and $Z$. Dose rate: $1.1 \times 10^{6} \mathrm{rad} /$ hour. . .

Figure 5.8 Elongation as a function of total dose for samples $A$ and $Z$. Dose rate: $6.26 \times 10^{5} \mathrm{rad} / \mathrm{hour}$.

Figure 5.9 Elongation as a function of total dose for samples $B$ and $Z$. Dose rate: $6.26 \times 10^{5} \mathrm{rad} /$ hour. .

Figure 5.10 Elongation as a function of total dose for samples $C$ and $Z$. Dose rate: $6.26 \times 10^{5} \mathrm{rad} / \mathrm{hour}$. .

Figure 5.11 Elongation as a function of total dose for samples $D$ and $Z$. Dose rate: $6.26 \times 10^{5} \mathrm{rad} / \mathrm{hour}$.

Figure 5.12 Elongation as a function of total dose for samples $E$ and $Z$. Dose rate: $6.26 \times 10^{5} \mathrm{rad} /$ hour . .

Figure 5.13 Elongation as a function of total dose for samples $F$ and $Z$. Dose rate: $6.26 \times 10^{5} \mathrm{rad} /$ hour . .

Figure 5.14 Elongation as a function of total dose for samples $A$ and $Z$. Dose rate: $3.31 \times 10^{5} \mathrm{rad} / \mathrm{hour}$. 


\section{LIST OF FIGURES (CONT.)}

PAGE

Figure 5.15 Elongation as a function of total dose for

samples $B$ and $Z$. Dose rate: $3.31 \times 10^{5} \mathrm{rad} /$ hour . .

Figure 5.16 Elongation as a function of total dose for samples $C$ and $Z$. Dose rate: $3.31 \times 10^{5} \mathrm{rad} / \mathrm{hour}$.

Figure 5.17 Elongation as a function of total dose for samples $D$ and $Z$. Dose rate: $3.31 \times 10^{5} \mathrm{rad} / \mathrm{hour}$. .

Figure 5.18 Elongation as a function of total dose for samples $E$ and $Z$. Dose rate: $3.31 \times 10^{5} \mathrm{rad} /$ hour. .

Figure 5.19 Elongation as a function of total dose for samples $F$ and $Z$. Dose rate: $3.31 \times 10^{5} \mathrm{rad} /$ hour . .

Figure 5.20 Effects of Pb0 concentration on elongation. Dose rate: $1.1 \times 10^{6} \mathrm{rad} / \mathrm{hour}$.........

Figure 5.21 Effects of Pbo concentration on elongation. Dose rate: $6.26 \times 10^{5} \mathrm{rad} /$ hour. ........

Figure 5.22 Effects of Pbo concentration on elongation. Dose rate: $3.31 \times 10^{5} \mathrm{rad} /$ hour. ........

Figure 5.23 Effects of $\mathrm{Sb}_{2} \mathrm{O}_{3}$ concentration on elongation. Dose rate: $1^{2} .1^{3} \times 10^{6} \mathrm{rad} /$ hour .........

Figure 5.24 Effects of $\mathrm{Sb}_{2} \mathrm{O}_{3}$ concentration on elongation. Dose rate: $6.26 \times 10^{5} \mathrm{rad} /$ hour. . . . . . . .

Figure 5.25 Effects of $\mathrm{Sb}_{2} \mathrm{O}_{3}$ concentration on elongation.

Dose rate: $3.3^{3} \times 10^{5} \mathrm{rad} /$ hour. .........

Figure 5.26 Elongation for unirradiated samples with different additive concentrations. . . . . . . .

Figure 5.27 Normalized elongation for samples $Z, A, C$, and $E$ irradiated at a dose rate of $1.1 \times 10^{6} \mathrm{rad} / \mathrm{hour}$. . .

Figure 5.28 Normalized elongation for samples $Z, A, C$, and $E$ irradiated at a dose rate of $6.26 \times 10^{5} \mathrm{rad} / \mathrm{hour}$. .

Figure 5.29 Normalized elongation for samples $Z, A, C$, and $E$ irradiated at a dose rate of $3.31 \times 10^{5} \mathrm{rad} / \mathrm{hour}$. .

Figure 5.30 Normalized elongation for samples $Z, B, D$, and $F$ irradiated at a dose rate of $1.1 \times 10^{6} \mathrm{rad} / \mathrm{hour}$. . 


\section{LIST OF FIGURES (CONT.)}

PAGE

Figure 5.31 Normalized elongation for samples $Z, B, D$, and $F$ irradiated at a dose rate of $6.26 \times 10^{5} \mathrm{rad} / \mathrm{hour}$.

Figure 5.32 Normalized elongation for samples $Z, B, D$, and $F$ irradiated at a dose rate of $3.31 \times 10^{5} \mathrm{rad} / \mathrm{hour}$. .

Figure 5.33 Effects of different dose rates on elongation of sample Z...............

Figure 5.34 Effects of different dose rates on elongation of sample A. . . . . . . . . . . . .

Figure 5.35 Effects of different dose rates on elongation of sample B. ...............

Figure 5.36 Effects of different dose rates on elongation of sample C..............

Figure 5.37 Effects of different dose rates on elongation of sample D. ...............

Figure 5.38 Effects of different dose rates on elongation of sample E. . . . . . . . . . . . .

Figure 5.39 Effects of different dose rates on elongation of sample F. .............. 


\section{LIST OF TABLES}

PAGE

Table 2.1 Classification of Polymers According to Their Predominant Degradation Mode When Irradiated Under Inert Atmosphere Conditions . . . . . .

Table 5.1 Comparison of the Dose Required to Reduce the Elongation at Break to $50 \%$ of Original, Under Low Dose Rate Condition in Air vs. High Dose Rate (or Inert Atm.) Conditions ........

Table 5.2 Compositions of Test Samples. . . . . . . 


\section{ACKNOWLEDGEMENTS}

The authors gratefully acknowledge the BNL Director's office for the funding that made this study possible. The authors also thank Mr. Daniel Masakowsky of Rockbestos Company for making polyethylene plates used for this study. Finally, Ms. A. Lopez is acknowledged for her patience and skills in the preparation of this report. 


\section{INTRODUCTION}

The first comprehensive study of gamma radiation damage to insulation and jackets for electrical cables in nuclear reactor systems was conducted by Blodgett [B1odgett, 1969] two decades ago. In this study, thirteen different kinds of polymer were evaluated up to a total dose of $5 \times 10^{3}$ rads at a dose rate of $5 \times 10^{5} \mathrm{rads} / \mathrm{h}$. It was estimated that the total radiation dose absorbed by a cable within the containment area may approach $5 \times 10^{7}$ rads during an assumed reactor lifetime of 40 years if there were no abnormal bursts of energy. One of the conclusions drawn from this study was that CSPE (chlorosulfonated polyethylene) or CPE (chlorinated polyethylene) jacketed insulation based on nonfilled CLPE (cross-linked polyethylene) or carbon filled CLPE should last at least 40 years when exposed to a total radiation dose up to $5 \times 10^{7}$ rads and would sti11 be serviceable after exposure up to $10^{8}$ rads.

However, in November 1976 an inspection of a pump suction valve in the Savannah River K-reactor at Aiken, South Carolina, revealed badly embrittled polyethylene (PE) insulation on the power control wiring. The maximum dose experienced by the cable materials was only $2.5 \times 10^{6}$ rads during the 12 years of operating life. The subsequent check of other cables in the C- and Preactors disclosed more embrittled cables [Clough, 1982]. It was surprising to find this faster-than-expected degradation of the cables, so Clough and Gillen [Clough, 1982] conducted an extensive investigation of cable.degradation by radiation.

The most important finding from the study of Clough and Gillen was that when oxygen exists in the environment, dose rate is another important parameter to consider in addition to total dose in the polymer degradation processes. It. was also shown that strong synergisms of radiation and elevated temperature, as we11 as dose rate, led to unexpectedly rapid degradation of the Savannah River reactor cables.

These findings can be explained by the effects of diffusion of oxygen into the cable materials during service (see next section for detailed discussion). Thus, the degradation process for the cable insulation and jacket under radiation can be termed radiation initiated oxidation (RIO).

More studies have since been conducted to understand the mechanisms for RIO and to find means to control the degradation processes. Sti11, current knowledge on this subject is not enough to accurately predict the service lifetime for the cables for a given environment.

The objectives of the current study are to:

1. develop a polymer insulation material with prolonged service 1 ifetime,

2. develop lifetime prediction procedures for the cables, by studying mechanisms for RIO. 
- To accomplish the above objectives, this study was conducted in two parts, which are described below:

PART 1. RIO Study on Polyethylene and Polyvinylchloride at Elevated Temperatures

To help understand RIO process on polyethylene (PE) and polyvinylchioride (PVC), samples were irradiated at a moderate dose rate $\left(6.2 \times 10^{5} \mathrm{rad} / \mathrm{h}\right)$ at $60^{\circ} \mathrm{C}$. This work is a joint study between BNL and Ontario Hydro of Canada; Ontario Hydro is responsible for experiments at $25^{\circ} \mathrm{C}$. The results from the two studies will be combined and compared, and a better understanding of RIO processes on PE and PVC is expected as a result of this study.

PART 2. Development of Radiation Resistant Cable Insulation

In this study, new polymer insulation will be formulated and tested. The data and experience from this study will be used for future cable insulation development.

2 


\section{CURRENT UNDERSTANDING OF RIO}

The two most important reactions induced by high energy radiation are main chain scission and crosslinking, which are schematically described below:

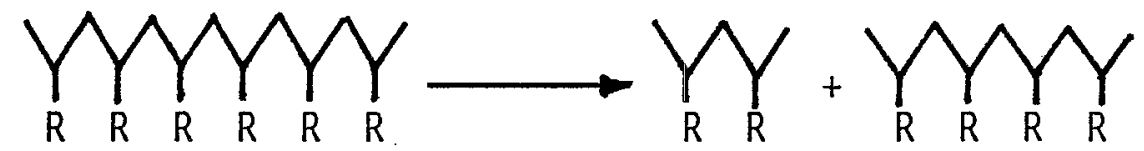

Main chain scission [Schnabe1, 1981]

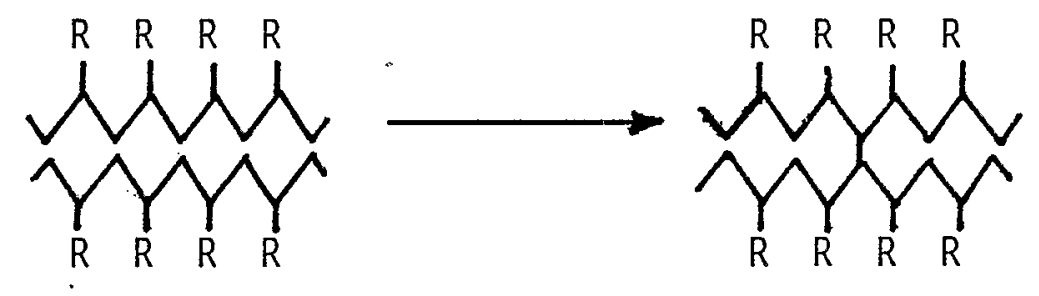

Crosslinking [Schnabe1, 1981]

Polymers typically undergo simultaneous scission and crosslinking, but in most cases with one or the other clearly predominating [Clough, 1988]. Polyethylene and polyvinylchloride predominantly undergo crosslinking when irradiated in the absence of oxygen as shown in Table 2.1 [Clough, 1988]. It is believed that crosslinking is also the major degradation process after the dissolved oxygen in the polymer is used up in the case of high dose rate radiation. For many polymers, radiation induced oxidation strongly favors chain scission. Very frequently, materials, which predominantly crosslink when irradiated under inert conditions, undergo predominantly scission under oxidizing conditions: Also, for many materials, the presence of oxygen strongly enhances the extent of degradation; this can apply when oxygen is present during irradiation, and also when materials are exposed to oxygen following irradiation [Clough, 1988]. Clough summarized the current knowledge on radiation induced oxidation mechanisms, and the following is quoted from his work [Clough, 1988]. 
Table 2.1

Classification of Polymers

According to Their Predominant Degradation Mode

When Irradiated Under Inert Atmosphere Conditions

[Clough, 1988]

Polymers Which Undergo Primarily

Chain Scission

Polyisobutalene

Poly- $\alpha$-methylstyrene

Polyvinylidenechloride

Polyvinylfluoride

Polychlorotrifluoroethylene

Polytetrafluoroethylene

Polyacrylonitrile

Polyvinyl formal

Polyvinylbutyral

Polymethylmethacrylate

Polymethacryl amide

Polymethacrylonitrile

Polyoxymethylene

Poly (propylene sulfide)

Poly (ethylene sulfide)

Cellutose

Polyalanine

Polylysine

DNA
Polymers Which Undergo Primarily Crosslinking

Polyethylene

Polypropylene

Polystyrene

Poly (vinylchloride)

Poly(vinyl alcohol)

Poly(vinyl acetate)

Poly (vinylmethylether)

Polybutadiene

Polychioroprene

Poly (styrene-co-acrylonitrile)

Poly (styrene-co-butadiene)

Poly (butadiene-co-acrylonitrile)

Natural Rubber

Chlorinated polyethylene

Chlorosulfinated polyethylene

Polyamides

Polyesters

Polyurethanes

Polysulfones

Polyacrylates

Polyacrylamides

Polydimethylsiloxane

Polymethylphenyl siloxane

Phenol-formaldehyde

Urea-formaldehyde

Mel amine-formaldehyde 
Oxygen, when present, will react with the free radicals generated. upon irradiation of polymers. The degradation mechanisms which occur are largely comprised of oxidative reactions that are basically similar to those that apply to the oxidation of organic materials under the influence of other environments (i.e., elevated temperature, ultraviolet light, mechanical stress, chemical initiation involving radicals, etc.). The equations below outline the important reactions in RIO.

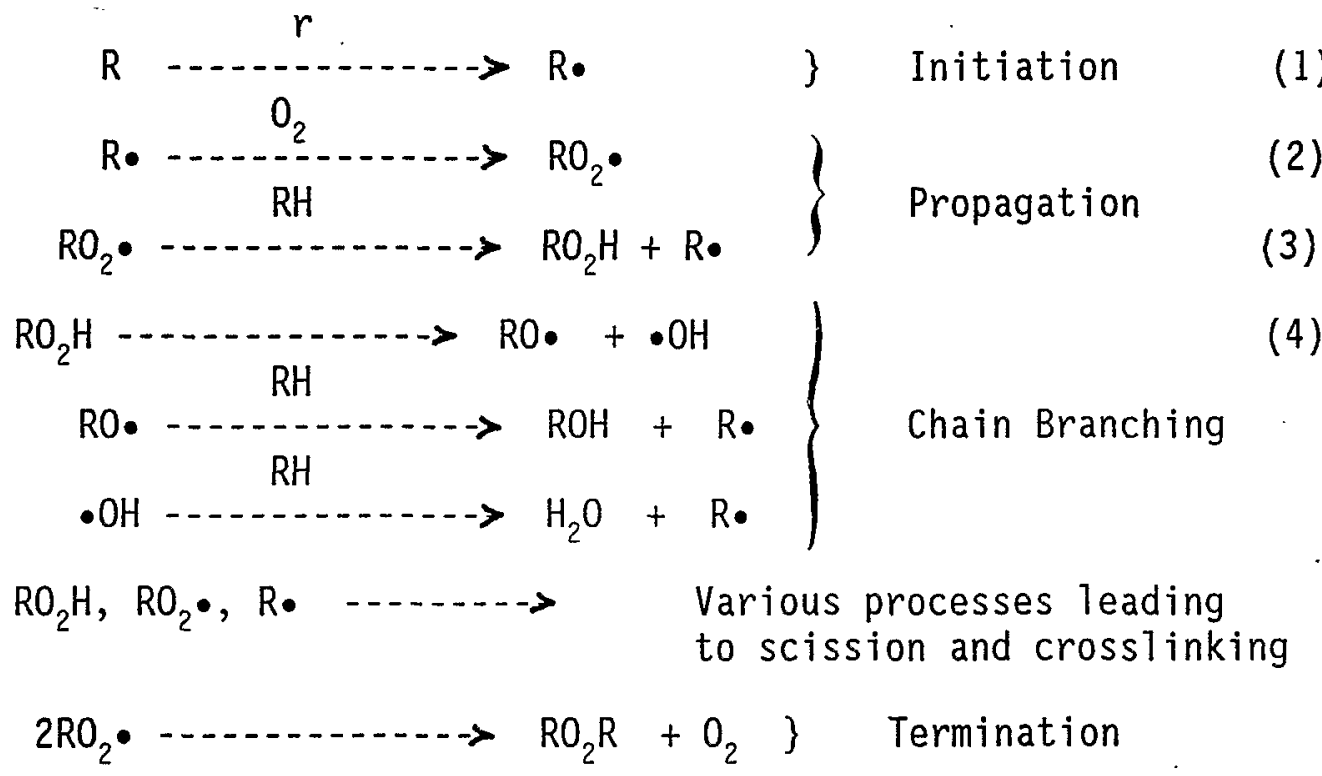

Because of its high diffusional mobility and its high reactivity toward radicals, oxygen serves to trap radicals in a very efficient manner, greatly impeding the radical reaction pathways which occur in the absence of $0_{2}$, and channelling the course of the reactions into predominantly oxidative routes. Chemical reaction products include oxidized structures within the polymer, such as ketone, carboxylic acid, and alcohol functionalities, as well as peroxidic species. Gaseous products generally include those arising under inert atmosphere irradiation, together with significant amounts of $\mathrm{CO}_{2}, \mathrm{CO}$, and $\mathrm{H}_{2} \mathrm{O}$. The oxidation chemistry which occurs can lead to entirely different molecutar changes compared with those resulting under inert atmosphere. Oxidative reactions frequently favor chain scission.

A particularly important feature of the radiation-oxidation mechanism above, as compared with the radiation mechanism for inert atmosphere conditions is the occurrence of chain branching steps. The breakdown of peroxides (eq. 4) generates further radicals which enter into chemical reactions just as do radicals generated directly by the action of the radiation. This has two important implications. First, since numerous peroxides can potentially be formed from each radicals via repetitive propagation steps (eqs. 2 and 3 ), and 
since each peroxide can decompose to yield two new radicals (eq. 4), this mechanistic feature can potentially give rise to an enormous enhancement of the total number of free radicals generated in the system, compared with the inert atmosphere situation. This type of chemical reaction has the potential for a greatly enhanced extent of degradation per equivalent dose. Secondly, peroxide decomposition (eq. 4) is a thermally-induced process having a moderately low activation energy, which introduces a time-temperature dependence into the degradation process. This in turn, can give rise to major dose-rate, temperature and post-irradiation effects." 


\section{GAMMA IRRADIATION FACILITY AT BNL}

The gamma pool facility contains more than 100,000 curies of cobalt- 60 . The pool is $8 \mathrm{ft}$. by $10 \mathrm{ft}$. by $13 \mathrm{ft}$. deep. The water depth provides shielding from the Cobalt-60 gamma sources located at the bottom of the poot. The pool liner is a stainless steel tank, $3 / 8$ in. thick at the sides and $1 / 2 \mathrm{in}$. thick at the bottom. A water chiller maintains the pool temperature at $10^{\circ} \mathrm{C}$ to prevent algae growth. The filter system contains two on-line fiber filters in the recirculation system, and a standby set of ion-exchange beds that can be valved into the system.

The cobalt is in the form of "pencil," "tabs," or "flat" sources encapsulated in stainless steel tubes or sleeves. The tubes are held in arrays in stainless steel source racks at the bottom of the pool in an upright, cylindrical orientation, arranged around the circumference parallel to the axis. The tubes form a cylinder about 6 in. diameter and $12 \mathrm{in}$. high. Most of the source arrays are inside open-topped lead casks. (The purpose of the casks was to provide shielding to prevent the arrays from interacting. Thus, dose rates at one source array were essentially entirely due to the cobalt contained in the array.)

There are 23 source arrays; the weakest sources contain less than 50 curies, the strongest has about 16,000 curies. Stainless steel air tubes $16 \mathrm{ft}$. long $\times 4$ in. od $\times 16$ gauge wall thickness are inserted vertically into the centers of the source arrays and rest on the bottom of the pool. One inch lead jackets around the air tube above the water level counterweigh the tube buoyancy, as well as providing shielding to personnel. The dose rates for the sources (at the bottom of the air tubes) range from kilorads per hour to megarads per hour. 


\section{RIO STUDY ON PE AND PVC AT ELEVATED TEMPERATURES}

As discussed in the previous section, the diffusion rate of oxygen through a polymer is one of the major parameters in the RIO process. For a given specimen, the diffusion rate is determined by boundary conditions such as the oxygen concentration in the atmosphere and by temperature. In this task, which is a joint effort with Ontario Hydro, BNL will study the effect of temperature while Ontario Hydro will study RI0 using oxygen concentration as an experimental parameter.

\subsection{Experimental}

\subsubsection{Sample Preparation}

Samples of polyvinylchloride (PVC) and crosslinked polyethylene (CLPE) were prepared by Ontario Hydro in a dogbone shape whose dimensions are shown in Figure 4.1.

\subsubsection{Description of the Heater}

Heating tape was wound around an alumina tube $(0$. d.: $5 \mathrm{~cm}$, i.d. : $3.9 \mathrm{~cm}$, length: $34 \mathrm{~cm})$. The tape was surrounded by glass wool insulation and aluminum foil. The assembly was inserted into a steel basket (i.d: $9 \mathrm{~cm}$, depth: $35 \mathrm{~cm}$ ). Two thermocouples were used, one connected to the temperature controller and the other to the recorder. After the first run in the gamma pool, it was found that the jackets of the thermocouple wires were severely damaged. Thus, alumina thermocouple jackets were used for the latter experiments.

A time proportioning type temperature controller (Model 22) from Omega Engineering Inc. was used to control the sample temperature. Cold junction compensation is built into the controller. For the temperature recorder an Electronic Ice point (model MCJ) from Omega Engineering Inc. was used for cold junction compensation.

\subsubsection{Irradiation}

A dose rate of $6.2 \times 10^{5} \mathrm{rad} /$ hour was used, and the sample temperature was kept at $60 \pm 0.5^{\circ} \mathrm{C}$.

\subsubsection{Mechanical Testing}

An Instron tensile testing machine was used to measure elongation and tensile strength. At first, wedge type grips were used, but later were switched to a pneumatic type which performed better. The wedge type grips sometimes caused premature failures at the grip sites due to the high stresses in that area.

A displacement rate of $5 \mathrm{~cm} /$ minute was used. A one inch gauge was marked at the center of the sample, and the distance between the gauge marks was followed until the sample failed. 


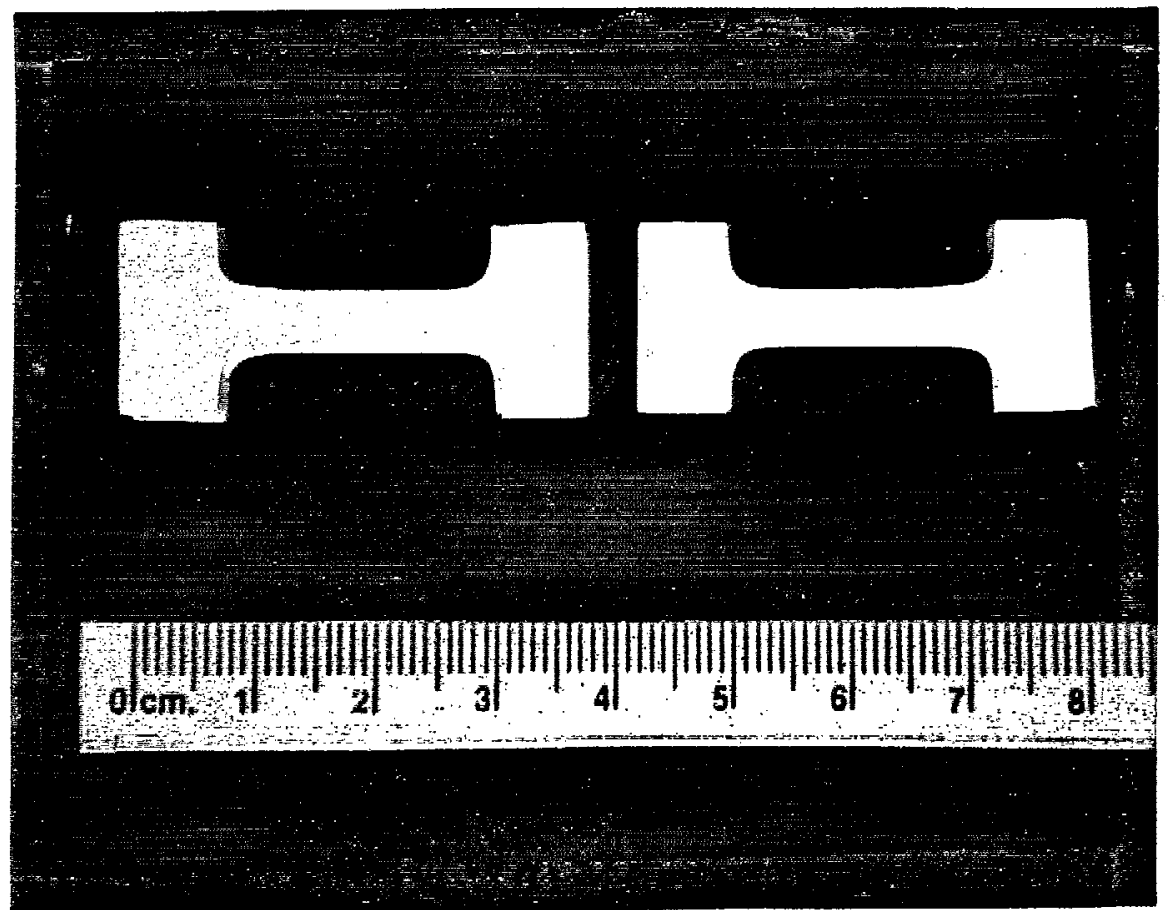

Figure 4.1 Samples used for RI0 study at $60^{\circ} \mathrm{C}$. Left: CLPE, Right: PVC 


\subsection{Results and Discussion}

The results from the mechanical tests for PE and PVC samples are shown in Figures 4.2. For the range of doses used, PE outperformed PVC, which may be partiy due to the higher ductilities of the unirradiated PE samples than those of PVC. The generally accepted criterion for nuclear cable insulation is that the elongation should be higher than $50 \%$ at a total dose of $10^{8}$, and both PE and PVC samples showed elongations higher than $50 \%$ at a total dose of $10^{8}$ rads. However, it should be noted that the dose rate used, $6.2 \times 10^{5} \mathrm{rad} / \mathrm{hour}$ is much higher than that expected in service.

\subsection{Summary and Recommendations}

For the dose rate and the temperatures used, PE performed much better than PVC. Unfortunately, the room temperature data from Ontario Hydro are not yet available. The following future studies are recommended.

1. It is recommended that room temperature elongation data be generated by BNL. In this way, two sets of tests run at different temperatures will be generated under the same radiation conditions, which will make the comparisons more meaningfut.

2. If time and resources permit, it is desirable that this study be expanded to include one more polymeric material and to study dose rate effects and temperature effects on polymer degradation. 


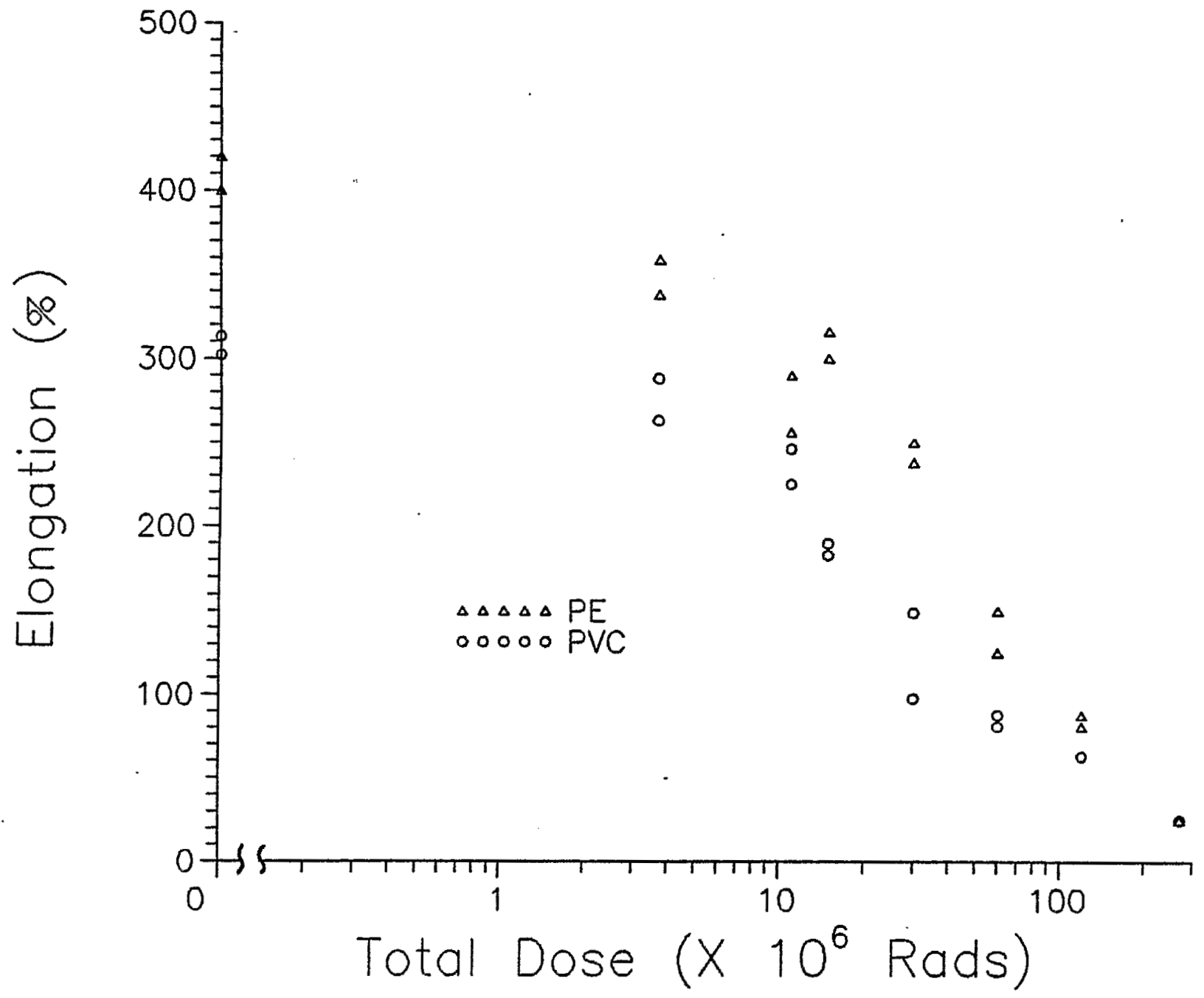

Figure 4.2 Elongation for CLPE and PVC as a function of total dose. 


\section{DEVELOPMENT OF A RADIATION RESISTANT POLYMER INSULATION}

\subsection{Development Strategy}

Some of the early ideas to use inorganic additives to enhance radiation resistant polymer insulation have been documented previously [Mackenzie, 1989]. A copy of MacKenzie's memorandum is attached as an Appendix.

In attempting to reduce radiation initiated oxidation, one could consider adding chemicals to the polymer so that oxygen or radicals are consumed by reacting with the additives rather than with the polymeric structure itself.

Adding conventional antioxidants might be a useful approach, but this is not at all clear. Antioxidants are of four main types, all organic -phenolics, amines, phosphites, and thioesters [Juran, 1988]. They have been developed to protect plastics against oxygen reactions initiated by heat and UV, but not gamma radiation. Thus, while they would presumably be of some help because of their chain terminating reactions, they themselves could form radicals and initiate oxidation under radiation, since they are also organic.

As an alternative to organic antioxidants, one could consider inorganic reducing agents. These would include, besides certain elements such as carbon, salts with cations in the reduced state, salts with reducing anions, or salts with both. Also, salts of certain organic acids might be appropriate, such as sodium gluconate, or sodium oxalate. Some of the cations and anions of interest include:

- Low valence states of the transition elements, e.g., $\mathrm{Fe}^{2+}$, $\mathrm{Mn}^{2+}, \mathrm{Cr}^{2+}, \mathrm{Co}^{2+}$. They might be used as oxides or as salts such as sulfate, phosphate, or possibly chloride.

- Multivalent cations in nitrogen family such as $\mathrm{As}^{3+}, \mathrm{Sb}^{3+}$ and $\mathrm{Bi}^{3+}$. Arsenic would probably not be welcomed by the user community.

- Multivalent cations in carbon family such as $\mathrm{Pb}^{3+}$.

- Reducing anions which might be useful are sulfite, selenite, and phosphite.

- The reduced form of a cation could possibly be used as a salt with a reducing anion.

\subsection{Choice of Polymer}

Currently, PVC and low density polyethylene (LDPE). are widely used for cable insulation due to their good extrudability combined with good insulation properties. These materials also show acceptable radiation resistance, and a fair amount of data on radiation effects on these is available. High density polyethylene (HDPE) is less radiation resistant than LDPE at both high and low dose rates [Clough, 1988]. PVC is more sensitive to dose rate effects than LDPE (see Table 5.1), and cable makers general1y prefer LDPE. Thus, LDPE was chosen as the base polymer for this study. 
Table 5.1

Comparison of the Dose Required to Reduce the Elongation at Break to $50 \%$ of Origina7, Under Low Dose Rate Condition in Air vs. High Dose Rate (or Inert Atm.) Conditions

[Clough, 1988]

Dose (in Gy) Req'd at 5-50 Gy/h in Air
Dose (in Gy). Req'd at Very High Dose Rate, and/or Inert Atmosphere

Phenol - formaldehyde

( $55 \%$ asbestos fiber,

$9 \%$ sawdust)

$3 \times 10^{6}$

$5 \times 10^{7}$

Phenol-formaldehyde

(47\% sawdust)

$2 \times 10^{6}$

$6 \times 10^{6}$

Polyester

(15\% glassfiber,

$56 \%$ inorganic filler)

$2 \times 10^{6}$

$5 \times 10^{7}$

Polystyrene

$5 \times 10^{5}$

$2 \times 10^{7}$

Chlorosulfonated

Polyethylene

$5 \times 10^{5}$

$8 \times 10^{5}$

Polystyrene-butadiene

(blend)

$4 \times 10^{5}$

$2 \times 10^{6}$

Poly (ethylene-co-

vinylacetate

$4 \times 10^{5}$

$2 \times 10^{6}$

Poly (ethyleneterephtha7ate)

$3 \times 10^{5}$

$3 \times 10^{6}$

Ethylene-propylene rubber

$3 \times 10^{5}$

$7 \times 10^{5}$

Polychloroprene

$3 \times 10^{5}$

$5 \times 10^{5}$

Silicone rubber

$2 \times 10^{5}$.

$3 \times 10^{5}$

Poly (vinylchloride)

(plasticized)

$10^{5}$

$2 \times 10^{6}$

Low-density polyethylene

$10^{5}$

$9 \times 10^{5}$

Poly (ethylene-co-

tetrafluoroethylene)

$8 \times 10^{4}$

$6 \times 10^{5}$

Natural rubber

$7 \times 10^{4}$

$1.5 \times 10^{6}$

Polyamide (aliphatic)

$2 \times 10^{4}$

$4 \times 10^{5}$ 


\subsection{Choice of Additives}

As discussed earlier, several additives could be tried for this study. However, due to the limitation on time and resources, only two additives were selected, $\mathrm{Sb}_{2} \mathrm{O}_{3}$ and $\mathrm{PbO}$, after discussions between the principal researchers at BNL and Rockbestos Cable Company in Connecticut. This company agreed to assist us in our work primarily by preparing the new polymer formulations.

\subsection{Experimental}

\subsubsection{Sämple Preparation}

As shown in Table 5.2, LDPE samples with seven different compositions were molded into sheets of $15 \times 15 \times 0.17 \mathrm{~cm}$ by Rockbestos. The seven compositions are a LDPE control without additives, and LDPE with two different additives at three different concentrations.

Dogbone shaped samples shown in Figure 5.1 were stamped from the sheets using a hydraulic press and an ASTM recommended die. Sample ID's were indented on both ends of the samples. A batch of 14 samples (two for each composition) were stacked together with spacers between samples. The samples were degreased with alcohol before irradiation.

\subsubsection{Mechanical Testing}

An Instron tensile testing machine was used to measure elongation and tensile.strength. At first, wedge type clamp was used, but later was switched to pneumatic type clamp which performed better. The wedge type grips sometimes caused premature failures at the grip sites due to the high stresses in that area.

A displacement rate of $5 \mathrm{~cm} /$ minute was used. A one inch gauge was marked at the center of the sample, and the distance between the gauge marks was followed until the sample broke.

\subsection{Results}

The results from the elongation measurements as a function of total dose are shown in Figures 5.2 - 5.19. The effects of different concentrations of $\mathrm{PbO}$ and $\mathrm{Sb}_{2} \mathrm{O}_{3}$ on the elongation are shown in Figures 5.20 - 5.22 and Figures 5.23 5.25, respectively. Figures $5.26-5.32$ show the effects of dose rates on the elongation properties of the samples with seven different compositions irradiated up to $5.4 \times 10^{8}$ rads.

The elongations of six samples with different compositions, A - F, irradiated at three different dose rates are compared with those of control samples $Z$ (no additives) in Figures 5.2 - 5.19. At the highest dose rate used, $1.1 \times 10^{6} \mathrm{rad} / \mathrm{h}$, samples A - D behaved very similarly to the control sample. Samples $E$ and $F$ seem to have a little higher elongations compared to the control samples up to the total dose of $5 \times 10^{7}$ rads, but the differences might not be significant. 
Table 5.2

Compositions of Test Samples

\begin{tabular}{|c|c|c|}
\hline Sample ID & Comp & sition (weight \%) \\
\hline A & LDPE homopolymer & $+\quad 1 \% \mathrm{PbO}$ \\
\hline B & " & $+1 \% \mathrm{Sb}_{2} \mathrm{O}_{3}$ \\
\hline C & $"$ & $+3 \% \mathrm{PbO}$ \\
\hline D & " & $+3 \% \mathrm{Sb}_{2} \mathrm{O}_{3}$ \\
\hline$E$ & $"$ & $+10 \% \mathrm{PbO}$ \\
\hline$F$ & $"$ & $+10 \% \mathrm{Sb}_{2} \mathrm{O}_{3}$ \\
\hline$z$ (Control) & $"$ & \\
\hline
\end{tabular}

At a dose ràte of $6.26 \times 10^{5} \mathrm{rad} / \mathrm{h}$, all six samples showed improvements in elongation over control samples up to a total dose of $3 \times 10^{7}$ rads, with the Pbo containing samples, $\mathrm{A}, \mathrm{C}$ and $\mathrm{E}$ outperforming the $\mathrm{Sb}_{2} \mathrm{O}_{3}$ added samples, $\mathrm{B}, \mathrm{D}$ and F. At total doses higher than $5 \times 10^{7}$ rads, a17 six samples behaved similarly to the control samples. Among the samples with the same kind of additive, the higher the concentration, the more distinct the improvement.

At a dose rate of $3.31 \times 10^{5} \mathrm{rad} / \mathrm{h}$, for the Pbo containing samples, only sample. $E(10 \% \mathrm{PbO})$ showed better performance compared with the control sample up to the total dose of $1.6 \times 10^{7}$. It seems that all three $\mathrm{Sb}_{2} \mathrm{O}_{3}$ containing samples, $B, D$ and $F$ showed slight improvements in elongation over the control samples up to a dose of $1.6 \times 10^{7}$ rads.

\subsection{Discussion}

\subsubsection{The Effects of Additives}

Figures $5.20-5.22$ show the effects of the added PbO at three different dose rates. As mentioned earlier, at a dose rate of $1.1 \times 10^{6} \mathrm{rad} / \mathrm{h}$, all three samples ( $A, C$ and $E$ ) behaved similarly to the control samples. However, at $6.26 \times 10^{5} \mathrm{rad} / \mathrm{h}$ and for the total dose of $3 \times 10^{7}$, the beneficial effects of the added $\mathrm{PbO}$ are clearly shown. The elongations are in order of the amount of the added $\mathrm{PbO}$. For the dose rate of $3.31 \times 10^{5} \mathrm{rad} / \mathrm{h}$, only sample $\mathrm{E}$ that has 10 $\% \mathrm{Pbo}$ showed clear improvements up to the total dose of $1.6 \times 10^{7}$ rads. 


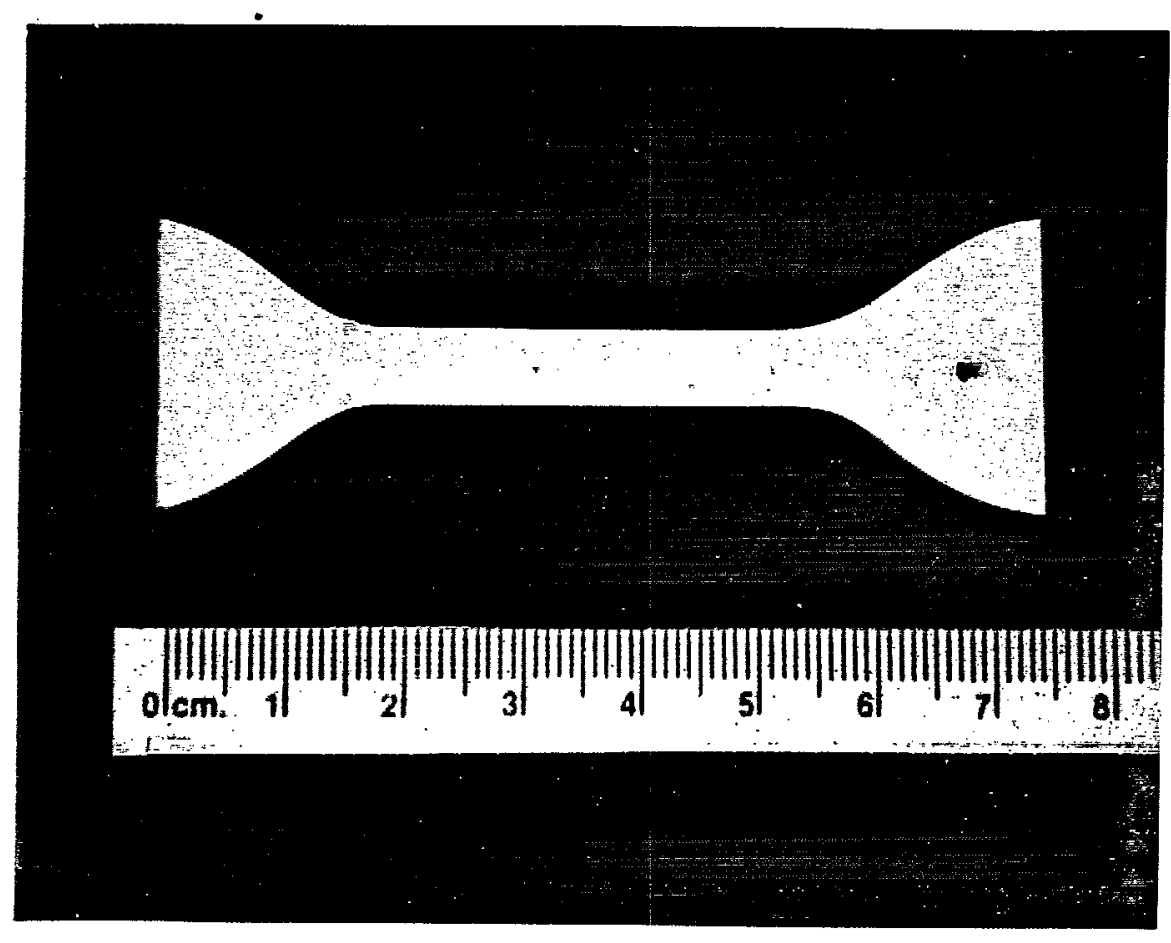

Figure 5.1 Standard sample used for radiation resistant polymer insulation development study. 


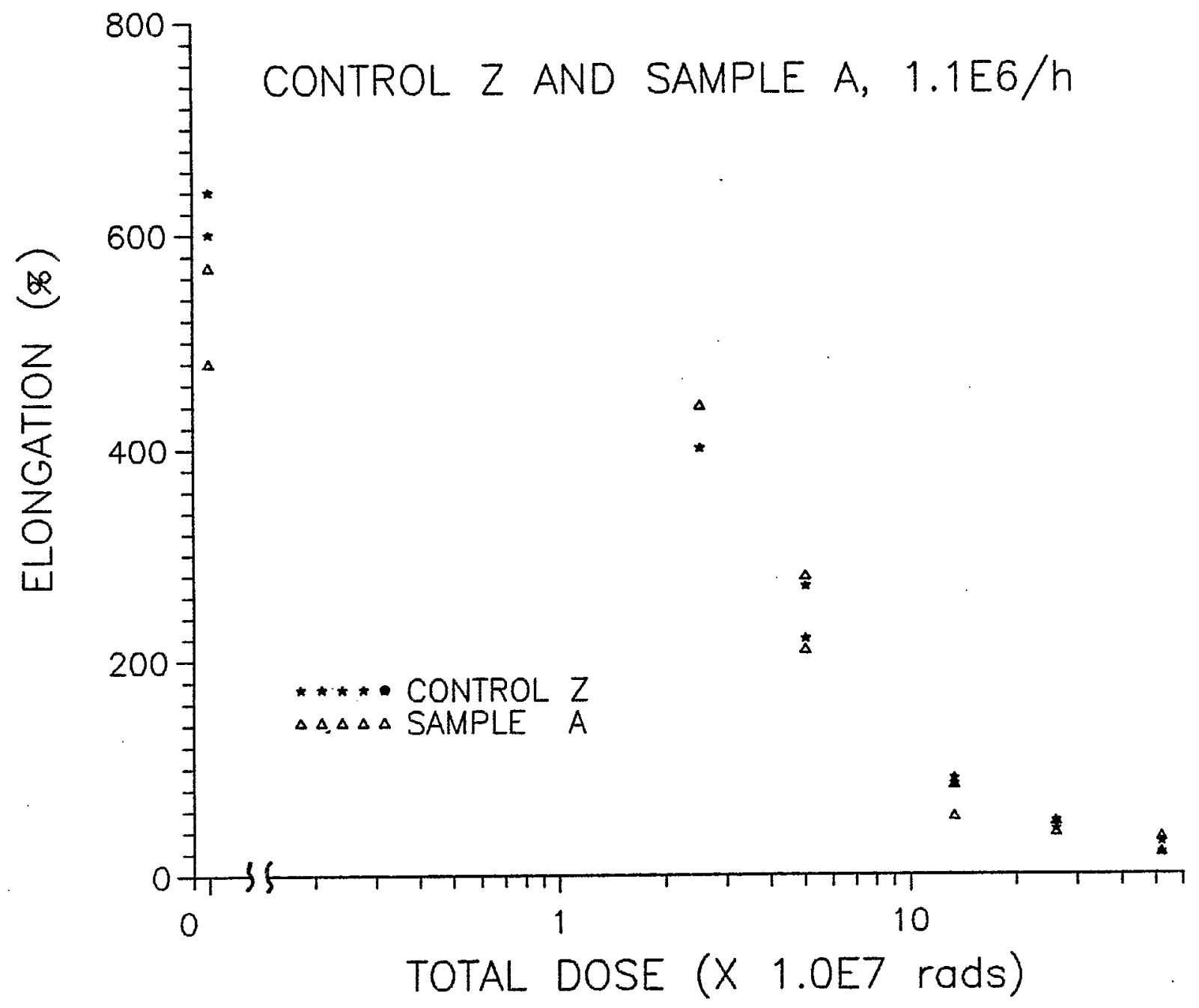

Figure 5.2 Elongation as a function of total dose for samples $A$ and $Z$. Dose rate: $1.1 \times 10^{6} \mathrm{rad} /$ hour. 


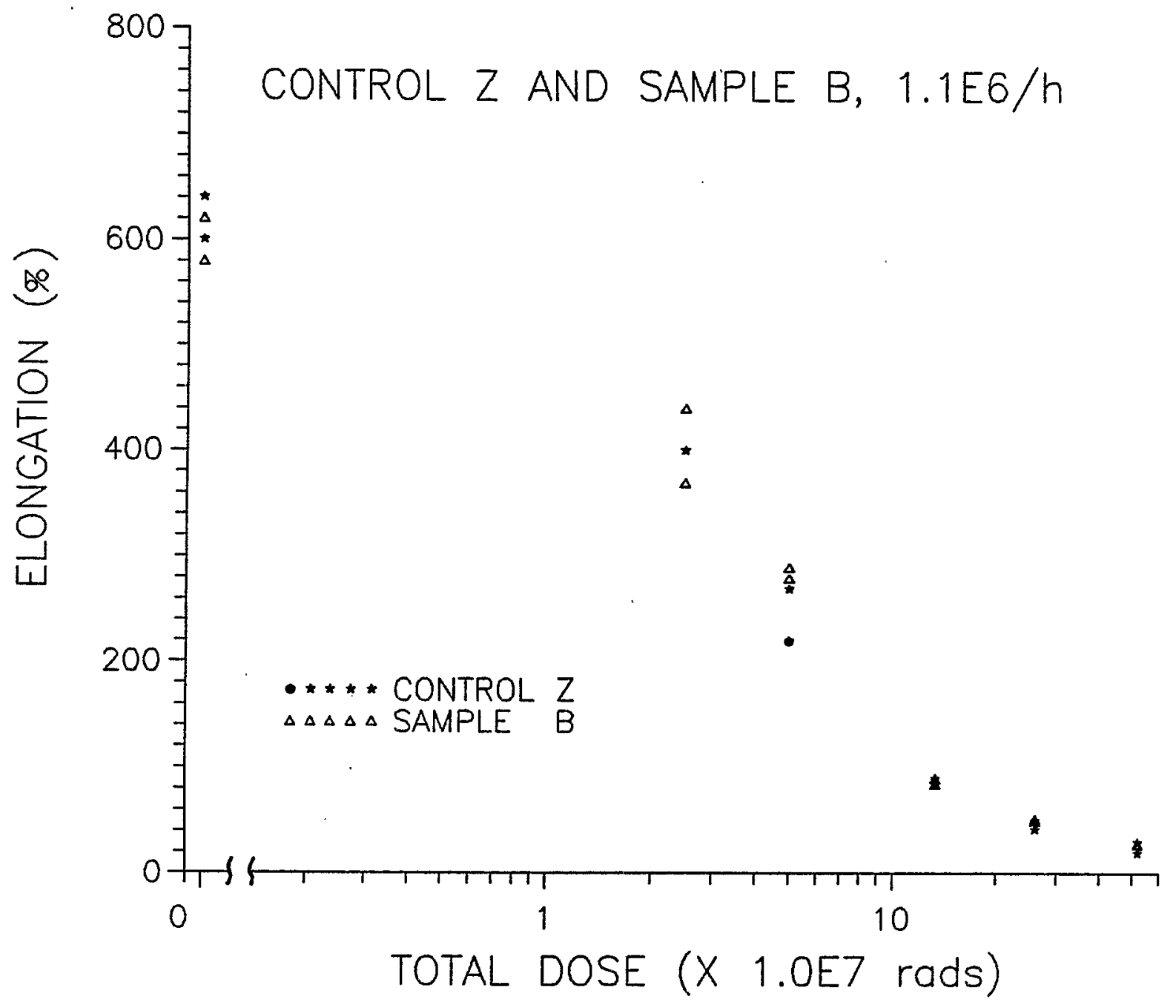

Figure 5.3 Elongation as a function of total dose for samples $B$ and $Z$. Dose rate: $1.1 \times 10^{6} \mathrm{rad} /$ hour. 


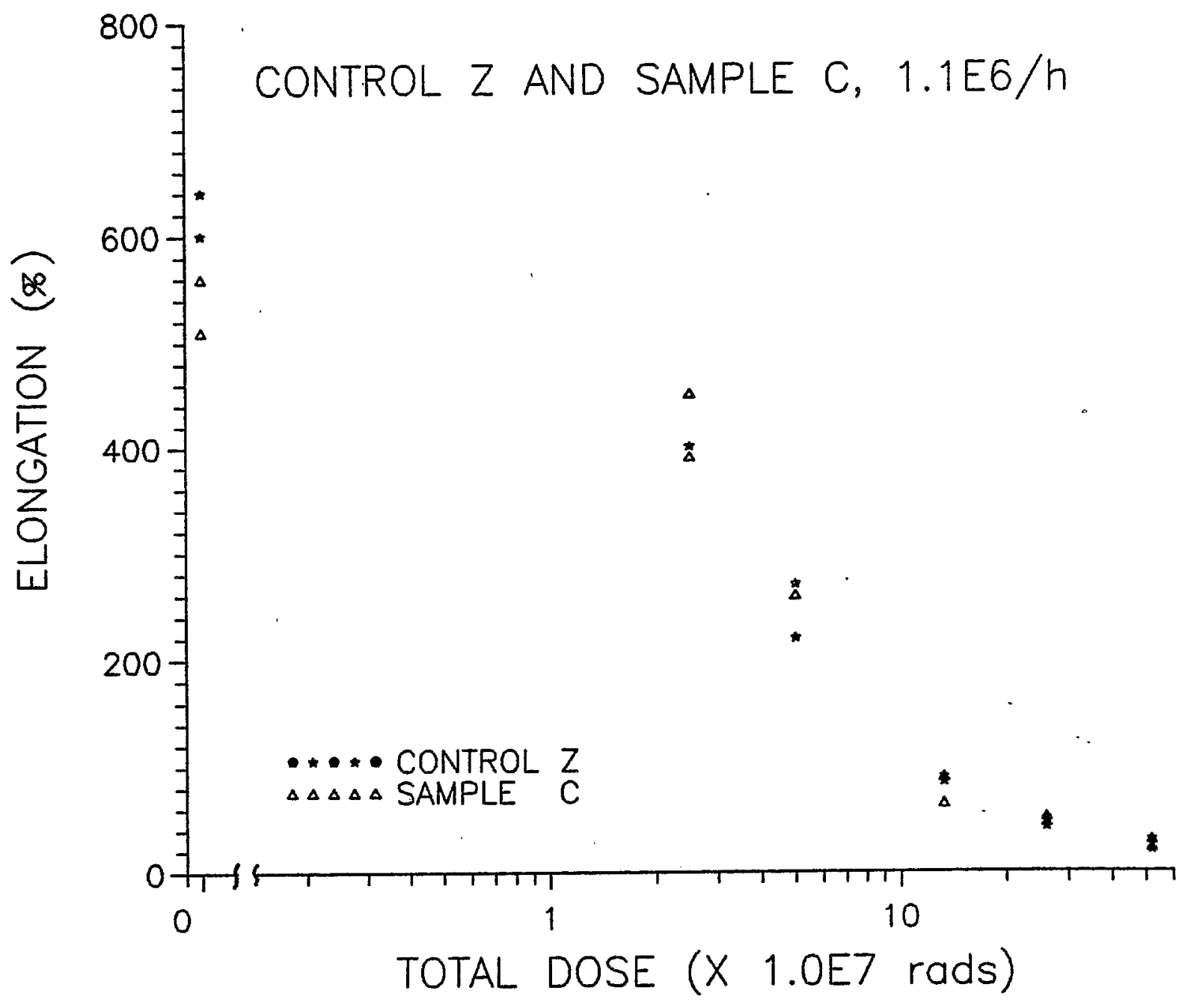

Figure 5.4 Elongation as a function of total dose for samples $C$ and $Z$. Dose rate: $1.1 \times 10^{6} \mathrm{rad} /$ hour. 


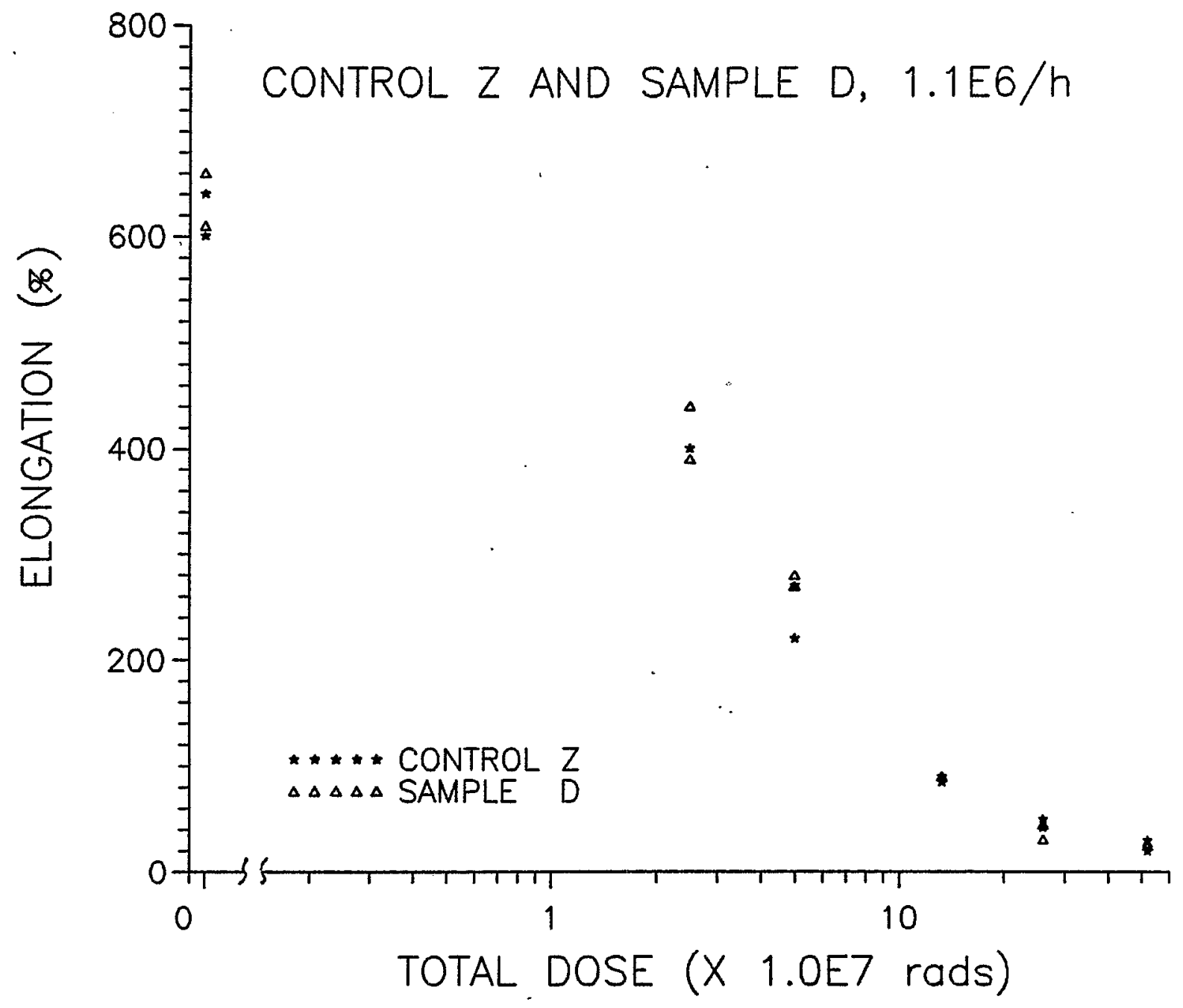

Figure 5.5 Elongation as a function of total dose for samples $D$ and $Z$. Dose rate: $1.1 \times 10^{6} \mathrm{rad} /$ hour. 


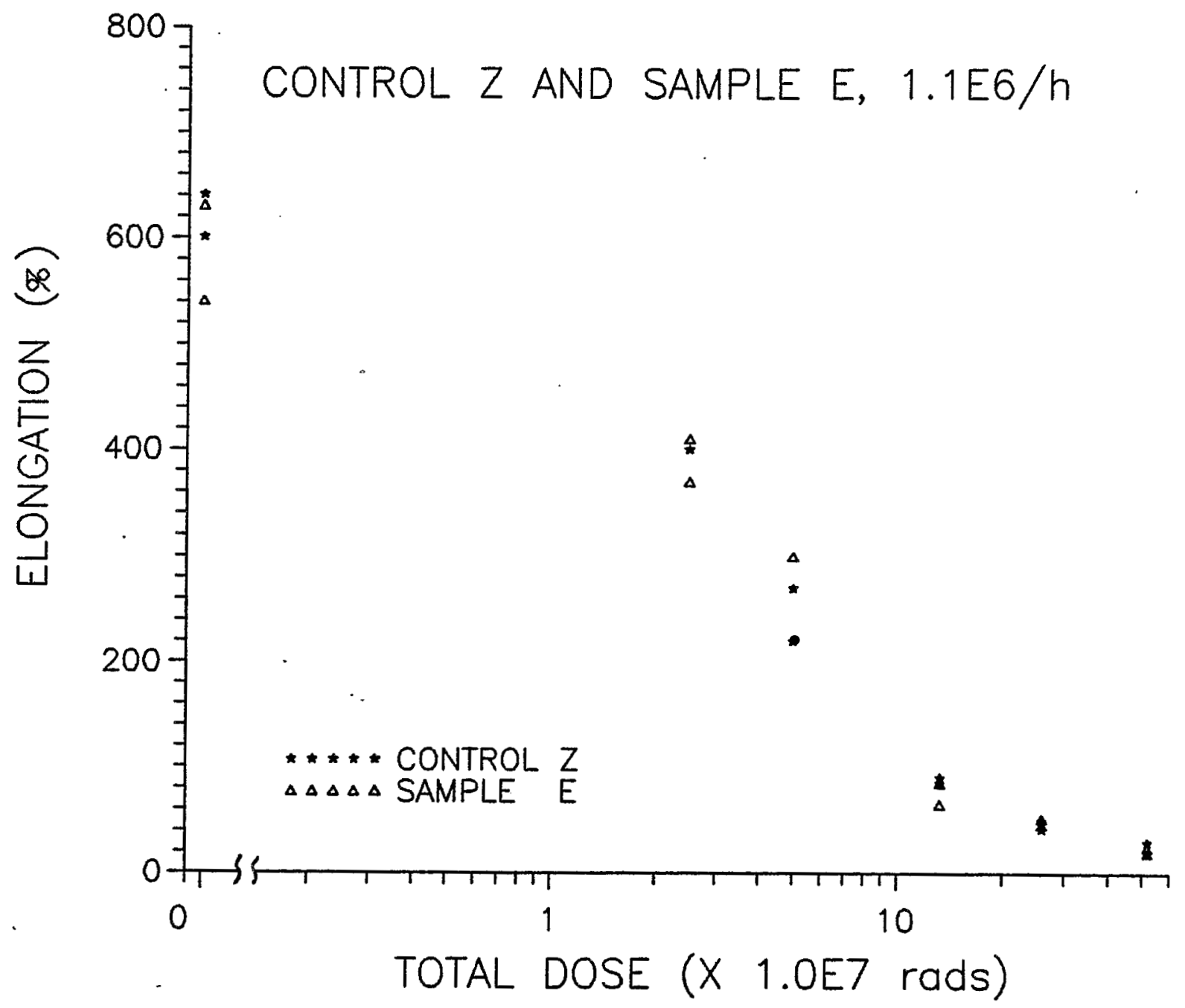

Figure 5.6 Elongation as a function of total dose for samples $E$ and $Z$. Dose rate: $1.1 \times 10^{6} \mathrm{rad} / \mathrm{hour}$. 


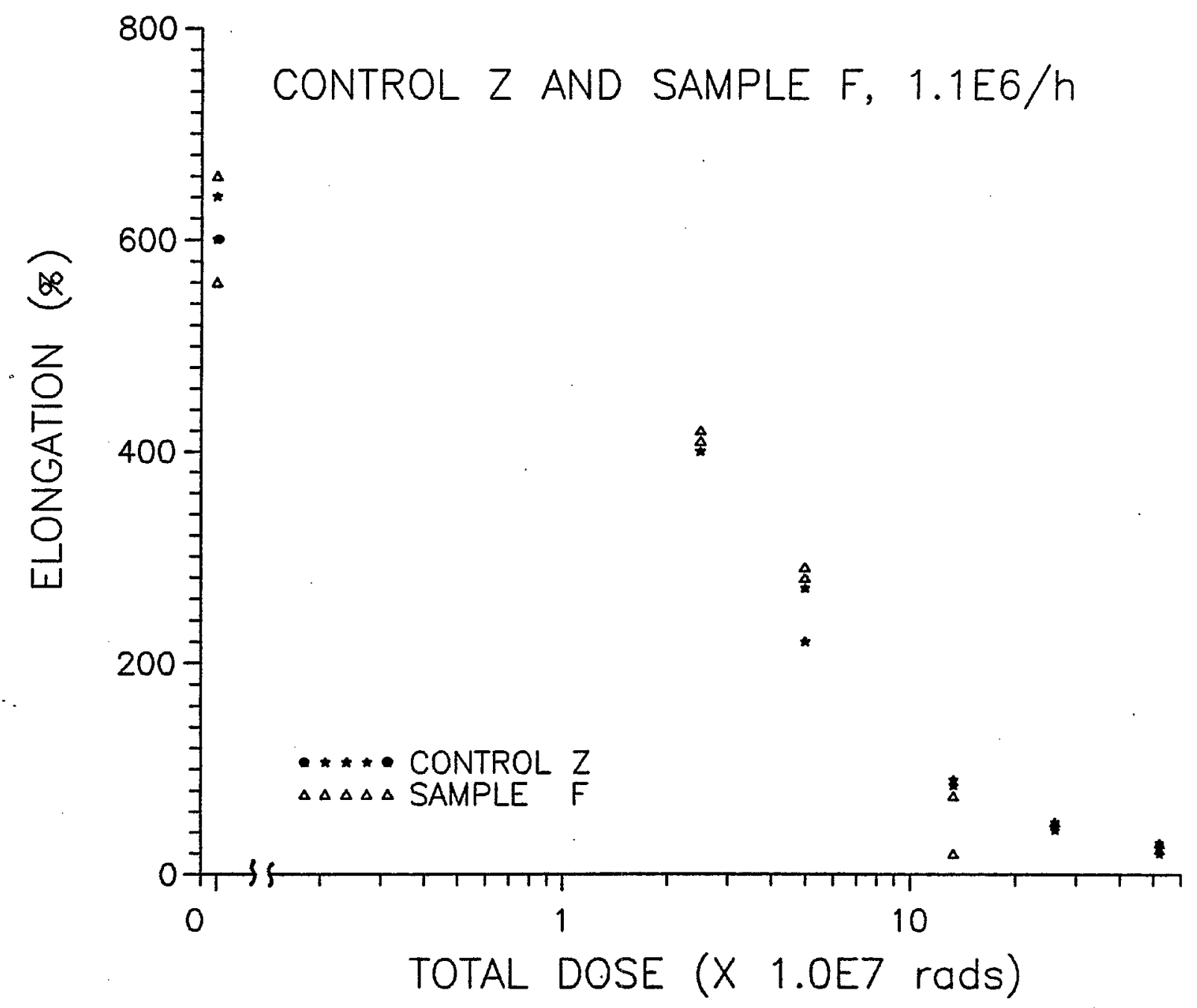

Figure 5.7 Elongation as a function of total dose for samples $F$ and $Z$. Dose rate: $1.1 \times 10^{6} \mathrm{rad} /$ hour. 


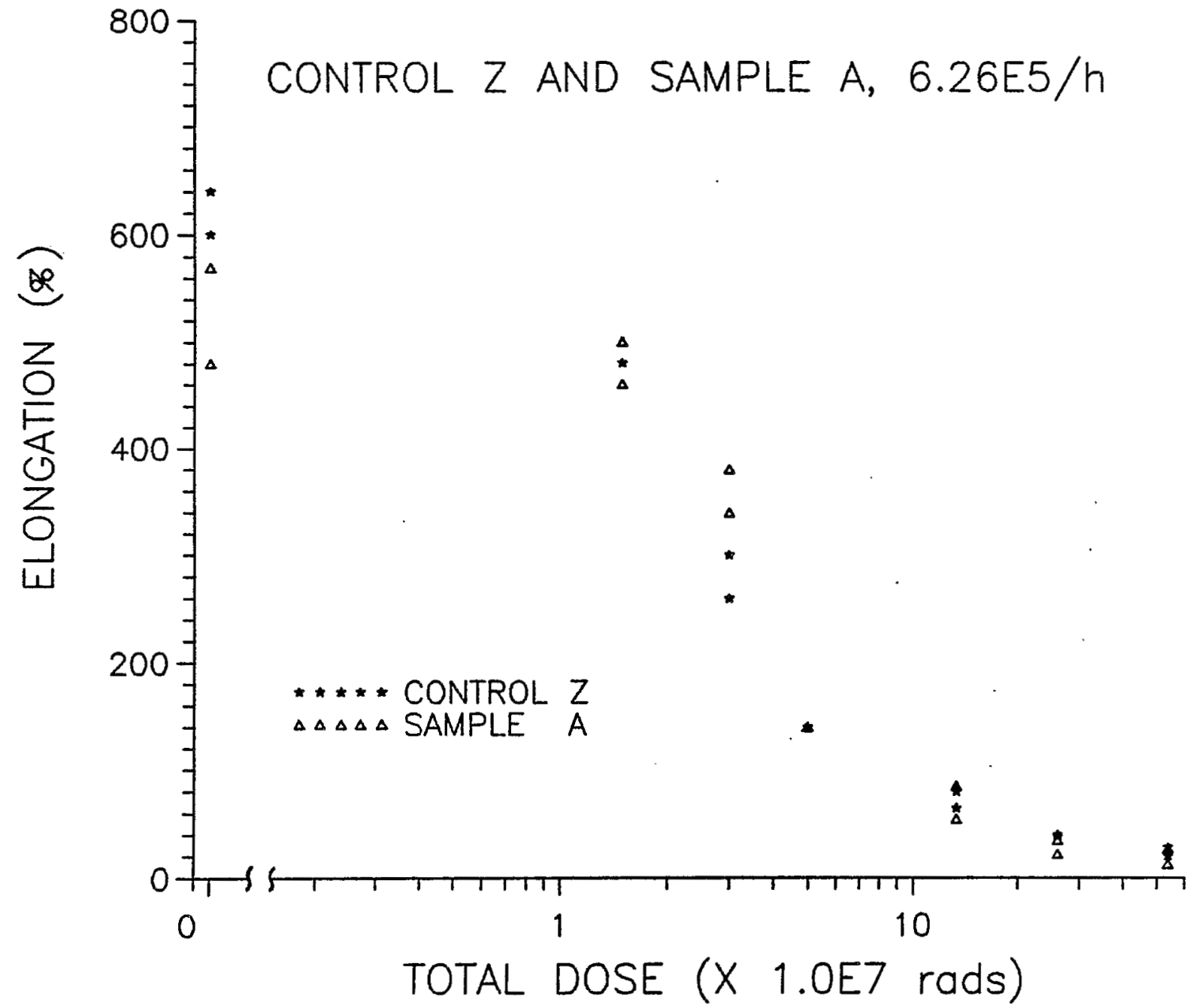

Figure 5.8 Elongation as a function of total dose for samples $A$ and $Z$. Dose rate: $6.26 \times 10^{5} \mathrm{rad} / \mathrm{hour}$. 


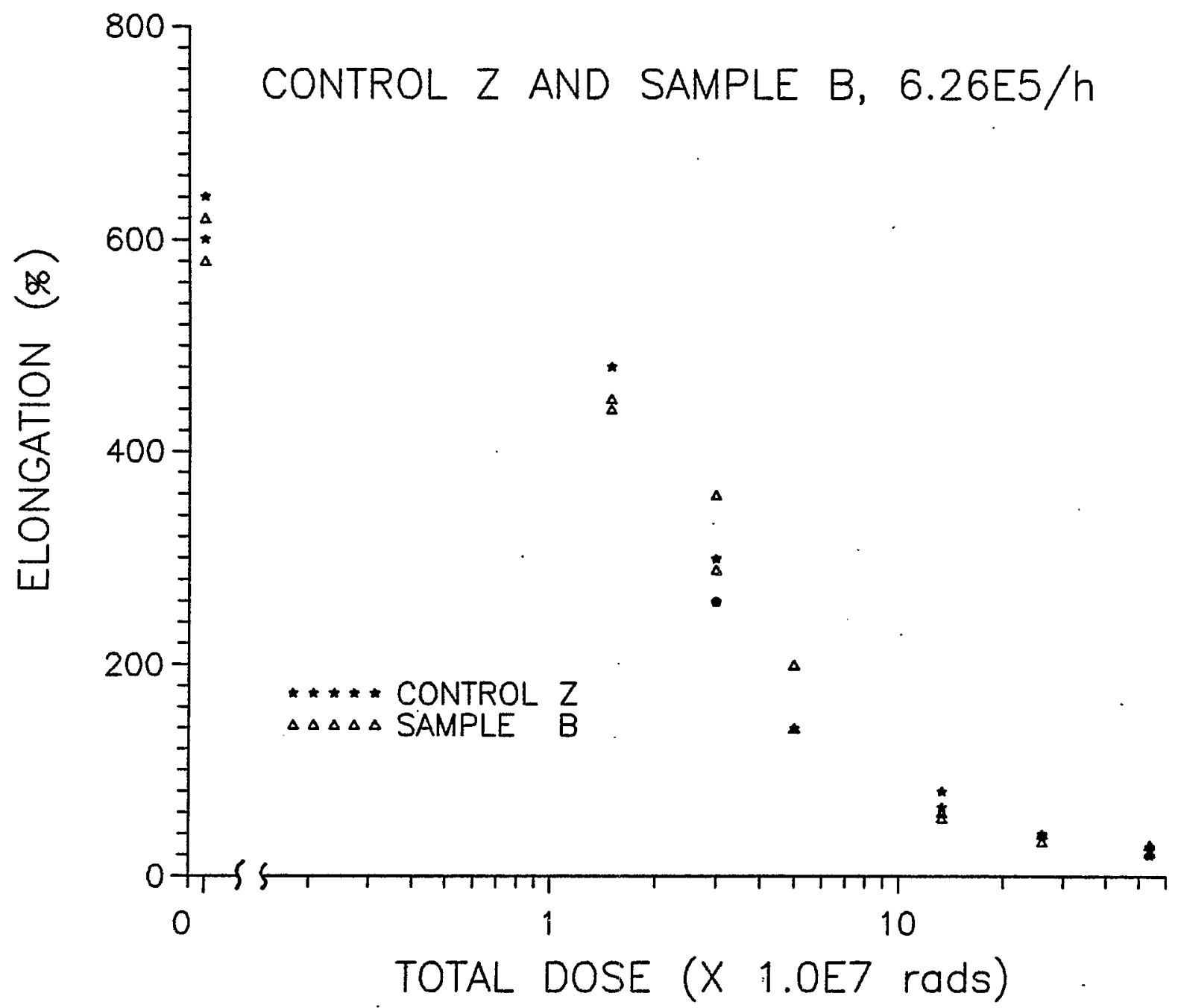

Figure 5.9 Elongation as a function of total dose for samples $B$ and $Z$. Dose rate: $6.26 \times 10^{5} \mathrm{rad} / \mathrm{hour}$. 


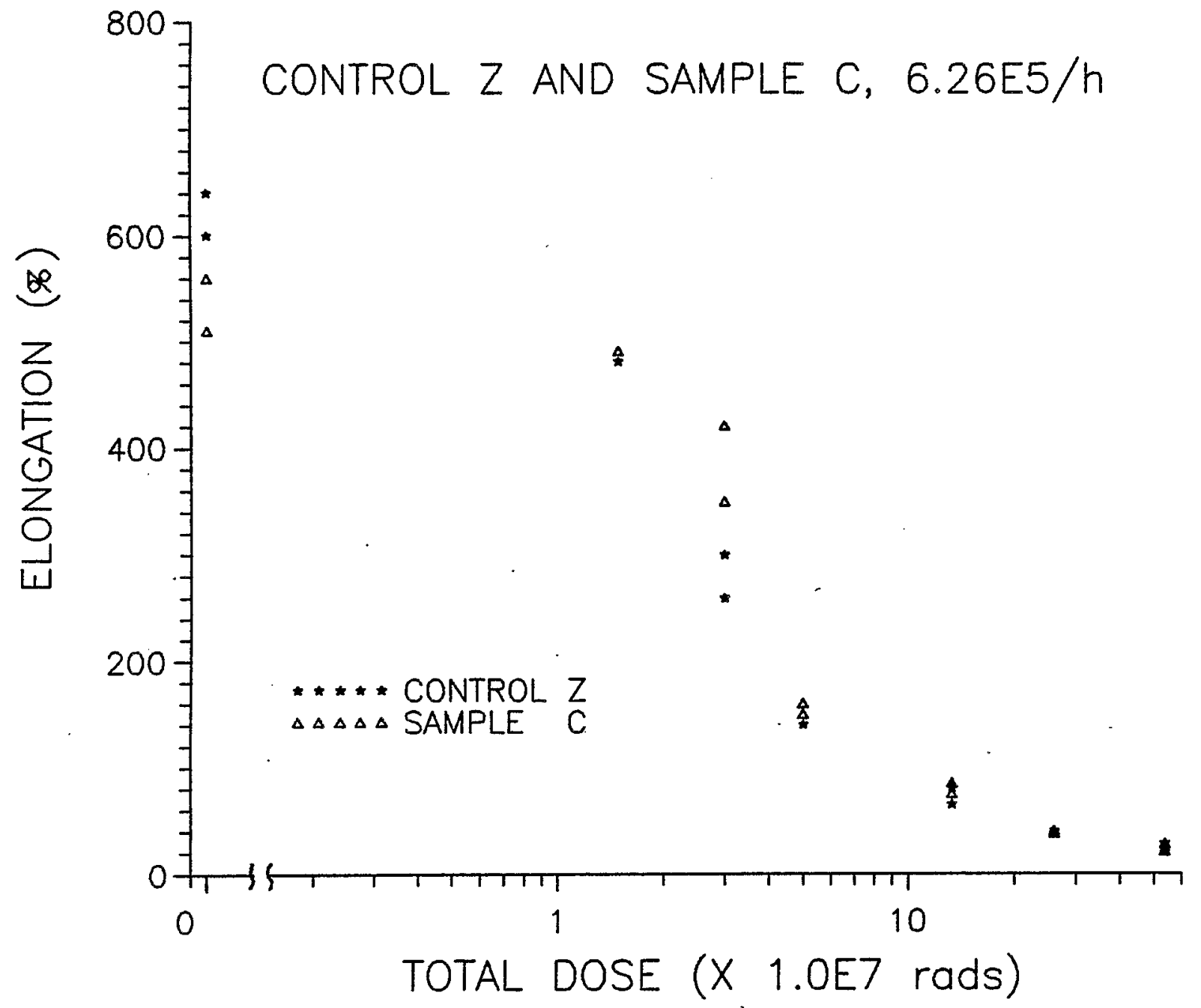

Figure 5.10 Elongation as a function of total dose for samples $C$ and $Z$. Dose rate: $6.26 \times 10^{5} \mathrm{rad} / \mathrm{hour}$. 


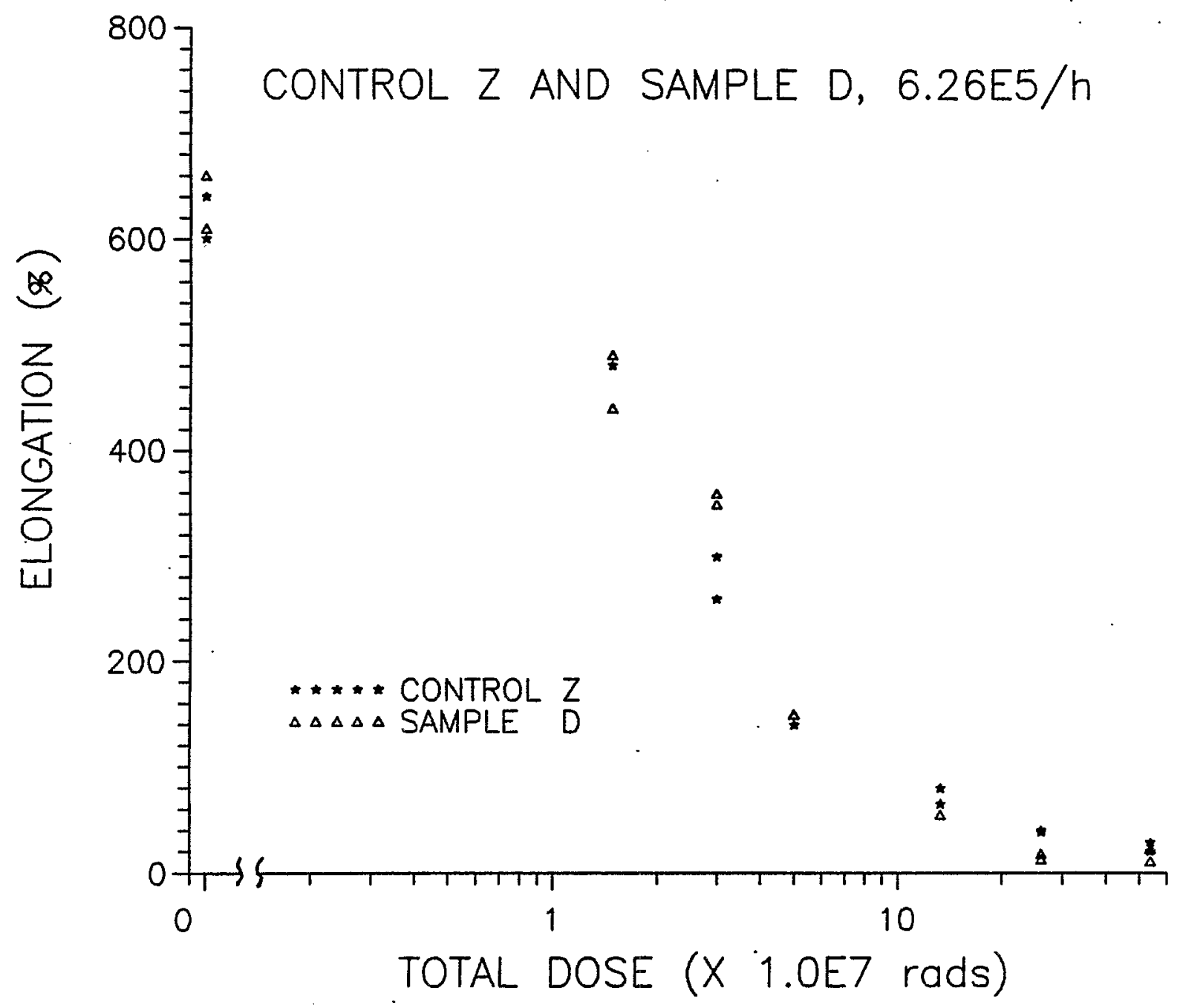

Figure 5.11 Elongation as a function of total dose for samples $D$ and $Z$. Dose rate: $6.26 \times 10^{5} \mathrm{rad} /$ hour. 


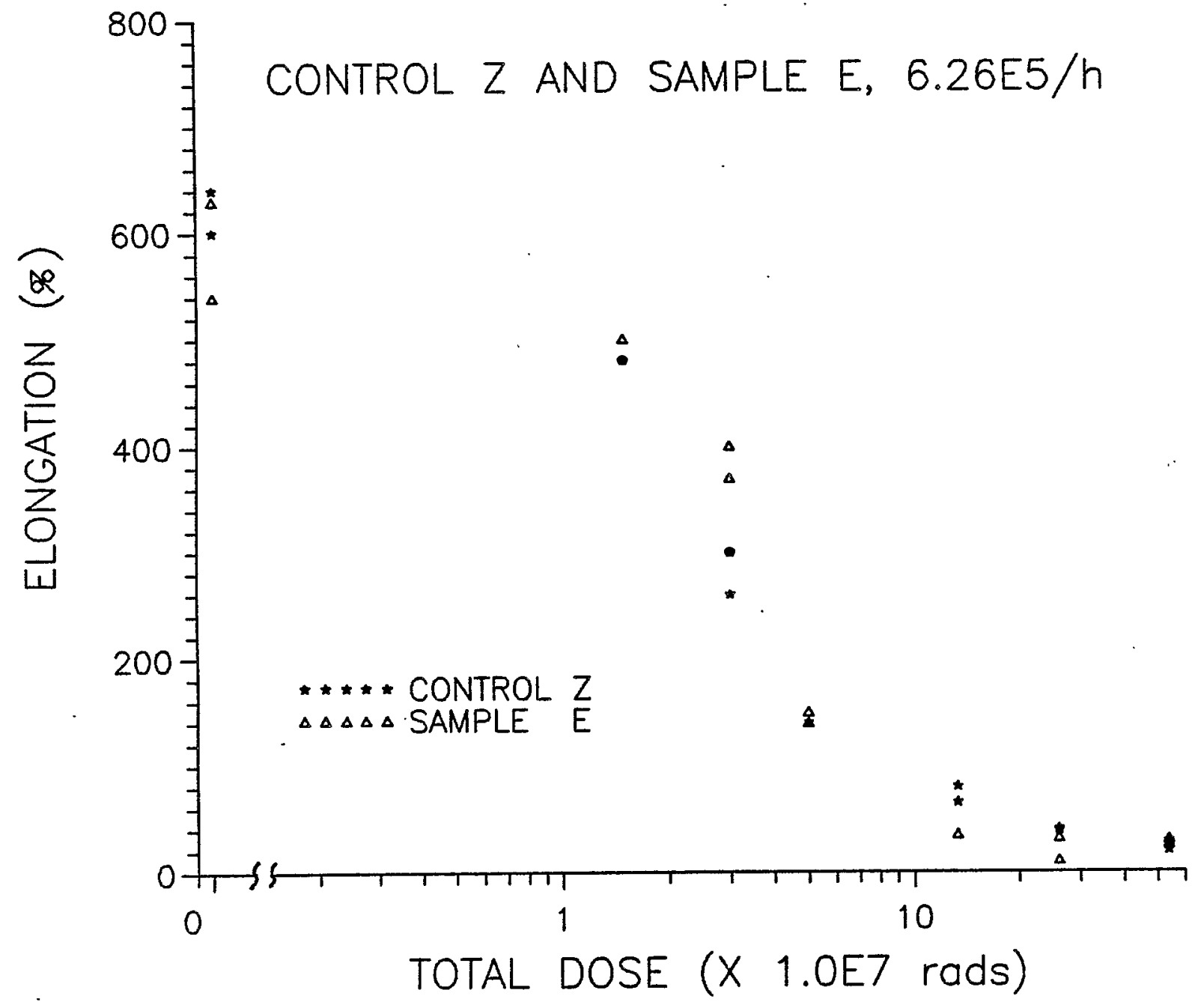

Figure 5.12 Elongation as a function of total dose for samples $E$ and $Z$. Dose rate: $6.26 \times 10^{5} \mathrm{rad} / \mathrm{hour}$. 


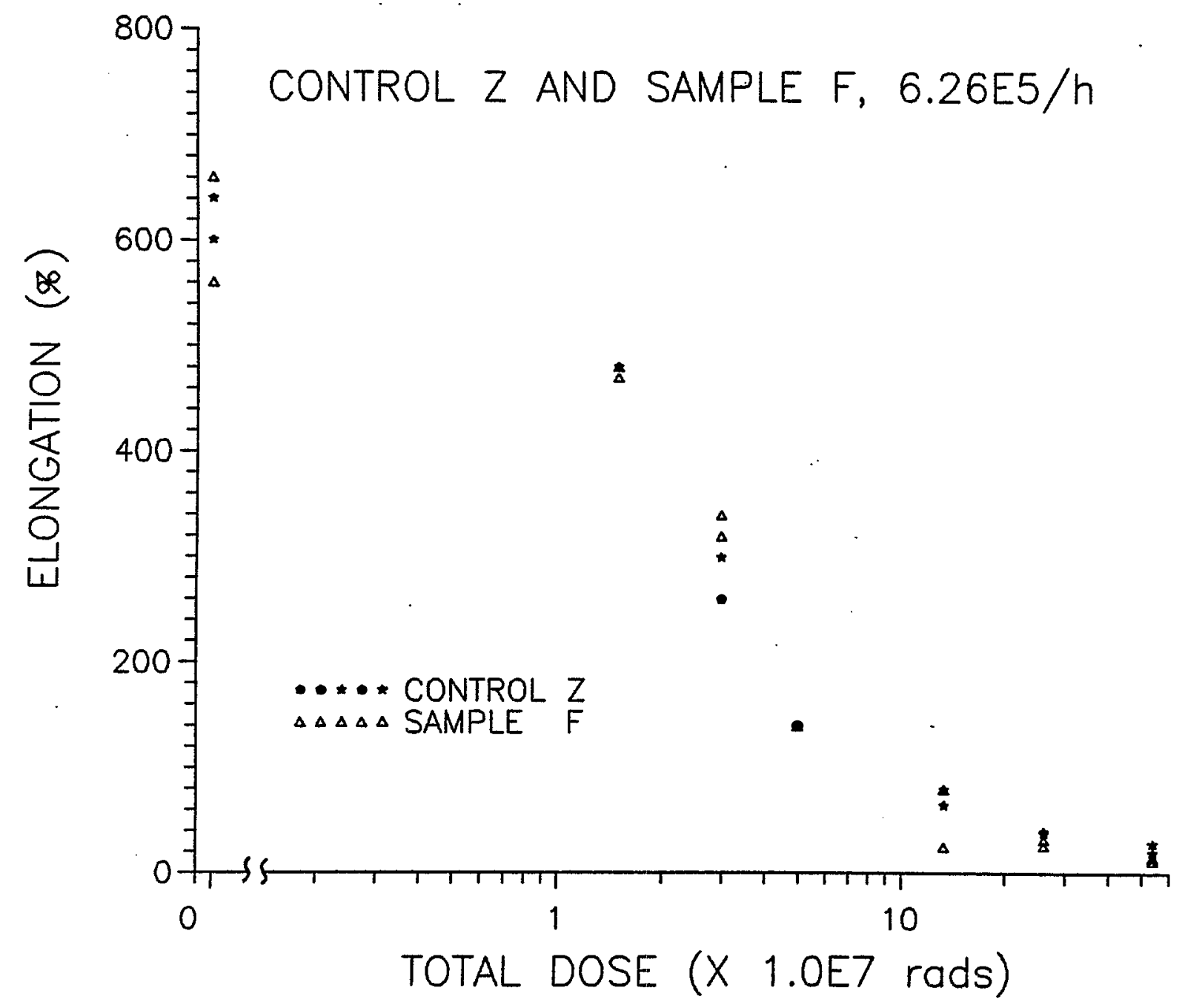

Figure 5.13 Elongation as a function of total dose for samples $F$ and $Z$. Dose rate: $6.26 \times 10^{5} \mathrm{rad} / \mathrm{hour}$. 


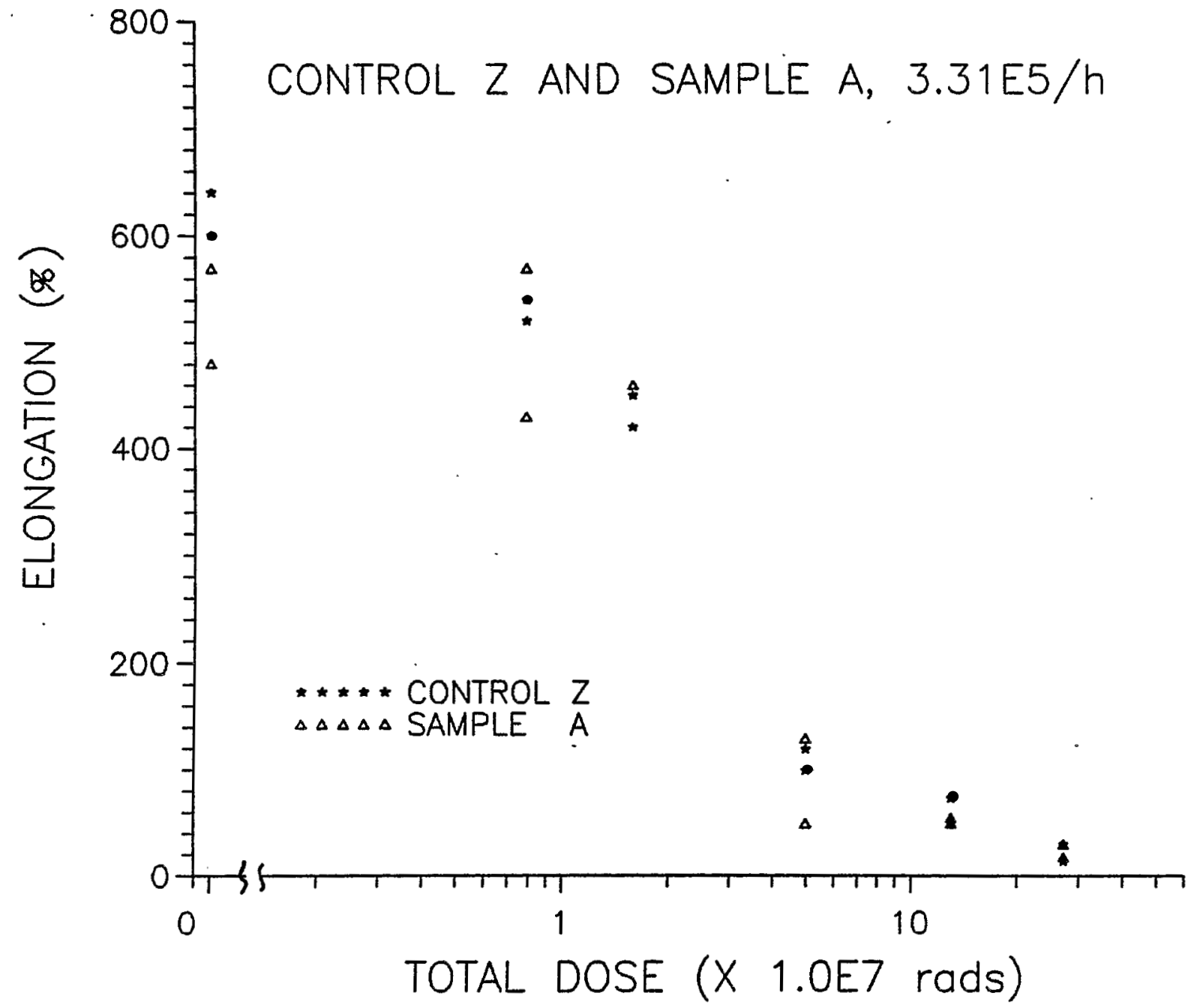

Figure 5.14 Elongation as a function of total dose for samples $A$ and $Z$. Dose rate: $3.31 \times 10^{5} \mathrm{rad} /$ hour. 


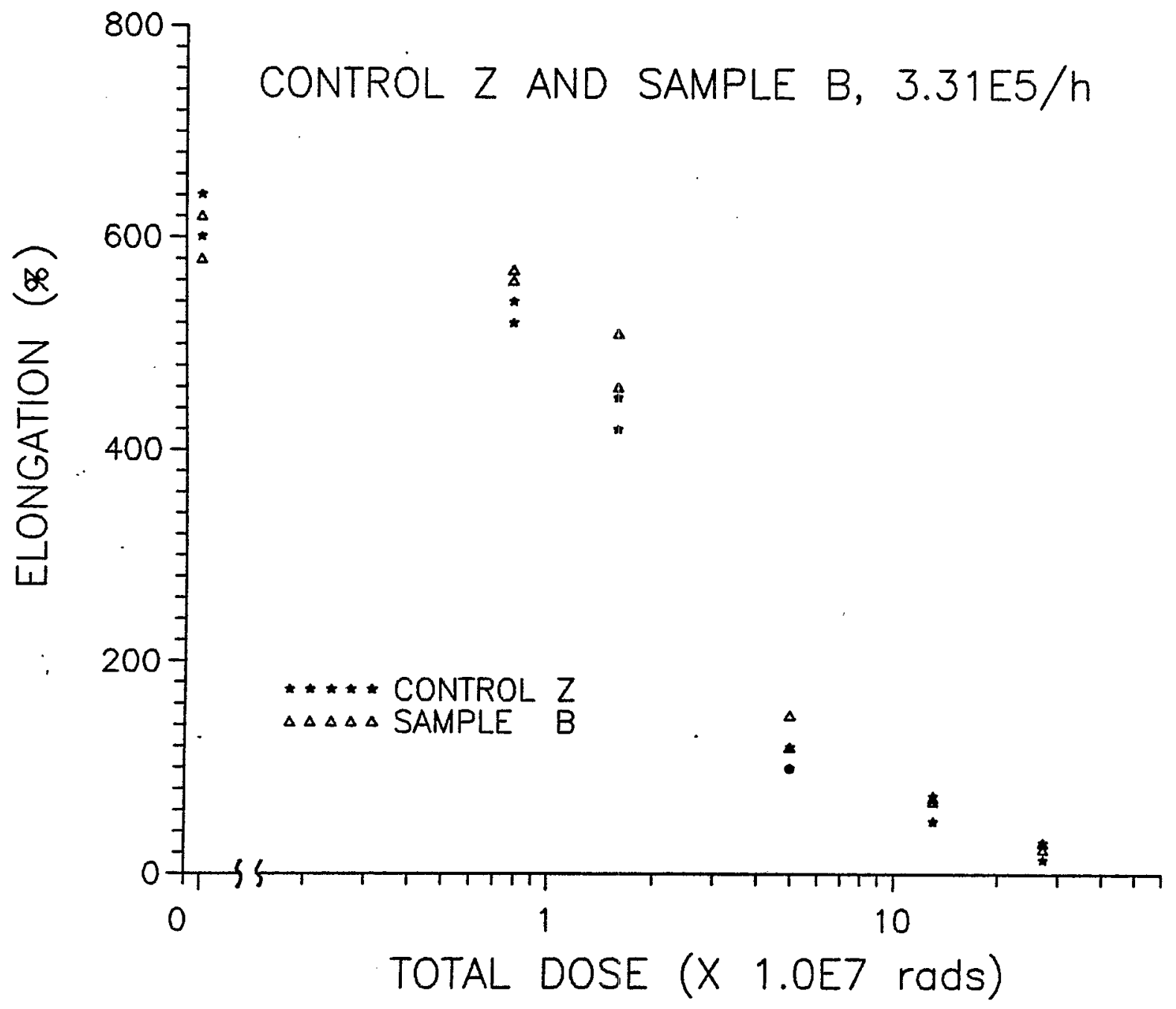

Figure 5.15 Elongation as a function of total dose for samples $B$ and $Z$. Dose rate: $3.31 \times 10^{5} \mathrm{rad} /$ hour. 


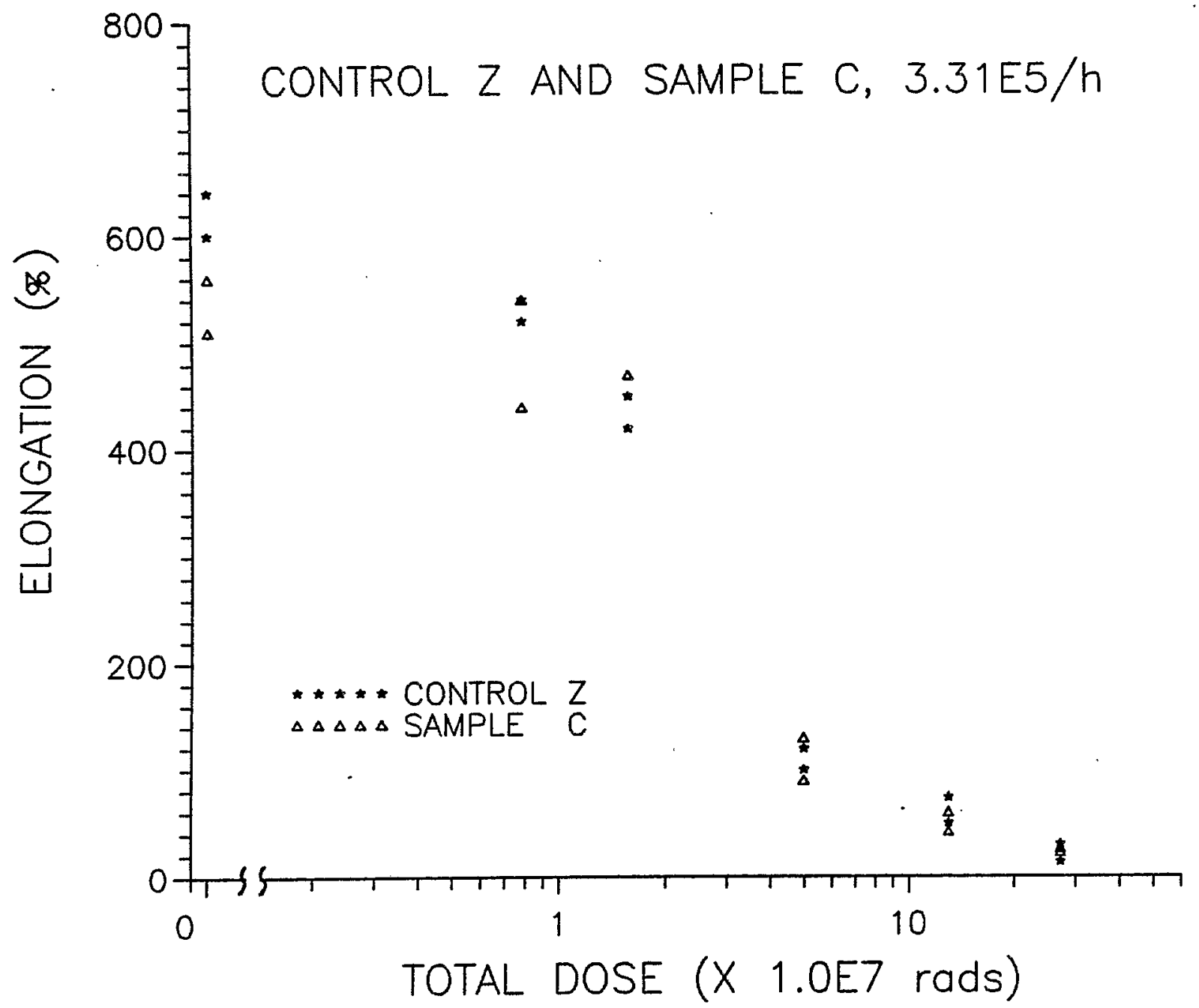

Figure 5.16 Elongation as a function of total dose for samples $C$ and $Z$. Dose rate: $3.31 \times 10^{5} \mathrm{rad} / \mathrm{hour}$. 


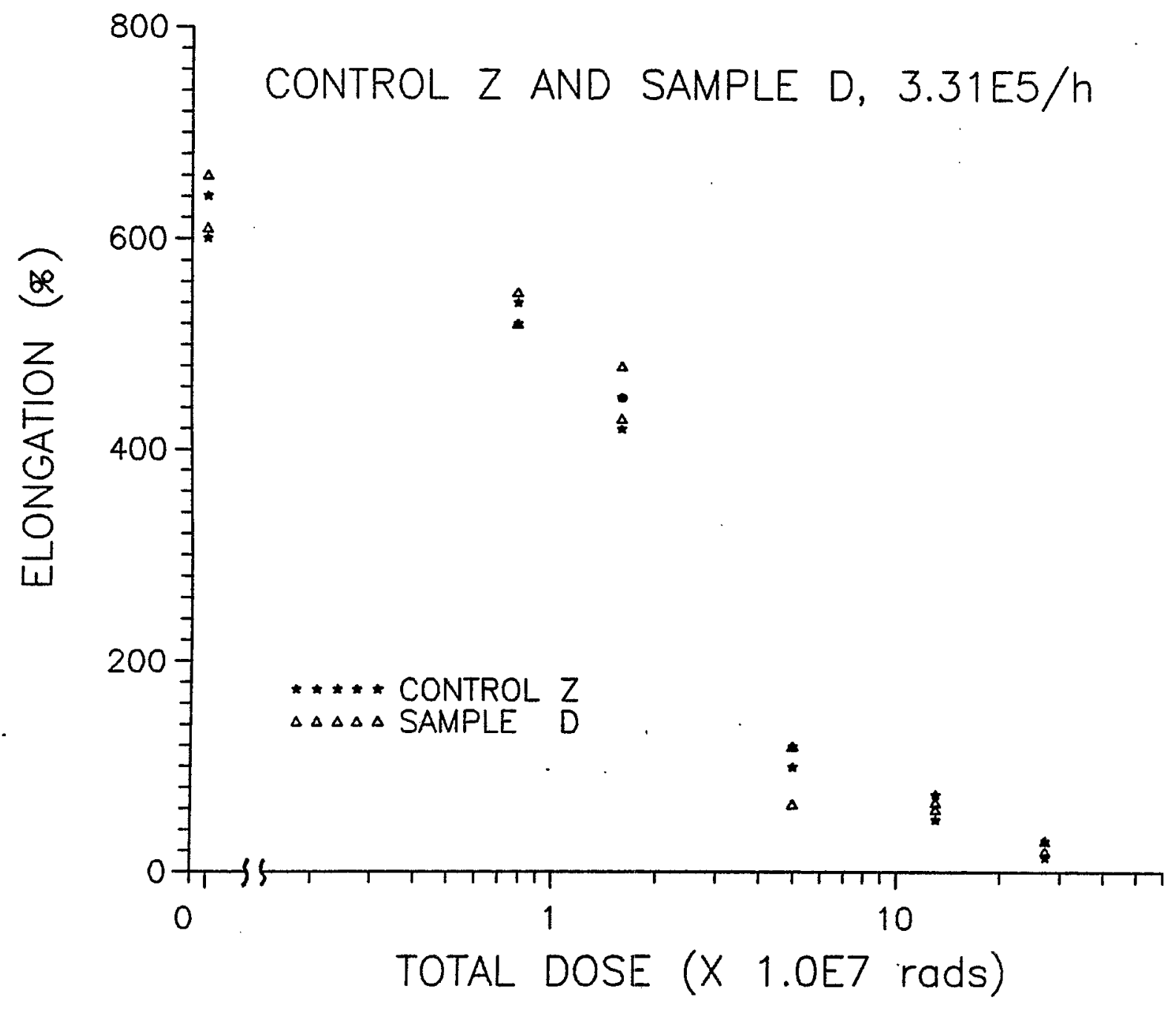

Figure 5.17 Elongation as a function of total dose for samples $D$ and $Z$. Dose rate: $3.31 \times 10^{5} \mathrm{rad} / \mathrm{hour}$. 


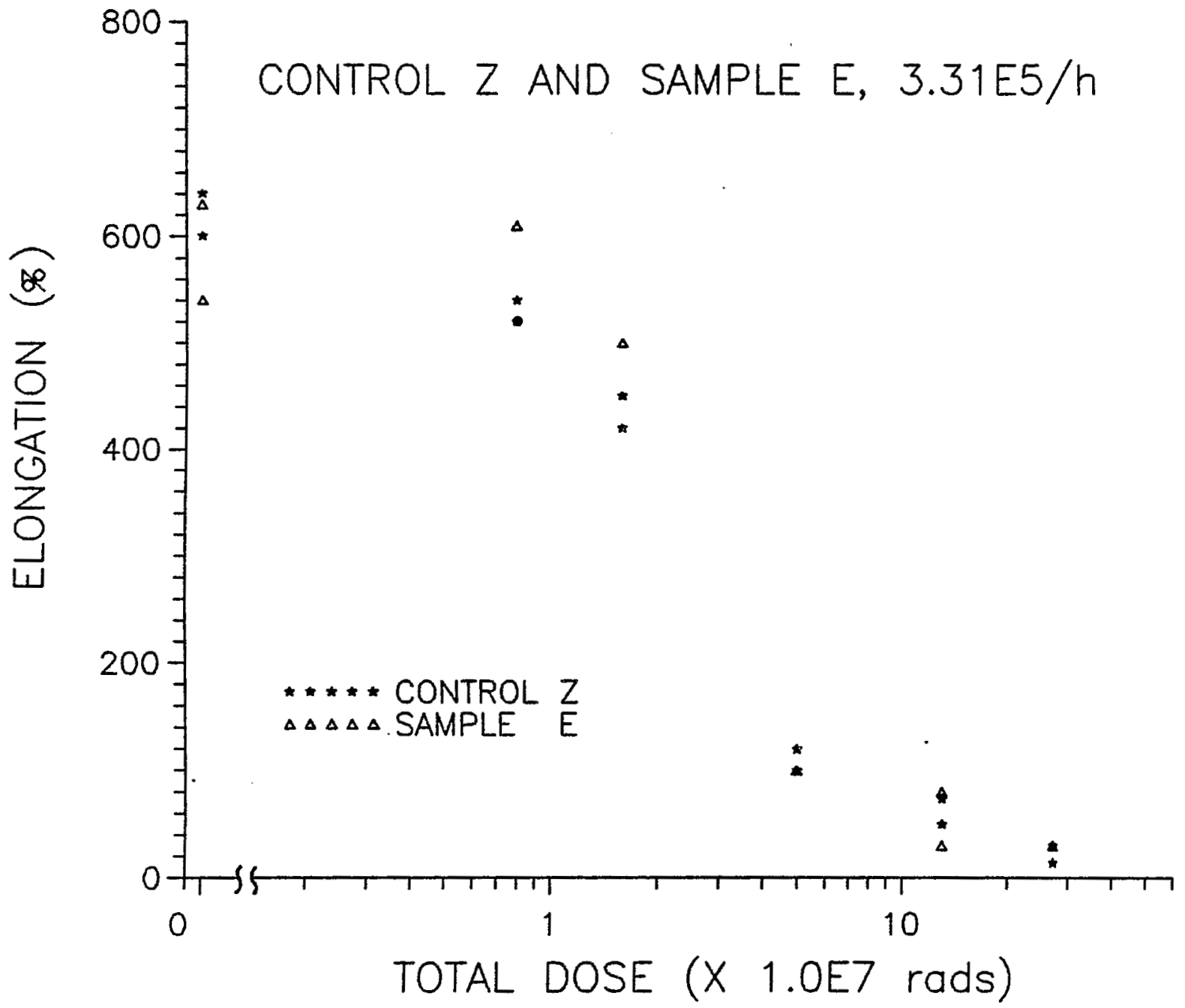

Figure 5.18 Elongation as a function of total dose for samples $E$ and $Z$. Dose rate: $3.31 \times 10^{5} \mathrm{rad} / \mathrm{hour}$. 


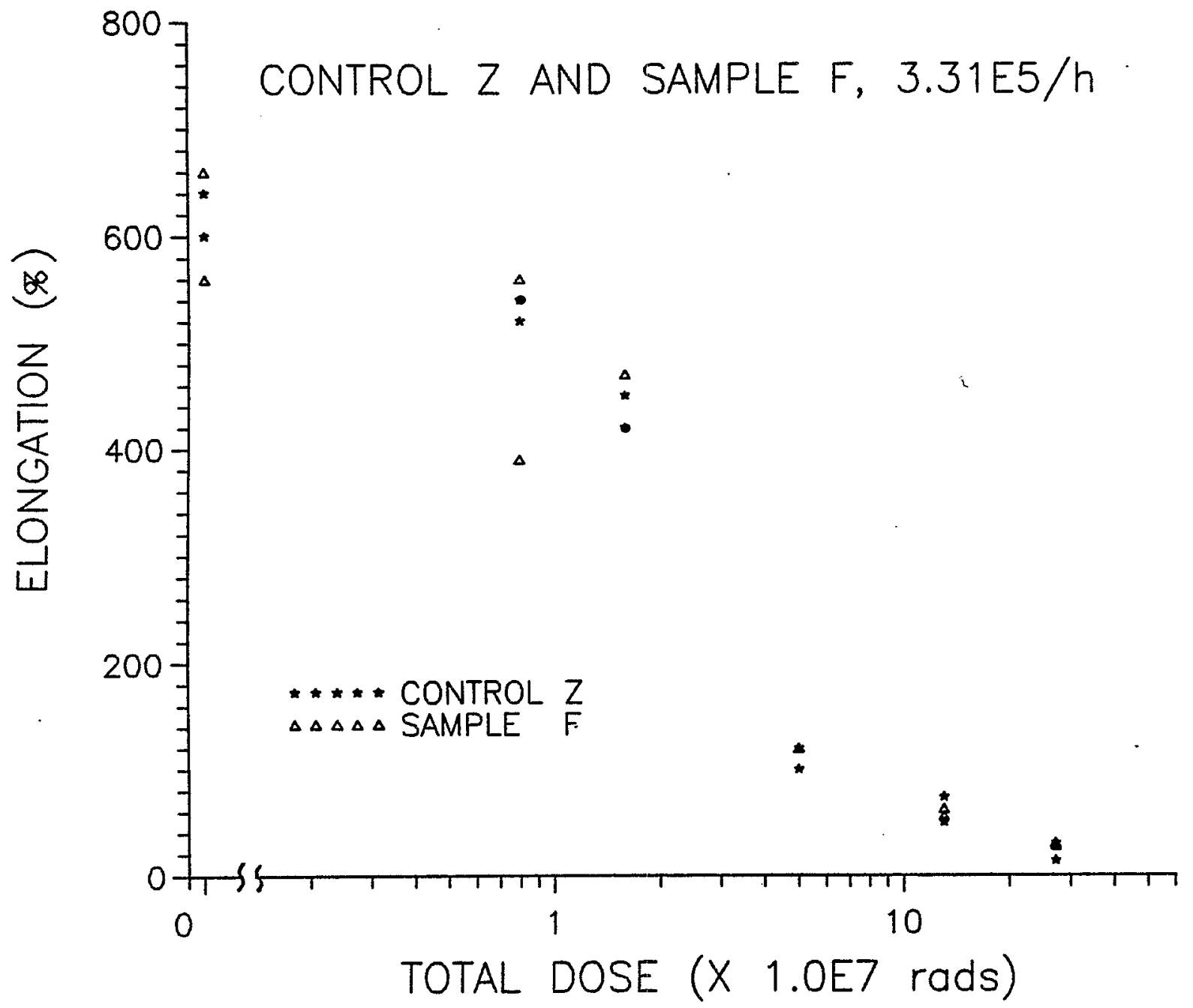

Figure 5.19 Elongation as a function of total dose for samples $F$ and $Z$. Dose rate: $3.31 \times 10^{5} \mathrm{rad} / \mathrm{hour}$. 


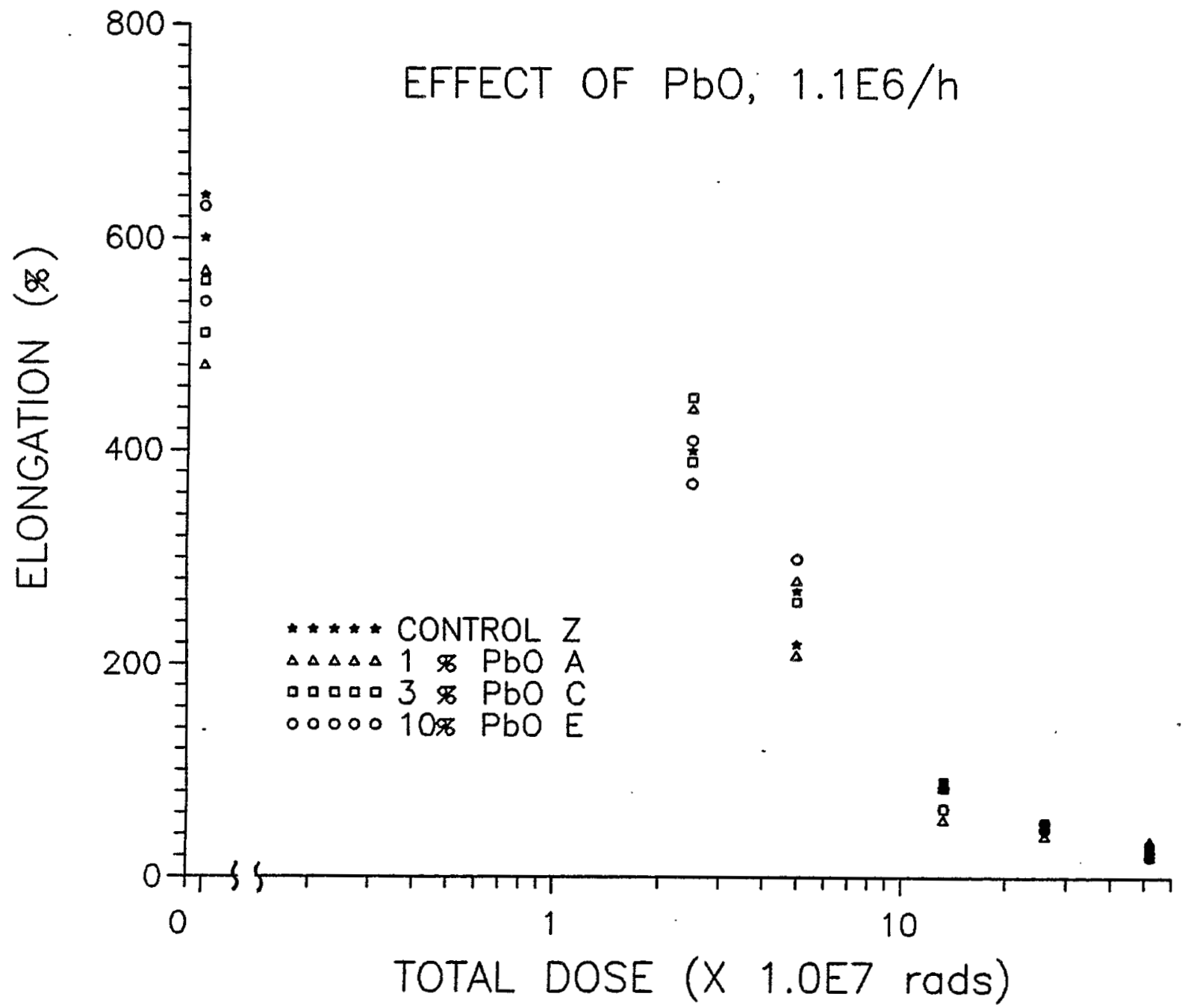

Figure 5.20 Effects of PbO concentration on elongation. Dose rate: $1.1 \times 10^{6} \mathrm{rad} / \mathrm{hour}$. 


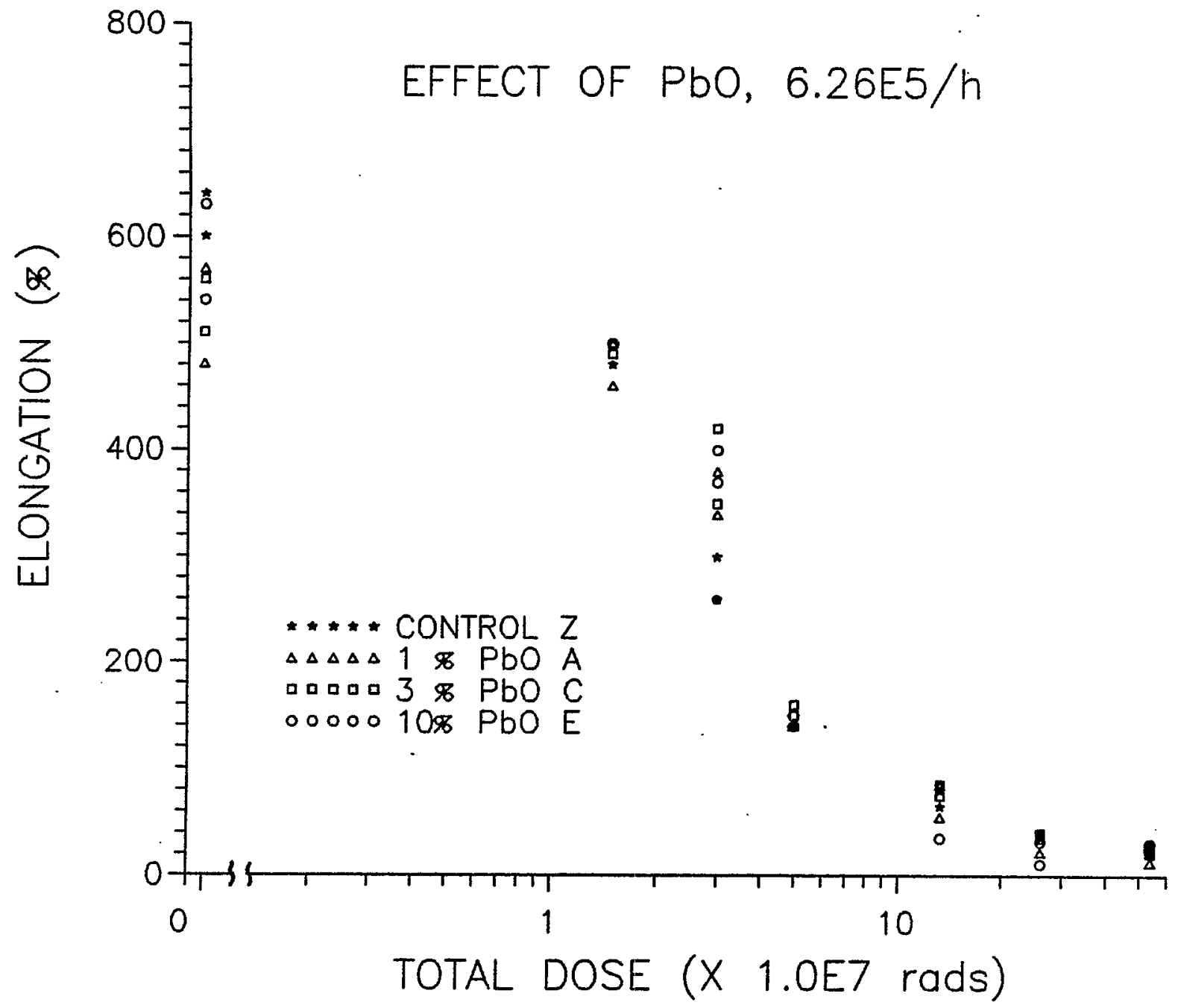

Figure 5.21 Effects Pb0 concentration on elongation. Dose rate: $6.26 \times 10^{5} \mathrm{rad} /$ hour. 


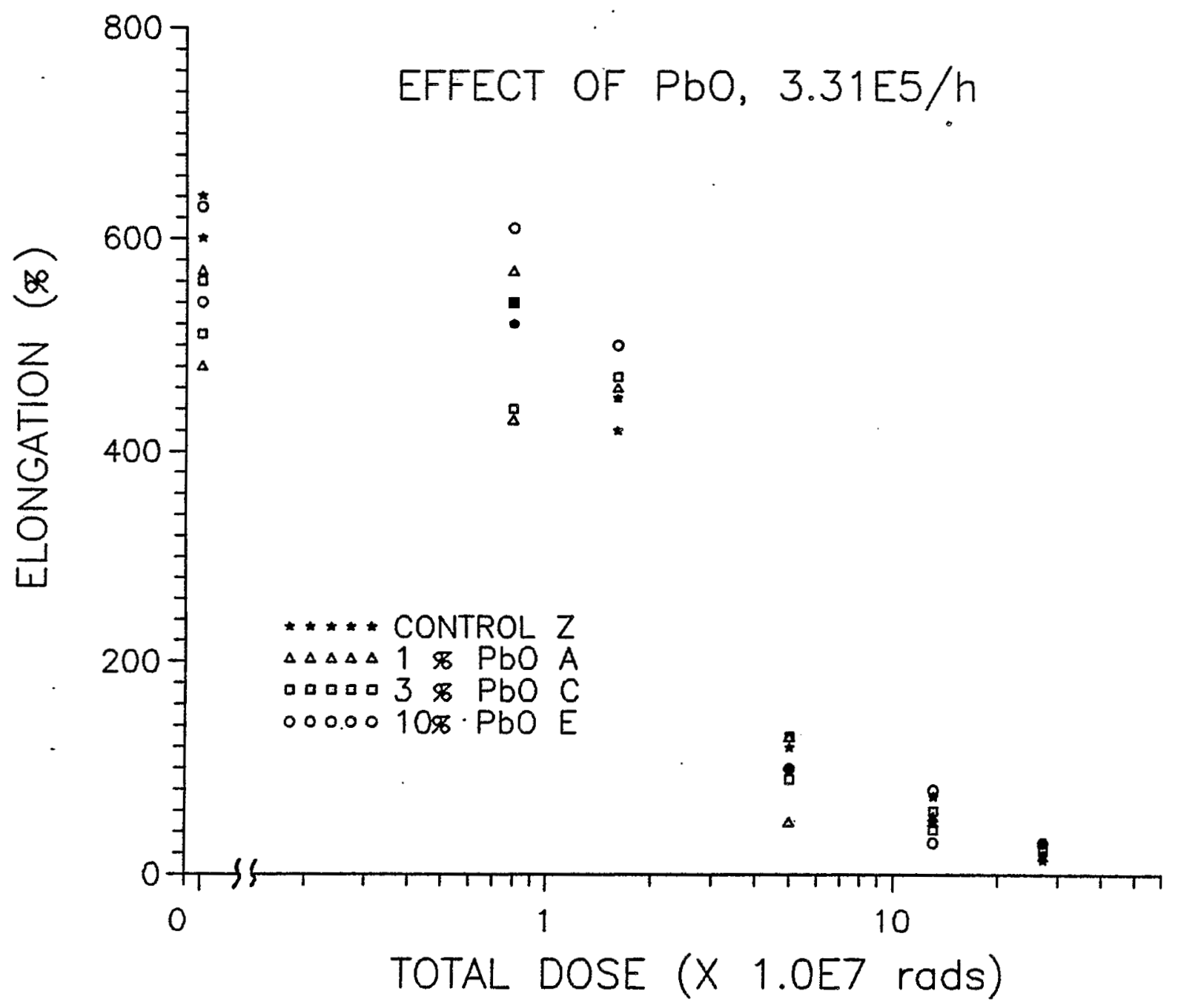

Figure 5.22 Effects of Pb0 concentration on elongation. Dose rate: $3.31 \times 10^{5} \mathrm{rad} /$ hour. 


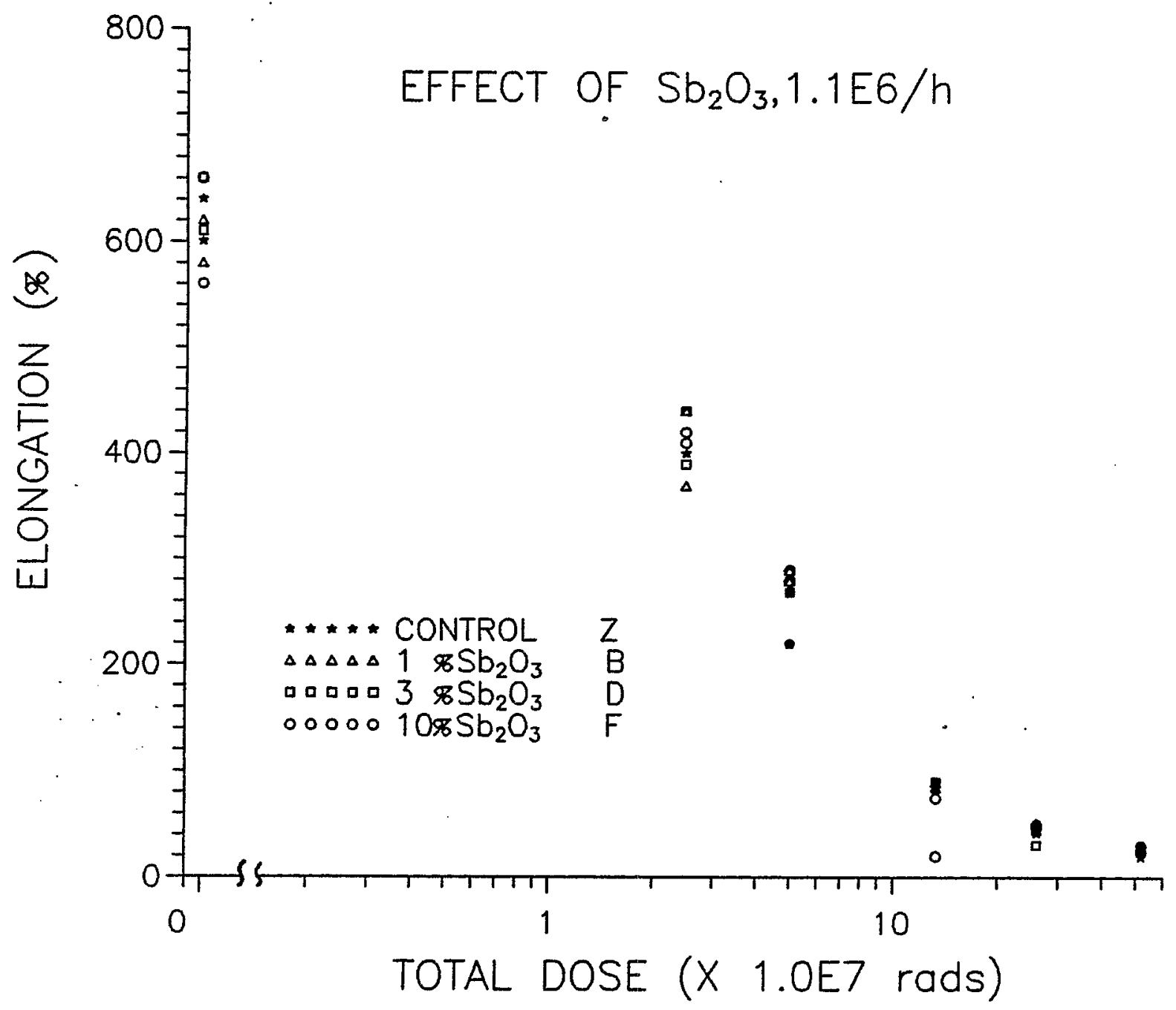

Figure 5.23 Effects of $\mathrm{Sb}_{2} \mathrm{O}_{3}$ concentration on elongation. Dose rate: $1^{2} .1^{3} \times 10^{6} \mathrm{rad} / \mathrm{hour}$. 


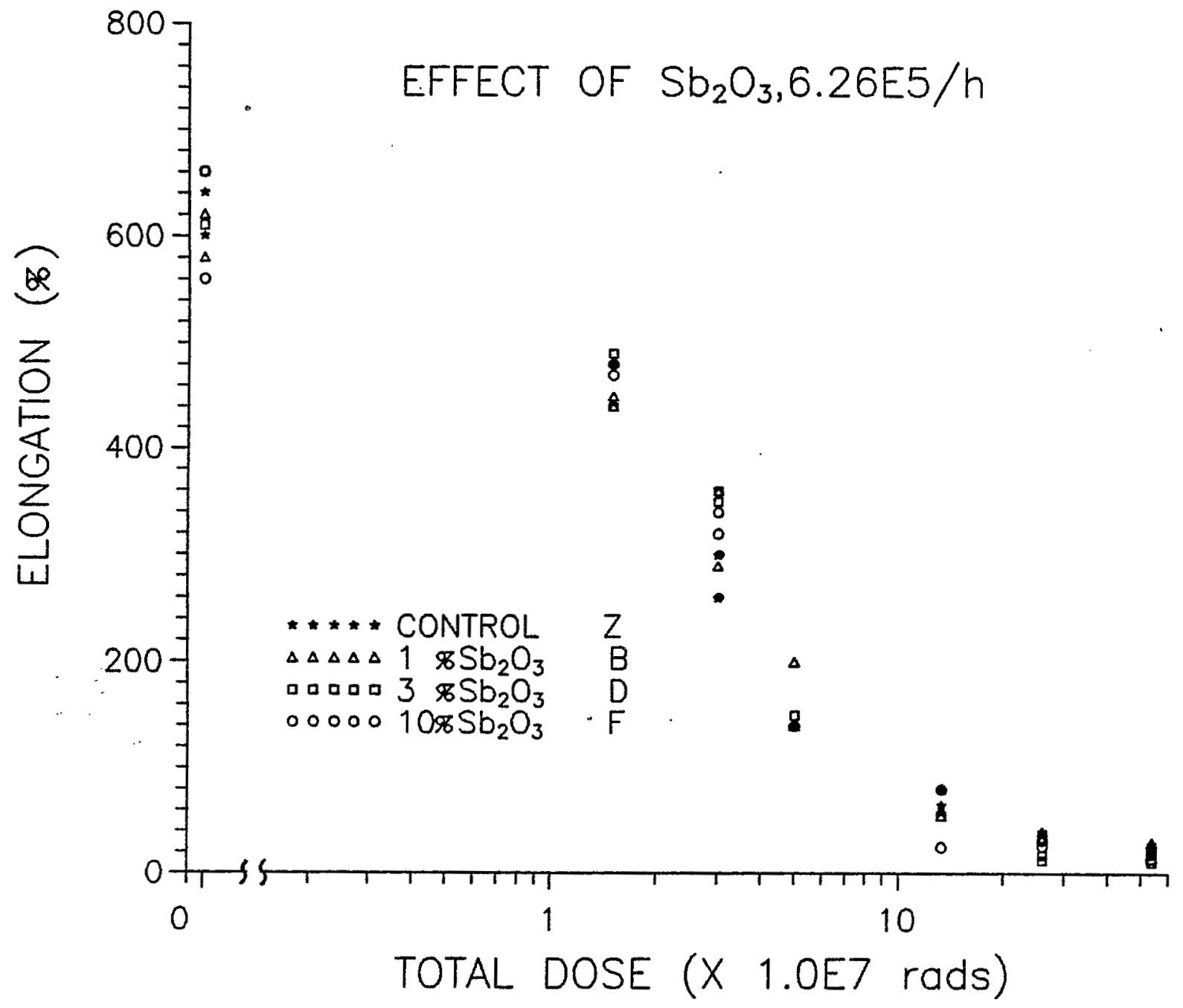

Figure 5.24 Effects of $\mathrm{Sb}_{2} \mathrm{O}_{3}$ concentration on elongation. Dose rate: $6.26 \times 10^{5} \mathrm{rad} / \mathrm{hour}$. 


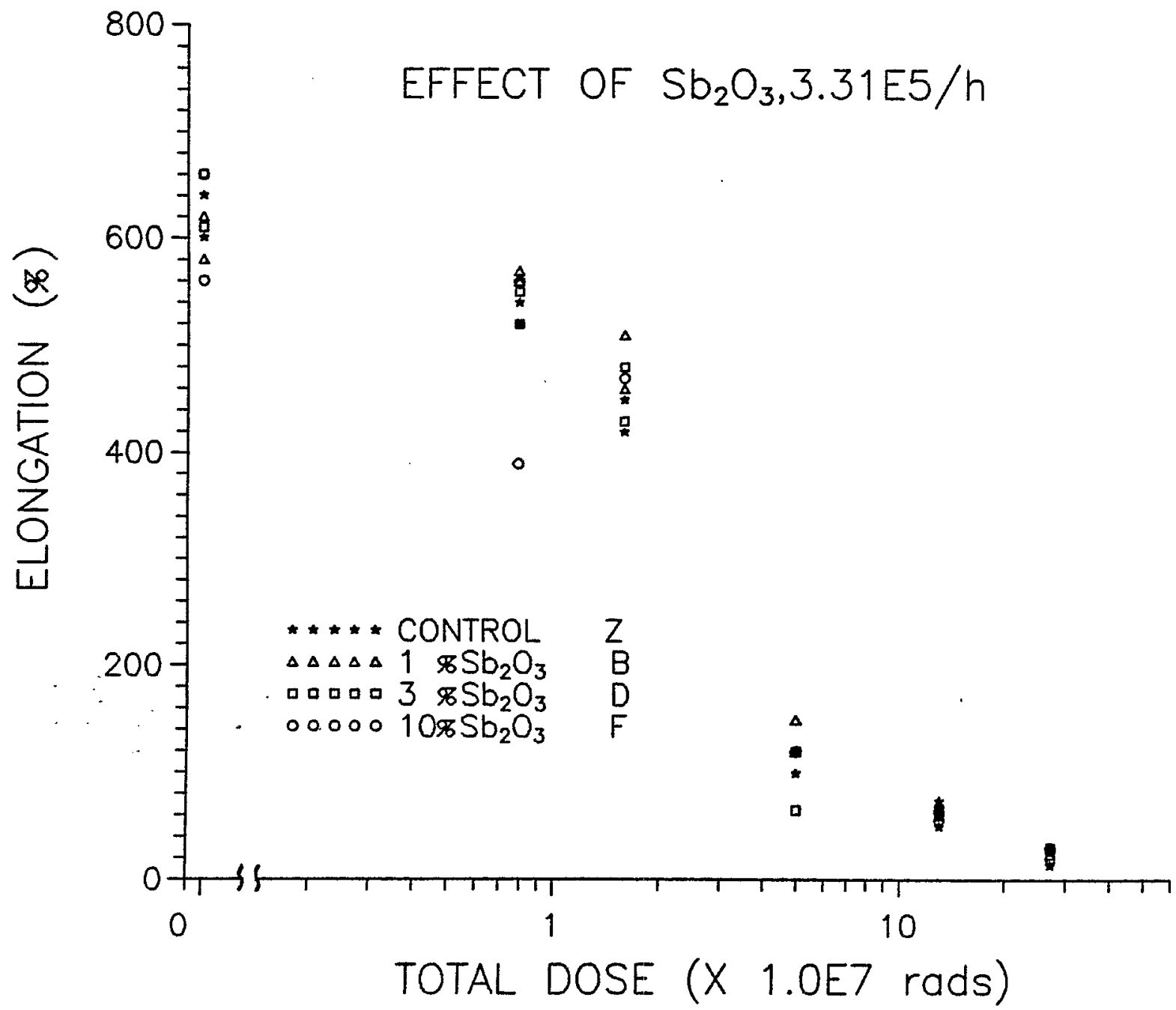

Figure 5.25 Effects of $\mathrm{Sb}_{2} \mathrm{O}_{3}$ concentration on elongation. Dose rate: $3^{2} .31 \times 10^{5} \mathrm{rad} /$ hour. 


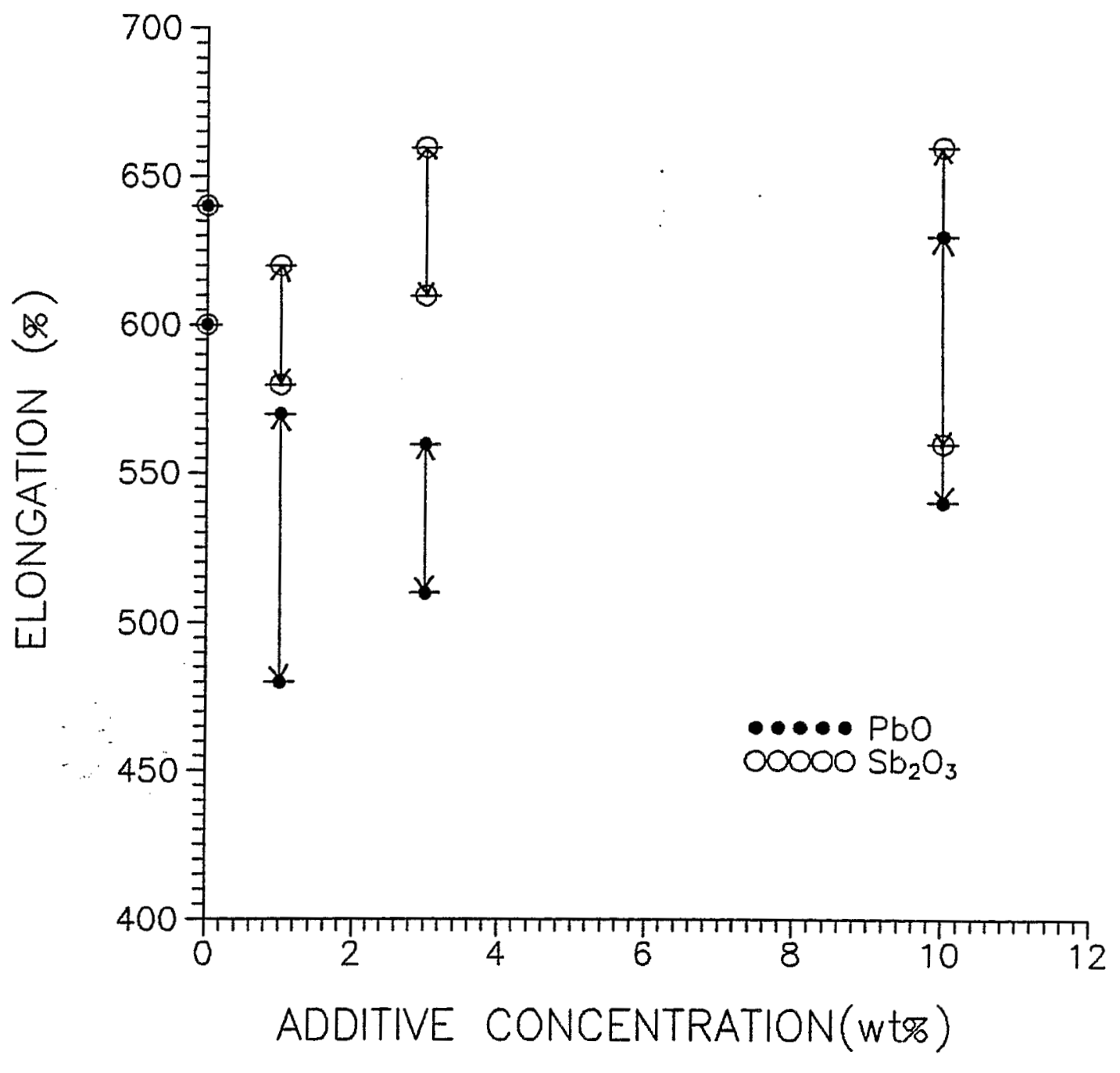

Figure 5.26 Elongation for unirradiated samples with different additive concentrations. 


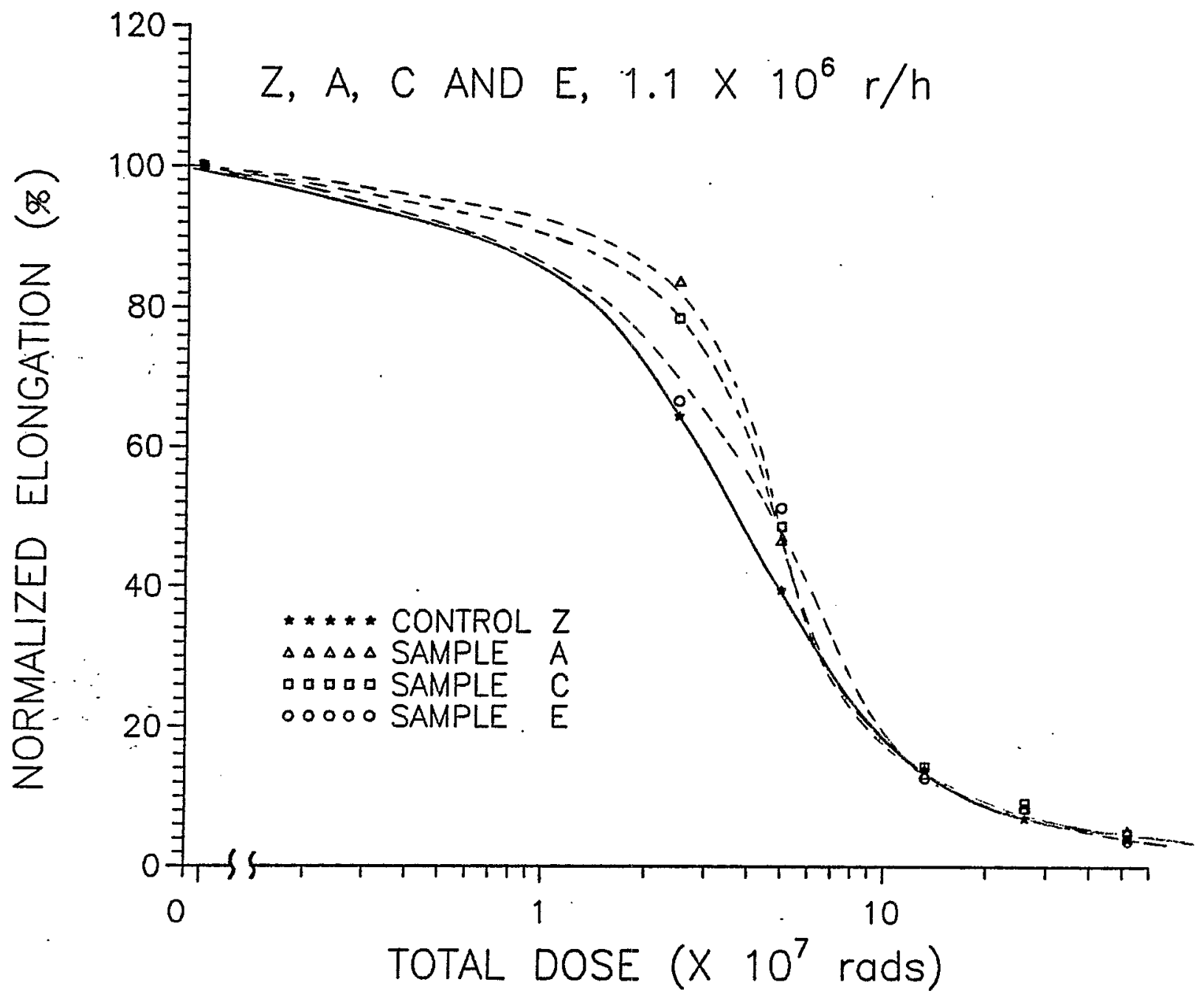

Figure 5.27 Normalized elongation for samples $Z, A, C$, and $E$ irradiated at a dose rate of $1.1 \times 10^{6} \mathrm{rad} / \mathrm{hour}$. 


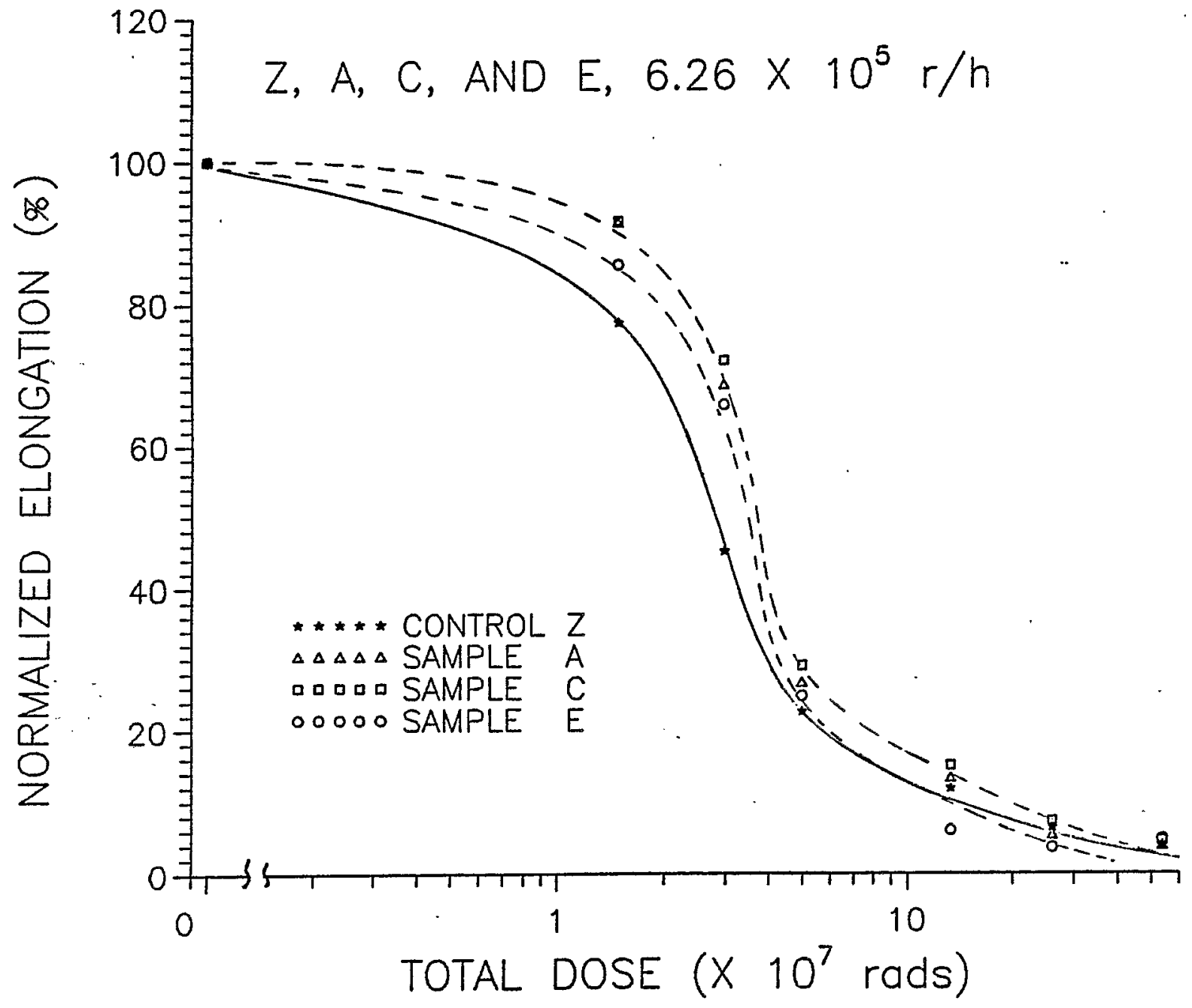

Figure 5.28 Normalized elongation for samples $Z, A, C$, and E irradiated at a dose rate of $6.26 \times 10^{5} \mathrm{rad} / \mathrm{hour}$. 


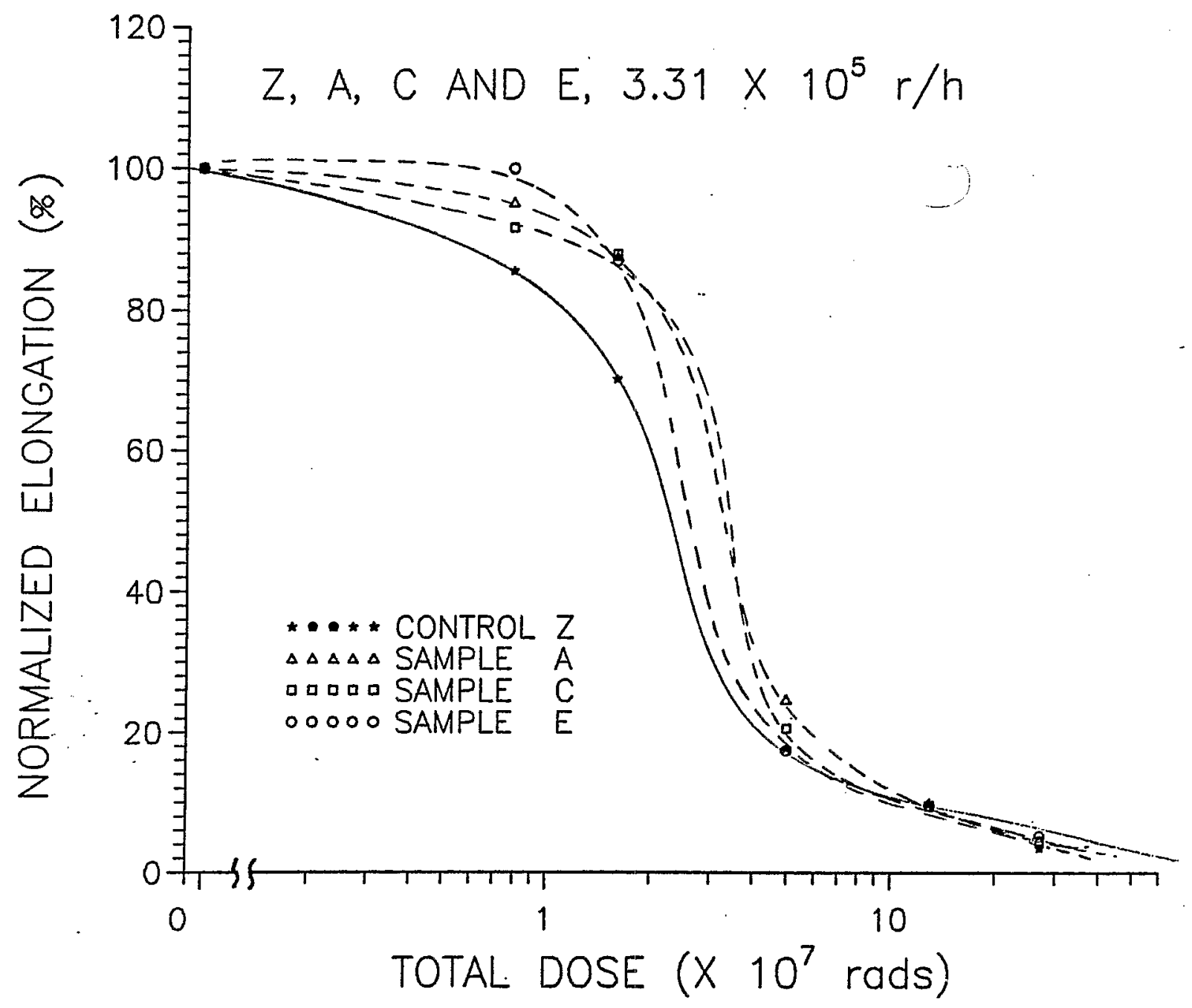

Figure 5.29 Normalized elongation for samples $Z, A, C$, and E irradiated at a dose rate of $3.31 \times 10^{5} \mathrm{rad} /$ hour. 


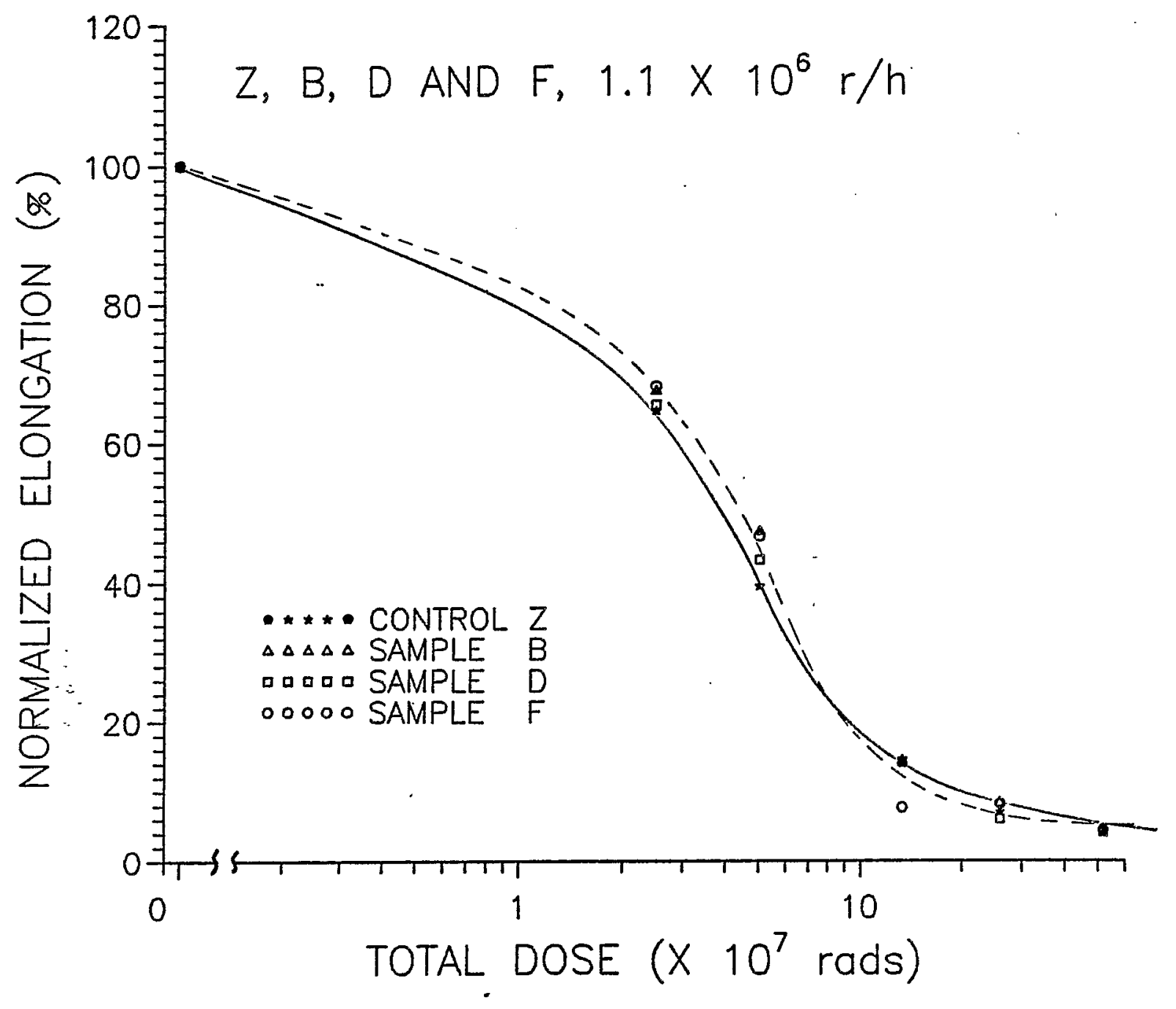

Figure 5.30 Normalized elongation for samples $Z, B, D$, and $F$ irradiated at a dose rate of $1.1 \times 10^{6} \mathrm{rad} /$ hour. 


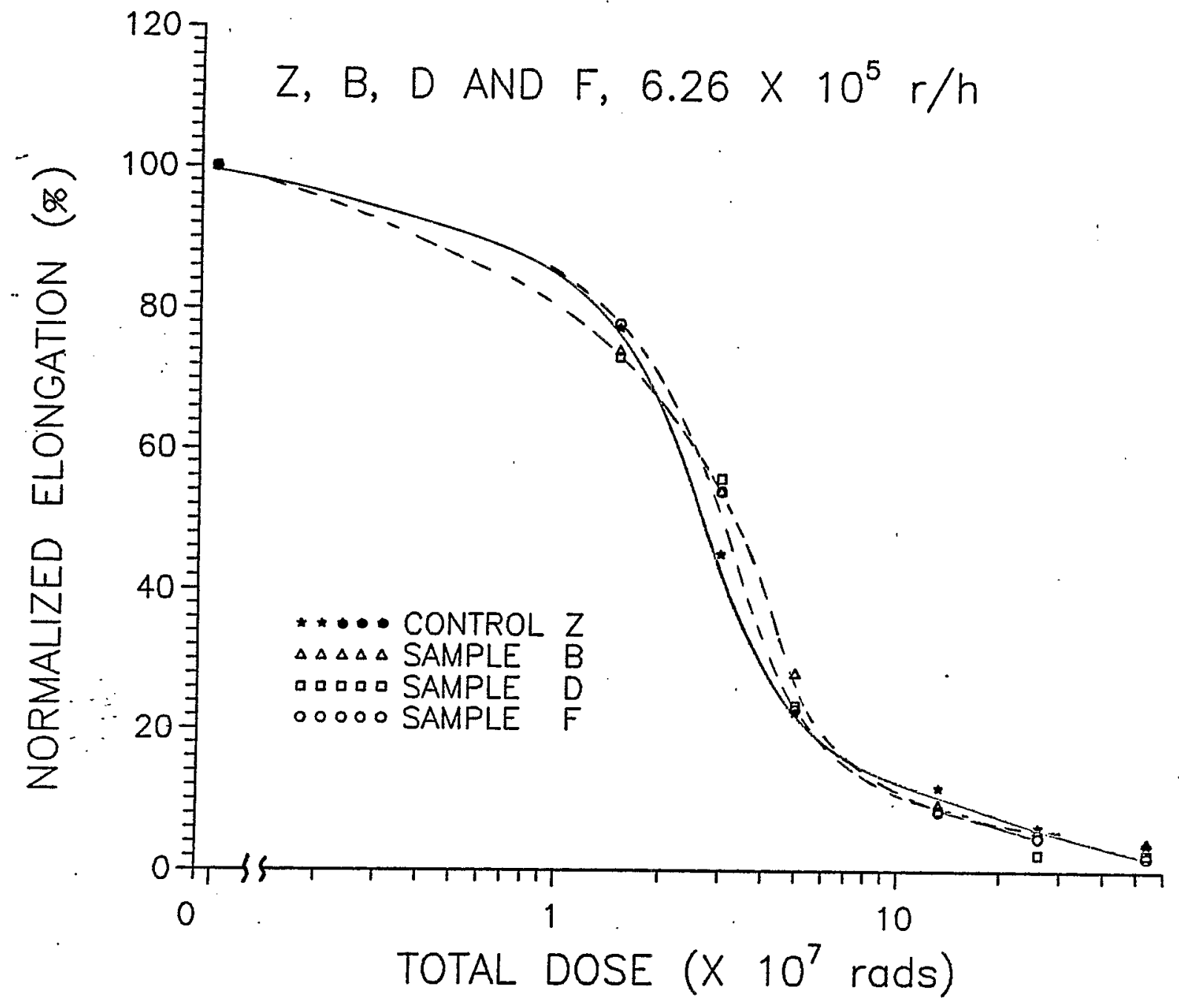

Figure 5.31 Normalized elongation for samples $Z, B, D$, and $F$ irradiated at a dose rate of $6.26 \times 10^{5} \mathrm{rad} / \mathrm{hour}$. 


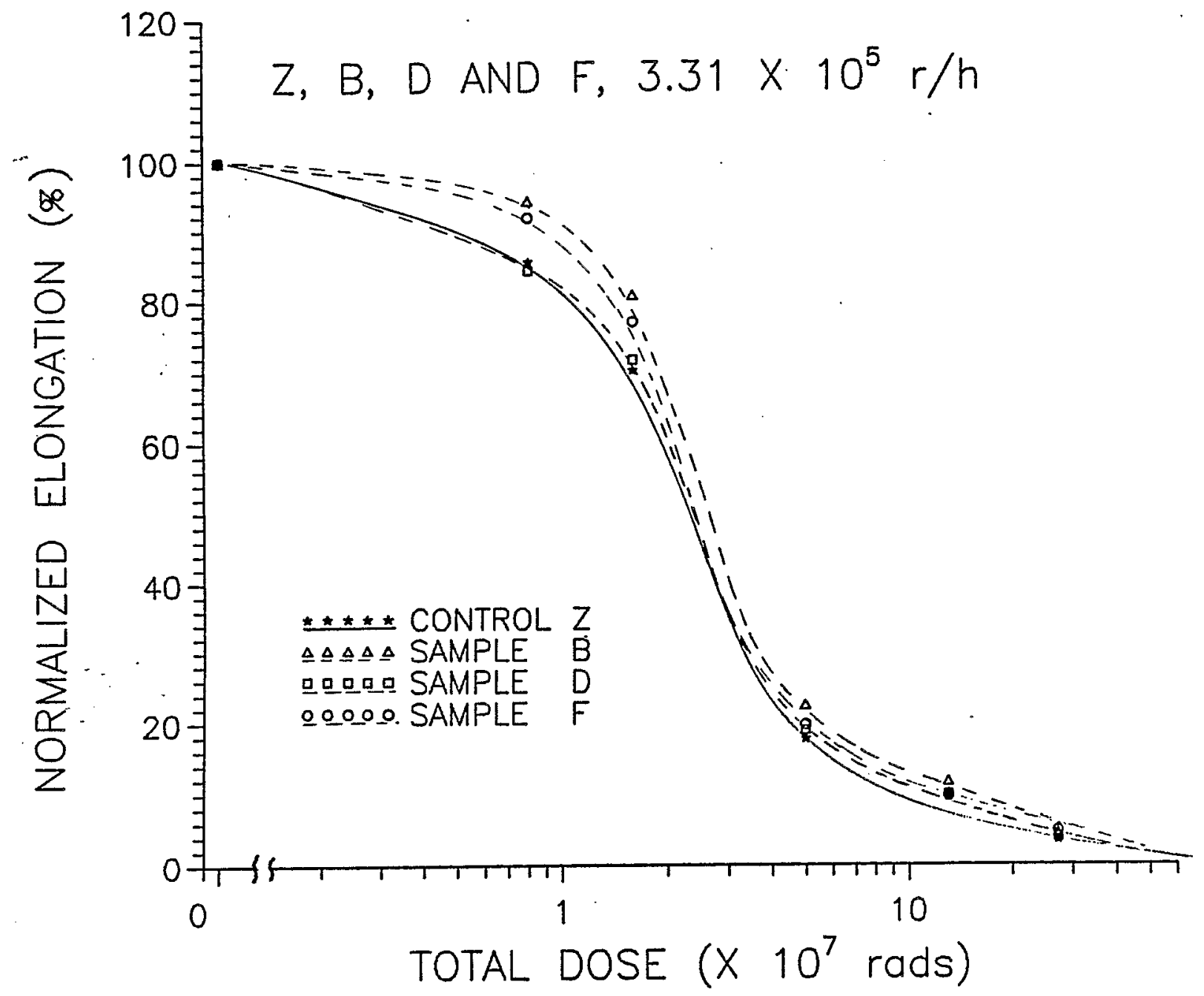

Figure 5.32 Normalized elongation for samples $Z, B, D$, and $F$ irradiated at a dose rate of $3.31 \times 10^{5} \mathrm{rad} / \mathrm{hour}$. 
Based on these results, it is believed that $\mathrm{PbO}$ works effectively as an antioxidant until the total dose reaches a certain level which is determined by the dose rate used and the amount of additive. For instance, at $6.26 \times 10^{5}$ $\mathrm{rad} / \mathrm{h}$, for total doses higher than $3 \times 10^{7}$ rads, the addition of $\mathrm{PbO}$ did not make much difference. For a dose rate of $3.31 \times 10^{5} \mathrm{rad} / \mathrm{h}$, the added $\mathrm{PbO}$ for the samples $A(1 \%)$ and $C(3 \%)$ does not seem to be effective in slowing down RIO after the total dose of $8 \times 10^{6}$ rads was reached, and only the sample $E$ showed improved elongations up to a dose of $1.6 \times 10^{7}$ rads.

Figures $5.23-5.25$ show the effects of $\mathrm{Sb}_{2} \mathrm{O}_{3}$ on the elongation. As can be seen in these figures, $\mathrm{Sb}_{2} \mathrm{O}_{3}$ seems to improve the elongation siightly, which can be said for all the three dose rates used. However, the degree of improvement is not as much as that for PbO.

It should be mentioned that the addition of $\mathrm{PbO}$ to $\mathrm{PE}$ reduces the ductilities, i.e., elongations of the unirradiated samples decrease significantly as shown in Figure 26. Thus, the real effects of the additives as antioxidants may be shown better if the elongation data are normalized to the elongations of the unirradiated samples. In Figures $27-32$ the elongation values were averaged, and normalized to those of unirradiated samples. The same trends as discussed earlier can be seen in these plots except that the rankings of performance are switched in some cases. Again, more data are needed to draw firmer conclusions regarding the optimum composition.

\subsubsection{Dose Rate Effects}

Another way of checking the effectiveness of the additives as antioxidants is by studying the dose rate effect on each sample. When samples are irradiated in an inert environment at different dose rates, the results should not make any difference,i.e, no dose rate effect is expected. By the same reasoning, when the antioxidants work, dose rate effects should be decreased.

Figure 5.33 shows the dose rate effect on the control sample that has no antioxidant. The dose rate effects are noticeable for most of the doses at which data were taken. For the Pbo containing samples, A, C and E, there is a trend that the total dose at which dose effects begin to be noticeable increases as the amount of Pb0 added increases (see Figures 5.34, 5.36 and 5.38). The same trend can be seen in the samples containing $\mathrm{Sb}_{2} \mathrm{O}_{3}$ (see Figures 5.35, 5.37 and 5.39).

The fact that dose rate effects are negligible for the samples with additives until the total doses reach certain levels while dose rate effects are noticeable for the control samples at most of the total doses used can be interpreted that the additives function as antioxidants. Thus, the information from this dose rate effects analysis also support the conclusions obtained from the effects of the additives analysis. 


\subsection{Conclusions and Recommendations}

The following conclusions may be drawn from this study:

1. The concept of using inorganic antioxidants to retard radiation initiated oxidation is viable.

2. $\mathrm{PbO}$ is more effective than $\mathrm{Sb}_{2} \mathrm{O}_{3}$ in slowing down radiation initiated oxidation.

The following future studies are recommended:

1. Add different inorganic antioxidants, including carbon b7ack, to a study so that the radiation initiated oxidation mechanism may be studied in detail.

2. Longer term experiments at lower dose rates should be conducted to test the ability to predict the cable lifetime under realistic conditions. 


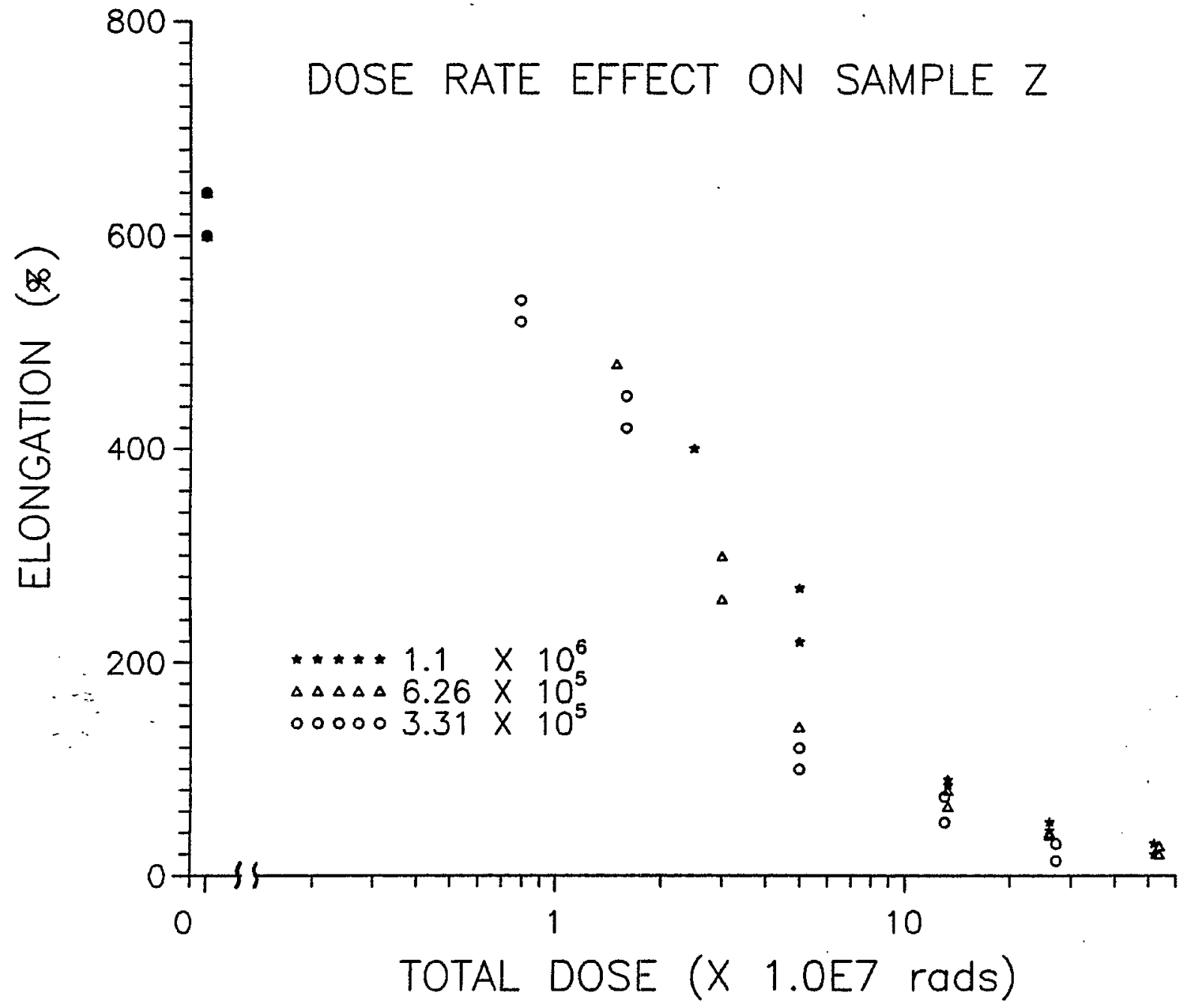

Figure 5.33 Effects of different dose rates on elongation of sample $Z$. 


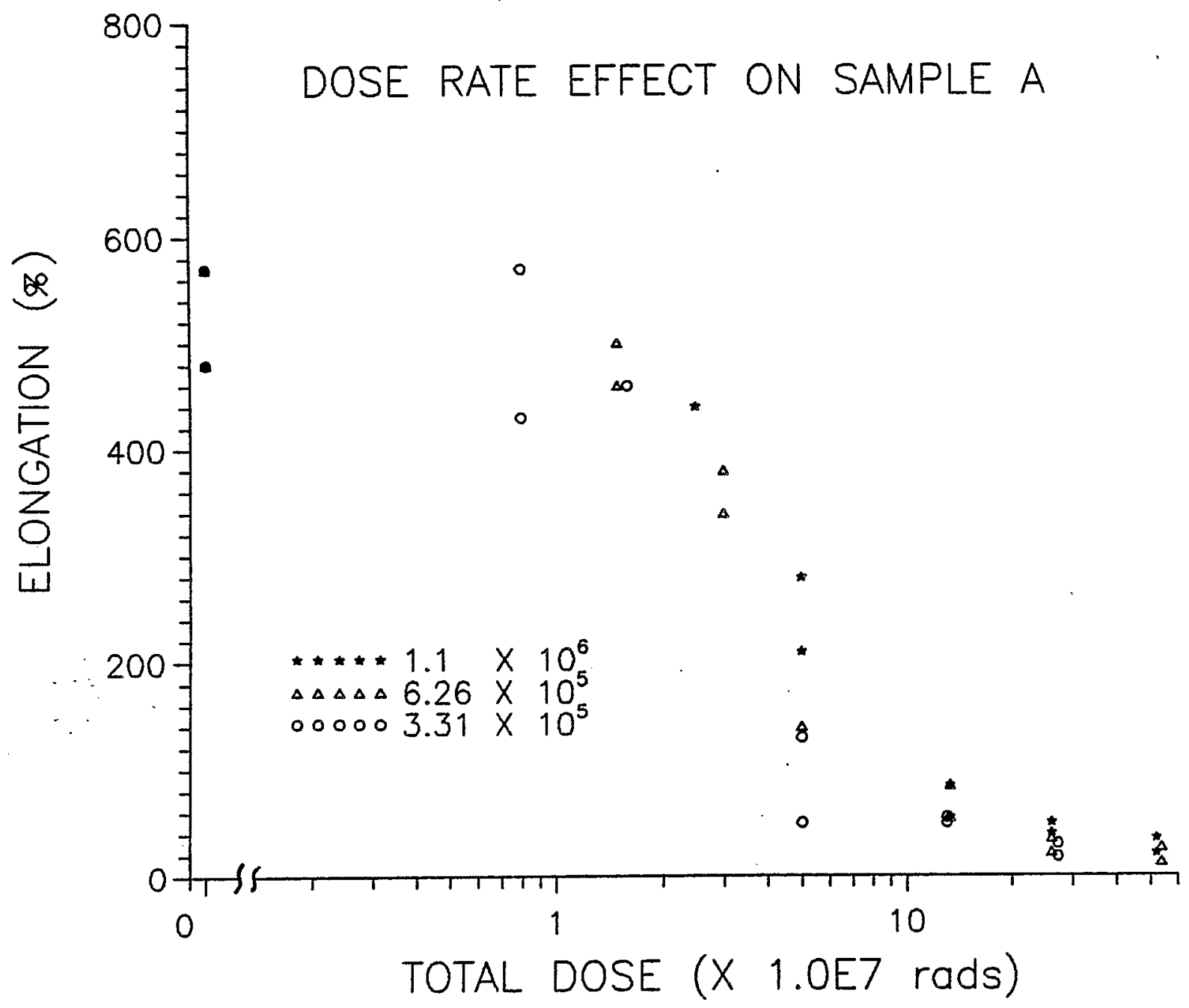

Figure 5.34 Effects of different dose rates on elongation of sample $A$. 


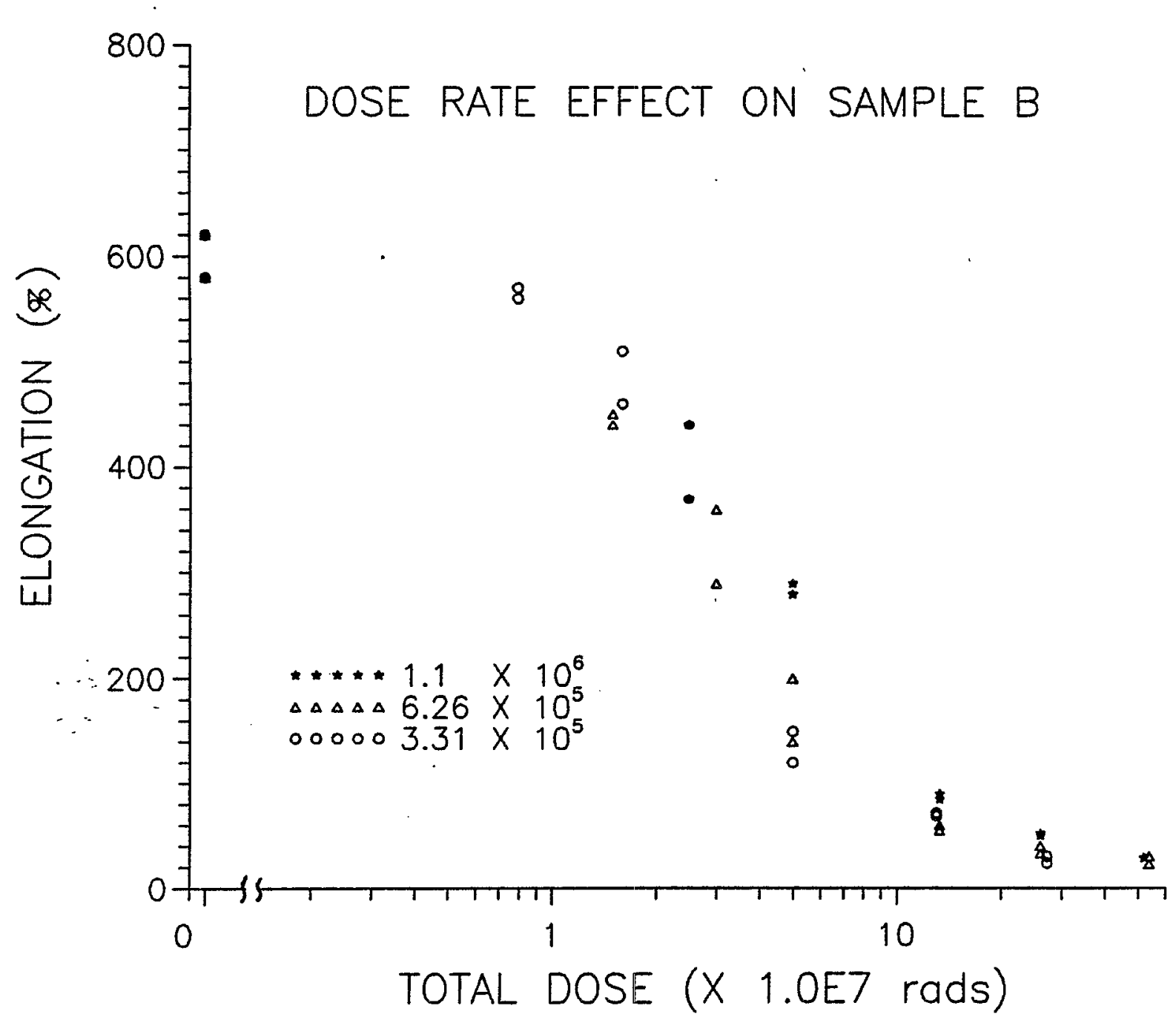

Figure 5.35 Effects of different dose rates on elongation of sample $B$. 


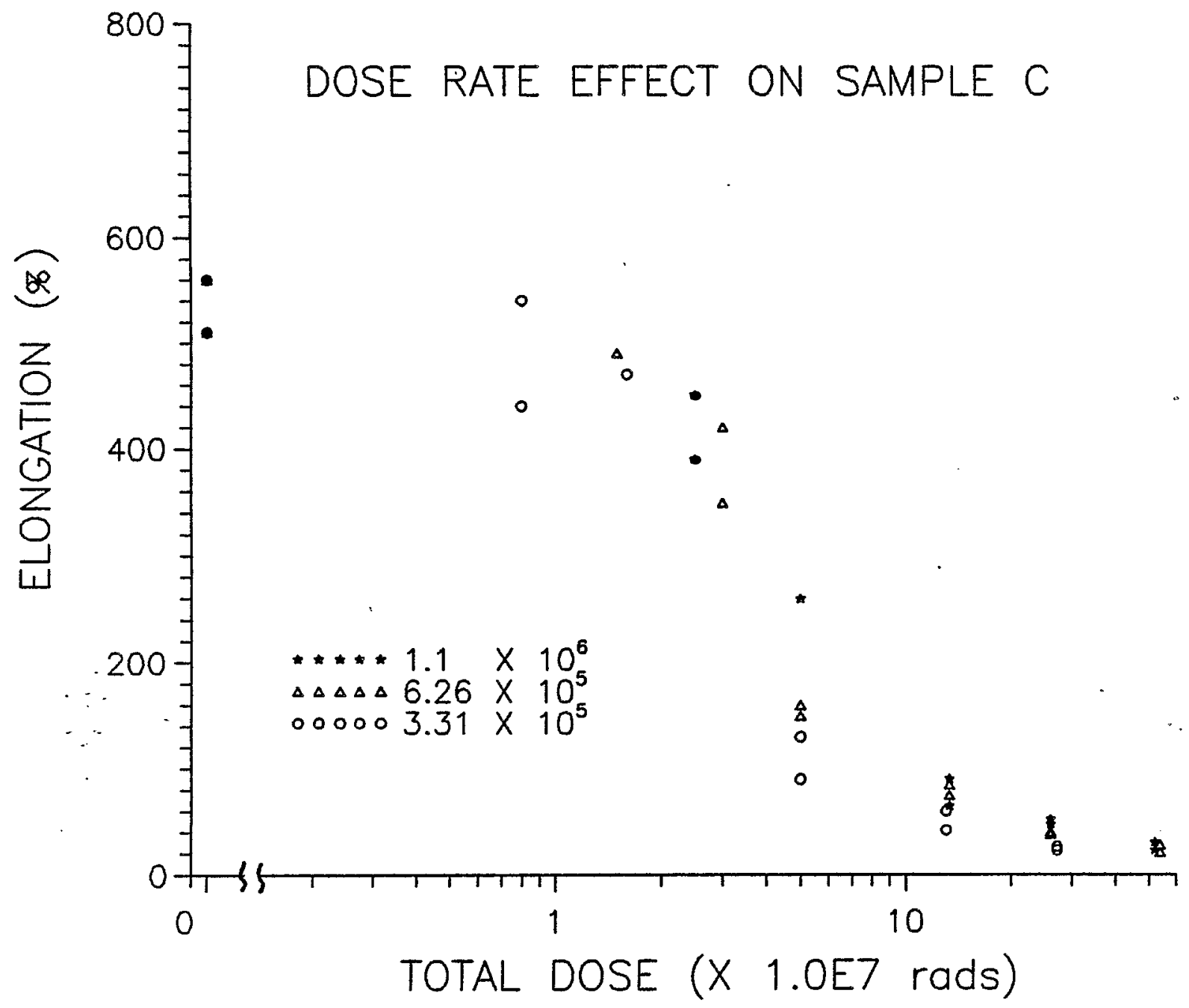

Figure 5.36 Effects of different dose rates on elongation of sample $C$. 


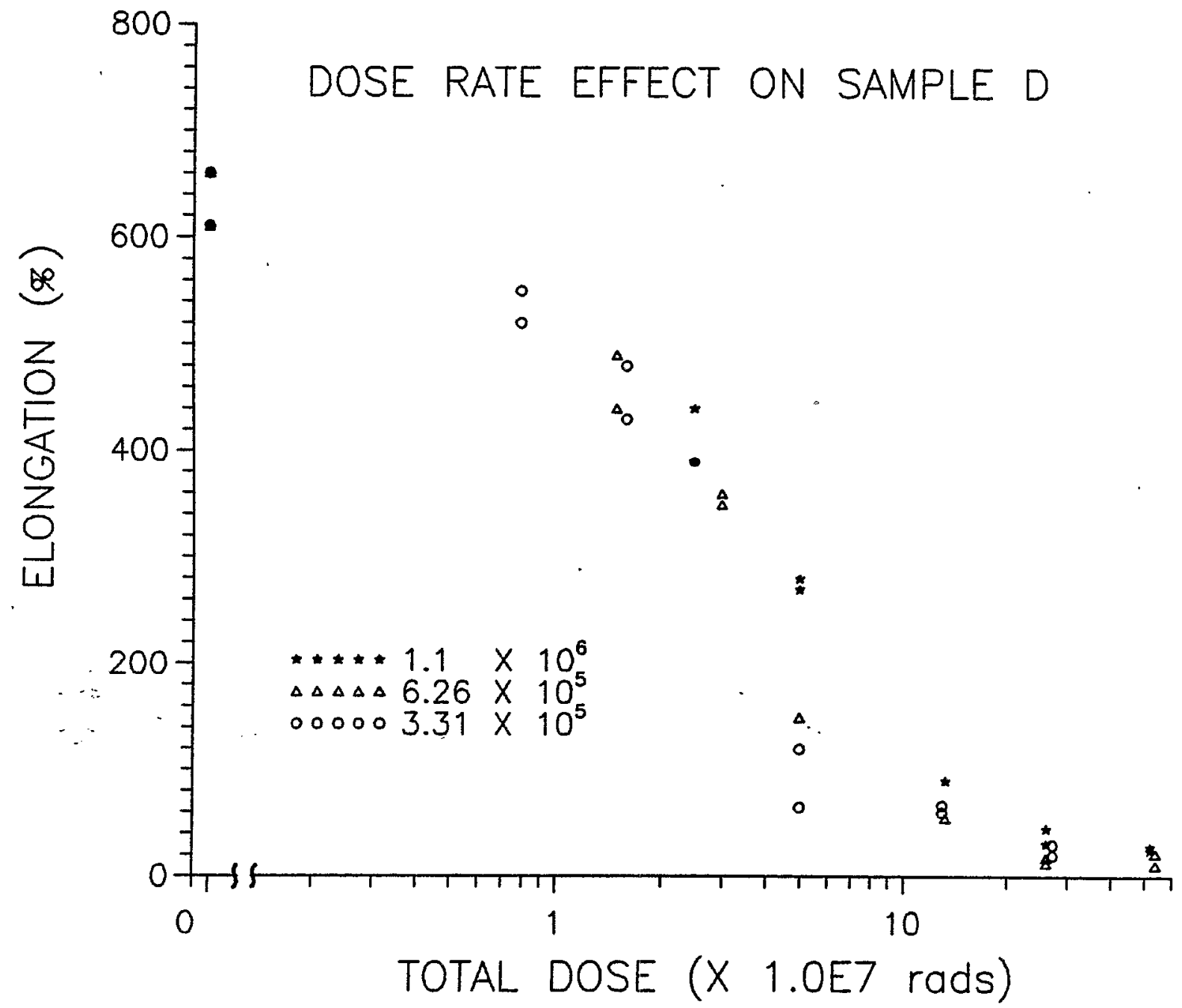

Figure 5.37 Effects of different dose rates on elongation of sample $D$. 


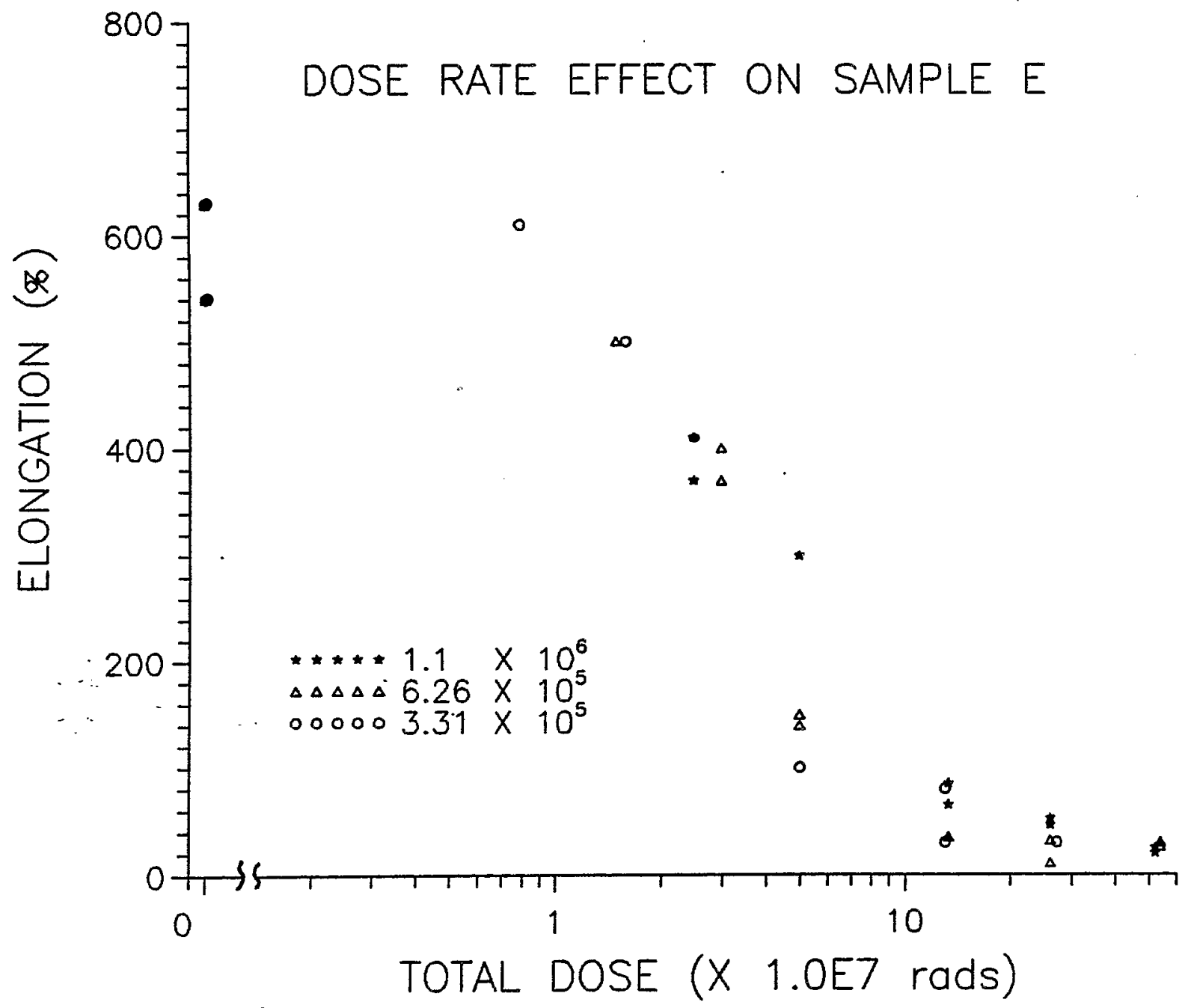

Figure 5.38 Effects of different dose rates on elongation of sample $E$. 


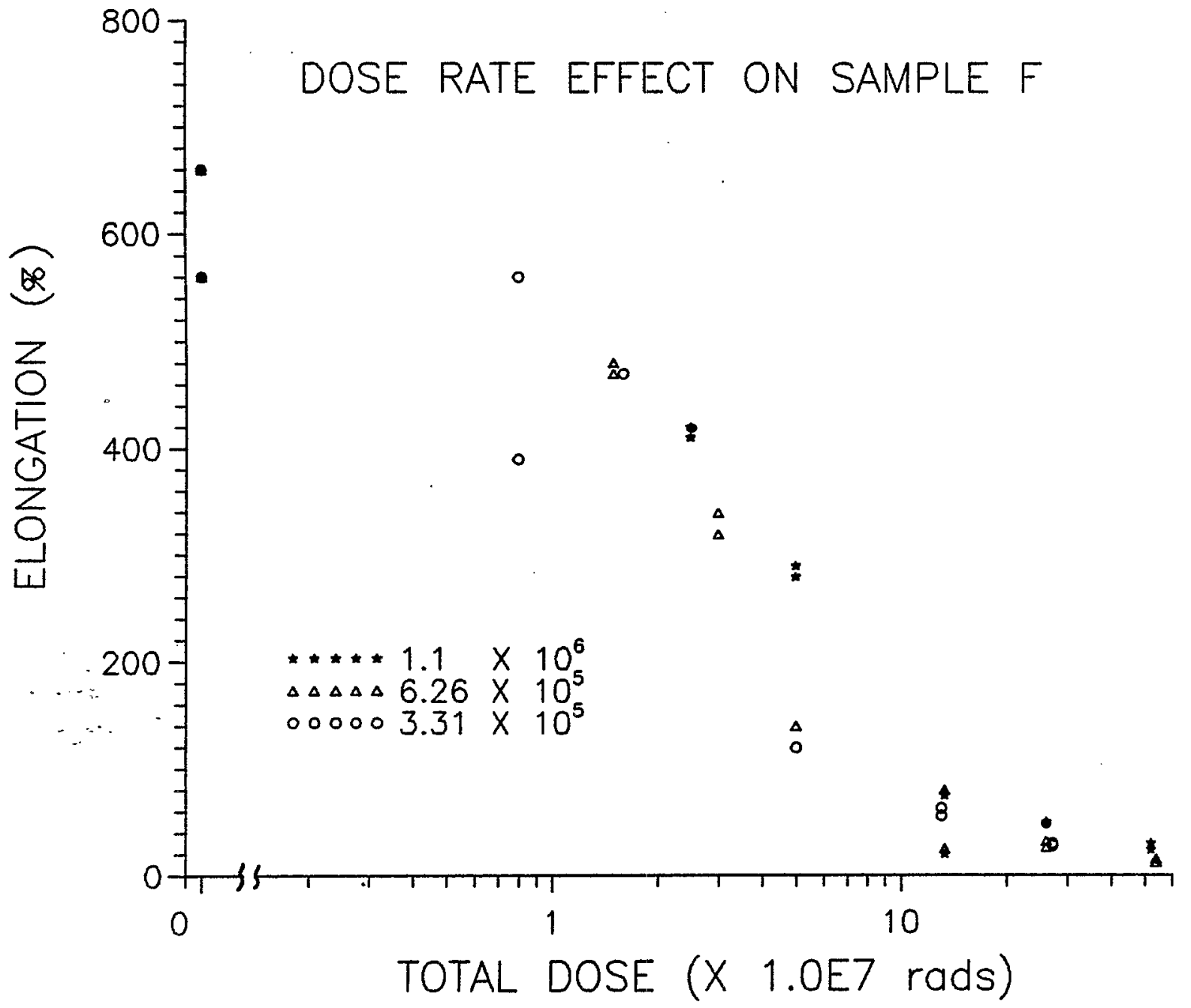

Figure 5.39 Effects of different dose rates on elongation of sample $F$. 


\section{REFERENCES}

[B] odgett, 1969]

R. B. Blodgett and R. G. Fisher, "Insulations and Jackets for Control and Power Cables in Thermal Reactor Nuclear Generating Stations," IEEE Trans. Power Apparatus and Sys., V. PAS-88, 529, 1969.

[Clough, 1982]

R. L. Clough and K. T. Gillen, "Investigation of Cable Deterioration Inside Reactor Containment," Nuc7.Technology 59, 344-54, 1982.

[Schnabel, 1981]

W. Schnabe1, Polymer Degradation, Hanser Internationa1, Munchen, 1981.

[Clough. 1988]

R. L. Clough, "Radiation Resistant Polymers," SAND 7-1, 1988, to appear as a chapter in Encyclopedia of Polymer Science and Engineering, John Wiley and Sons, Inc.

[Juran, 1988]

R. Juran, editor, Modern Plastic Encyclopedia 89, McGraw-Hi11, Inc:, New York, pp 143-144, 1988 .

[Mackenzie, 1989]

D. R. Mackenzie, "Radiation Studies on Plastics Used for Insulation and Sheathing of Electric Cables in Reactor Containment and other Relatively High Radiation Areas," BNL Internal Memorandum, 1989; see Appendix to this report. 


\section{APPENDIX}


DATE: $\quad$ March 1, 1989

TO: $\quad$ File \#90

FROM :

D. R. Mackenzie

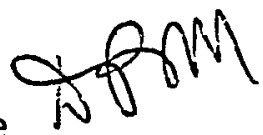

SUBJECT: Radiation Studies on Plastics Used for Insulation and Sheathing of Electric Cables in Reactor Containment and Other Relatively High Radiation Areas.

In the past dozen years, many studies have been carried out on the effects of radiation on polymeric materials used for electrical insulation, sheathing, gasketing and other applications in the relatively high radiation fields inside nuclear reactor containment buildings and around high-energy particle accelerators [1-7]. Much of this work was initiated when it became apparent that polymeric materials in service had become seriously degraded at radiation doses much lower than it had been thought would be damaging -- i.e., their service lives were much shorter than predicted on the basis of the previousiy standard radiation tests performed on them. The principal differences between service conditions and test conditions were in the dose rates and temperatures -- dose rates in service were several orders of magnitude lower, and temperatures were often modestly, though significantly, higher. Thus, the important work in this area has concentrated on dose rate effects and synergy between dose rate and temperature (see particularly references 1 and 2 ).

Although the exact reasons for and precise mechanisms of the radiation and thermal effects are not known in detail, a general idea of the chemical processes involved has begun to emerge. As an indication of the types of effects observed in the field, the following items are reproduced from R. L. Clough's chapter in the recently published, "Encyclopedia of Polymer Science and Engineering" [8].

"Dose-rate effects can have dramatic practical consequences. Several illustrative examples are given below. When preirradiated pipes constructed of low density polyethylene were subsequentiy pressurized to $4 \mathrm{~N} / \mathrm{mm}^{2}$, and the time to rupture measured, the following observation was made. For pipes preirradiated at high dose rate $\left(10^{4} \mathrm{~Gy} / \mathrm{h}\right)$, material properties improved: rupture time was increased from the initial (unirradiated) value of $100 \mathrm{hr}$ up to $10^{4} \mathrm{hr}$ at doses of $2 \times 10^{5}$ Gy or higher. For pipes irradiated at low dose rate (4 Gy/h), material properties decreased rupture times dropped to iess than one minute at doses above $7 \times 10^{4}$ Gy. For power cables 
exposed to long-term irradiation at low dose rate $(.25 \mathrm{~Gy} / \mathrm{h})$ in the containment room of a nuclear reactor, the polyethylene insulation was completely embrittled after a dose of $2.5 \times 10^{4}$ Gy. In short-term, high-dose-rate laboratory experiments $\left(10^{4}\right.$ $G y / h)$, there was no detectable change in mechanical properties of this same material (within experimental error) after the same dose; embrittlement of the material required $>10^{6}$ Gy. When a Viton gasket material was irradiated at $6 \times 10^{3} \mathrm{~Gy} / \mathrm{h}$, the material became progressively harder as it degraded, eventually becoming embrittled. In contrast, when samples of the same Viton material were irradiated at $10^{2} \mathrm{~Gy} / \mathrm{h}$, the material became progressively softer, weaker, and more easily stretched as it degraded."

The effects of high-dose-rate or inert atmosphere irradiation had been studied for many years before the low-dose-rate effects were realized. The former were determined to be largely due to polymer chain breakage or crosslinking between chains or a combination of the two. These reactions can be presented, for hydrocarbon chains, as:

$$
\begin{aligned}
& \mathrm{R}-\mathrm{CH}_{2}-\mathrm{CH}_{2}-\mathrm{R}^{\prime} \frac{\text { radiation }}{\mathrm{R}-\mathrm{CH}_{2}-\mathrm{CH}_{-} \mathrm{R}^{\prime}+\mathrm{H}} \\
& \mathrm{R}-\mathrm{CH}_{2}-\dot{\mathrm{CH}}-\mathrm{R}^{\prime} \frac{\text { chain }}{\text { scission }} \mathrm{R} \cdot+\mathrm{CH}_{2}=\mathrm{CH}-\mathrm{R}^{\prime} \\
& \therefore \\
& \mathrm{R}-\mathrm{CH}_{2}-\mathrm{CH}-\mathrm{R}^{\prime} \quad \frac{\text { chain }}{\text { Tinking }}-\mathrm{CH}_{2}-\left.\right|_{\mathrm{CH}} ^{\prime \prime}-\mathrm{R}^{\prime} \\
& \mathrm{R}^{\prime \prime}-\mathrm{CH}_{2}-\mathrm{CH}-\mathrm{R}^{\prime \prime} \quad \mathrm{CH}_{2}-\mathrm{CH}-\mathrm{R}^{\prime \prime}
\end{aligned}
$$

At low dose rate in an atmosphere containing oxygen (e.g., air) the primary radicals formed from interaction of radiation with the polymer molecules undergo rapid reaction with molecular oxygen.

$$
\mathrm{R}-\mathrm{CH}_{2}-\dot{\mathrm{CH}}-\mathrm{R}^{\prime} \stackrel{\mathrm{O}_{2}}{\mathrm{R}}-\mathrm{CH}_{2}-\mathrm{CHO}_{2}-\mathrm{R}^{\prime}
$$

the oxygenated radical being represented simply by the formula $\mathrm{RO}_{2} \cdot$. The $\mathrm{RO}_{2}$. radicals then undergo various types of reactions, including chain propagation and chain branching. This generally leads to much higher G-values for polymer degradation than in the absence of oxygen, depending, of course, on the chemical nature of the particular polymer (e.g., it does not apply to silicones, but does apply to sheathing materials such as PE and PVC). 
Approach to be taken by BNL

As stated earlier, there has recently been a great deal of work on the effects of dose rate and temperature on the radiation stability of polymers, particularly those used in radiation fields around nuclear reactors and particle accelerators. This work has encompassed property-oriented studies designed to understand what changes in properties occur under different conditions, as an aid to materials development as well as to gain some insight into what chemical reactions may be occurring, and also fundamental studies to try to determine reaction mechanisms. Changes in such properties as hardness, brittleness (measured, for example, by bend strength), tensile strength and elongation at break have been quite thoroughly studied, and it does not seem to be fruitful to try to extend such studies for the program proposed by the NWM division. Also, fundamental mechanistic studies, while they would certainty be useful, would be inappropriate in view of the need to obtain specialized equipment and manpower before they could be started. Rather it seems more relevant and appropriate to engage in a study to develop materials which would undergo relatively little damage under real life conditions of low dose rate and somewhat elevated temperature. In particular, the need for indepth studies on the role of various additives in radiation-degradation behavior has been pointed out by $\mathrm{Cl}$ ough et al. [3], and it is felt that this is the direction which BNL should pursue.

Statement of the Problem

In high-dose-rate $\left(10^{5}-10^{6} \mathrm{rad} / \mathrm{h}\right)$ irradiation of organic polymeric materials of reasonable thickness (e.g., $>1 \mathrm{~mm}$ ), the oxygen gas present in the organic matrix is rapidly consumed in the initial stages of the irradiation. Deleterious reactions of the oxygen throughout the material are insignificant -- dissolved oxygen is consumed after $-10^{5}$ rad total dose [9]. Subsequent reactions involving oxygen gas occur essentially only at the surface since the oxygen will react with radicals there before it can diffuse into the body of the material. Thus, relatively high total doses can be delivered to the material with oxygen reactions occurring only near the surface, and the radiation damage to the bulk material will be the same as that which occurs under inert atmosphere conditions for the same total dose.

On the other hand, at low dose rates (on the order of $10^{2} \mathrm{rad} / \mathrm{h}$ ) oxygen gas will diffuse into the bulk material of most plastics rapidly enough that a steady state will be maintained in which the dissolved oxygen content is the same as in unirradiated material. [It is estimated by Maier and Stolarz [7] that samples irradiated at CERN were oxygen saturated when the dose rate was as high as approximately $\left.10^{4} \mathrm{rad} / \mathrm{h}(30 \mathrm{mgy} / \mathrm{s})\right]$. Thus, any deleterious oxygen reactions which can occur with a given plastic, will occur throughout the bulk material. In practice, with many plastics these oxygen reactions lead to a very large increase in polymer damage for a given total dose, due to the chain reactions which they initiate [10].

Approaches to Solving the Problem

In attempting to prevent this greatly increased damage, one can consider adding chemicals to the plastic which are designed to react with oxygen or its initial reaction products before they cause significant damage. Reaction with oxygen itself (before the 02 can react with polymer radicals) does not seem to 
be practical, since an additive which reacted with oxygen would, by definition, be unstable in air and thus not of much help as a long-term protective material. The other option, however, should be feasible. That is, it should be possible to find additives which can react with the primary oxygen products, $\mathrm{RO}_{2} \cdot$ and $\mathrm{HO}_{2}$. radicals, to compete with, and hopefully prevent (depending on relative reaction rates), the chain propagation reactions of $\mathrm{RO}_{2}$ and $\mathrm{HO}_{2}$ ' with polymer molecules. To the extent that this can be accomplished, the oxygen-related damage occurring at low dose rates would be mitigated or prevented. The radiation damage effects which occur in inert atmosphere presumably would not be reduced.

Adding conventional antioxidants might be a useful approach, but this is not at all clear. Antioxidants are of four main types, all organic -phenolics, amines, phosphites, and thioesters [11]. They have been developed to protect plastics against oxygen reactions initiated by heat and UV, not gamma radiation. Thus, while they would presumably be of some help in irradiated plastics because of their chain terminating reactions, they could also be "part of the problem" so to speak, since, being organic, they would form radicals in a gamma field which could pick up $\mathrm{O}_{2}$ to form the $\mathrm{RO}_{2}$ (peroxy) radicals which lead to the accelerated damage characteristic of low- dose-rate irradiation.

As an alternative to the organic antioxidants, one could consider inorganic reducing agents. These would include, besides certain elements such as carbon, salts with cations in the reduced state, salts with reducing anions, or salts with both. Also salts of certain organic acids might be appropriate, such as sodium gluconate, or sodium oxalate. Some of the cations and anions of interest will now be mentioned.

- Low valence states of the transition elements, e.g., $\mathrm{Fe}^{2+}$, $\mathrm{Mn}^{2+}, \mathrm{Cr}^{2+}, \mathrm{Co}^{2+}$. They might be used as oxides or as salts such as sulfate phosphate, or possibly chloride.

- Certain other multivalent cations such as $\mathrm{As}^{3+}, \mathrm{Sb}^{3+}$ and $\mathrm{Bi}^{3+}$. Arsenic would probabiy not be welcomed by the user community.

- Reducing anions which might be useful are sulfite, selenite, and phosphite.

- The reduced form of a cation could possibly be used as a salt with a reducing anion, providing twice the bang for the buck, so to speak.

Reactivity of Inorganic Ions with $\mathrm{RO}_{2}$.

We must be concerned with both the ability of the reducing ions to react with $\mathrm{RO}_{2} \cdot$ and the rates relative to those for reaction of $\mathrm{RO}_{2}$ - with polymer molecules. That is, for this approach to be useful, the proposed reactions must be thermodynamically feasible, and they must be fast enough to compete with the radical reactions which degrade the polymer. There seems no reason to think that the reaction with reducing ions will not occur in a polymer 
matrix. Reactions of $\mathrm{O}_{2}^{-}$and $\mathrm{HO}_{2}$. with reduced metal ions have been studied in aprotic solvents $[12,13]$, which should be a reasonable stand-in for the organic polymer matrix, the main difference being that of phase (solid vs. liquid) and the consequent very large difference in mobility of large molecules and radicals.

It is not known how mobile inorganic ions and elemental carbon are in solid polymer matrices, and thus how well they could interfere with the reactions of reactive (albeit large) iradicals with polymer molecules. One way of aiding their effectiveness would be to make their concentration high enough that the probability of a reducing ion being "within range" of the active oxygen site of the $\mathrm{RO}_{2}$ e radical was relatively high. A simplistic picture can be imagined where an additive thoroughly mixed into a polymer would have a molecule of additive in a cube of 125 carbon atoms ( $\mathrm{i} . \mathrm{e} ., \mathrm{CH}_{2}$ groups, $\mathrm{CHOH}$ groups, etc.) which was 5 carbons to a side, when the additive concentration was one molecule to 125 carbon atoms. That would mean, for a uniform distribution of additives, that the additive would always be within 2-3 carbon atoms of any radical that formed and would have a reasonably high probability of being able to react with it. Such a concentration is well within the range used for antioxidants, and well below that often used for fillers. In practice, of course, it would presumably not be feasible during formulation to achieve the sort of uniform distribution just described. However, reasonable effectiveness should still be attained.

Suggestions for Experimental Program

The-scope of the initial BNL program must obviously be quite 1 imited. Rather than attempting to develop one or more products to a "ready for market" stage, its object should be to obtain a proof of principle for the general approach being advocated, namely use of inorganic additives to inhibit oxidative polymer degradation at low dose rates. The various steps in carrying out such a program are discussed below:

1. Choice of Polymer

Ideally, several polymers which are or could be used as cable sheathing should be tested in parallel. However, there is probably not sufficient effort available to test more than one at this stage. Using as a criterion for radiation degradation the dose required to reduce elongation at break to $50 \%$ of original, PVC (plasticized) is 20 times more sensitive at low dose rate than at high (or under inert atmosphere) while LDPE is roughly 10 times more sensitive [14]. The PVC tested was somewhat more stable than the LDPE at high dose rate. Thus, either polymer should be a suitable choice for our purposes, and both are standard materials for cable sheathing. HDPE is a few times less stable than LDPE at high dose rate, and some 40 times more sensitive at low dose rate than at high. It presents the sharpest contrast between results at high and low dose rates, but probably should not be considered as the sole material to be used in this study since its radiation resistance at high dose rate is not at all impressive. If only one material is to be used, one might well opt for LDPE, since it appears that some ready-made samples of LDPE containing carbon black may be available from a veindor. 


\section{Choice of Additives}

Carbon black has been considered an anti-oxidant (see p. 351 of Ref. 2), and should be tried in this program, especially if manufacturer's samples are available. It is not clear to the author that salts would be preferable to oxides as a source of reduced cations from a chemical standpoint. If one wishes to use a reducing anion, a salt is obviously required. Choices may have to be made on the basis of availability of a finely divided form of the desired materials, since suitable mixing during formulation will presumably require a very small particle size. Reduced $\mathrm{Fe}, \mathrm{Cr}$ and $\mathrm{Mn}$ compounds should be considered for cations, and sulfites, phosphites, selenites and possibly cyanides and iodides for anions. Reduced cations combined with reducing anions represents a useful approach. Complex inorganic anions such as ferrocyanide; and organic anions such as gluconate, phosphinate, and oxalate may be more appropriate than simple inorqanic anions.

\section{Effect of Additives}

The additives chosen for testing must not change the properties of the polymers to which they are added so as to appreciably decrease their effectiveness as insulating and sheathing materials. At the level of a few per cent, which is suggested for - this program, it is felt that there should be no large effect to either insulating or other required-properties such as flexibility.

\section{Sample Preparation}

The size and shape of samples will depend on the particular tests to be performed. If material containing additives can be obtained from vendors in sheets of suitable thickness, it can be cut into the geometry required for the chosen tests. If it cannot be obtained from a supplier, it will have to be formulated at BNL. In this case, flake or granular polymer (available from suppliers) can be melted, additive stirred in until thoroughly mixed, and the melt poured into molds of the geometry required for samples. It would be preferable to have the additive dispersed as a colloid -- ideally particle size would be near molecular dimensions, but it may not be feasible to achieve this. Although it might save time if polymer having the additive in it could be obtained from a supplier, an advantage of preparing material here is that BNL would have control over exactly what was put into the polymer and at what concentrations. 
5. Experimental Parameters

(a) Specific Tests to be Performed on Irradiated Samples

Changes in a polymer due to irradiation cä be followed by measurement of a number of different properties, including spectroscopic. Probably the most appropriate properties to monitor are those which affect the material's use in its actual application, i.e., mechanical strength and flexibility, as determined by measurement of tensile strength, bending strength, elongation at break, etc. It is thus appropriate, for this program, to measure at least one of these properties. Elongation at break has been used by Clough [8] as a means of ranking polymers in terms of resistance to radiation at low versus high dose rates, and should be the property measured if only one must be chosen. [Presumably tensile strength could be measured at the same time, and the results would constitute a useful addition to the data base.]

\section{(b) Irradiation Conditions}

The biggest problem with any study of the effect of low dose rate is to reach reasonable total doses within the time frame of the study period. For instance, one might like to irradiate material at $100 \mathrm{rad} / \mathrm{h}$ to a total dose of $10^{6} \mathrm{rad}$, a rather modest total dose for real-life situations. This would require a littel more than a year, which could only be fitted into a study period of about $1.1 / 2$ years, when one considers that - several months are required to prepare samples before they can be irradiated and to test them afterward. In order to fit a meaningful experimental program into a period of a year or less, some sort of accelerated testing will be required.

Design and use of accelerated testing as an aid in predicting the extent of radiation degradation in organic polymers are described in Reference 3. There are two principal ways to carry out accelerated tests in the proposed BNL program. One involves irradiating at several different dose rates, from the low rate desired up to one a factor of perhaps 100 higher but still in the dose-rate range in which oxygenation reactions are deleterious. Careful interpretation of trends in test results should indicate how the material being tested will be expected to perform at the low dose rates for higher total doses than can be achieved in the available time. The other way to accelerate testing is to use increased temperature. This is a standard way of carrying out accelerated tests of any kind, but is particularly useful here because of the synergism between the thermal and radiation effects in these deleterious reactions involving oxygen and $\mathrm{RO}_{2}$ radicals. It is recommended that several different elevated temperatures be used in the BNL experiments, since in practice in reactor containment use the polymers used for cable insulation are maintained at elevated temperatures most of the time. 
Thus, for the BNL experiments, both dose-rate and temperature should be varied. Varying dose rate will, of course, permit a range of total doses to be covered. It is suggested that dose rates from $100 \mathrm{rad} / \mathrm{h}$ to $\approx 10^{4} \mathrm{rad} / \mathrm{h}$ be used, and temperatures from ambient up to perhaps 60 or $70^{\circ} \mathrm{C}$. In addition, a set of samples containing the chosen additives and no additive. (as control) should be irradiated at high dose rate $\left(10^{5}\right.$ to $10^{6}$ $\mathrm{rad} / \mathrm{h}$ ) at ambient temperature. The number of different sets of conditions chosen will determine the level of effort needed, and the number of samples which will have to be prepared, as discussed below.

6. Number of Samples

The number of samples which can be used in the test program will be limited by the capabilities of the irradiation facility, e.g., the number of samples which can be simultaneously irradiated at the same dose rate. Let us assume that the properties to be measured are tensile strength and elongation at break and that they can both be measured on the same sample. Ideally several samples should be tested to obtain a "precise" average strength value for each particular set of irradiation conditions for each polymer and additive. It will probably not be feasible to irradiate enough samples simultaneously to have more than two for each additive plus two for the control (which will-: be the polymer without additive) for each temperature used. If, as seems likely, a choice will have to be made between the number of replicate samples to be used and the number of additives (and/or polymers) to be investigated, it is recommended that duplicate samples be tested (rather than a larger number giving higher precision), and several additives and temperatures be used. While it would be useful to investigate more than one polymer, this initial program need not try to cover so much ground, bearing in mind that we are trying merely to establish a "proof of principle" not carrying out a definitive research study.

cc: P. Soo 
References

1. R. L. Clough and K. T. Gillen, "Radiation-Thermal. Degradation of PE and PVC: Mechanism of Synergism and Dose Rate Effects," NUREG/CR-2156, SAND 80-2149, June 1981.

2. R. L. Clough and K. T. Gillen, "Investigation of Cable Deterioration Inside Reactor Containment," Nuci. Technology 59, 344-54, 1982.

3. R. L. Clough, et al., "Accelerated-Aging Tests for Predicting Radiation Degradation of Organic Materials," Nuclear Safety 25, 238-54, 1984.

4. R. Grub, et a1., "Life Performance of an EPR-Insulated Power Cable Exposed in Service Beyond 3 MGy in a High-Level Radiation Area, "Nuclear Instruments and Methods 214, 469-80, 1983.

5. D. K. Das-Gupta, K. Doughty and D. E. Cooper, "Electrical Aging of CrossLinked Polyethylene Cables," Proceedings of Conference, Polymer 85: An International Symposium on Characterization and Analysis of Polymers Me1bourne, Aust., February 11-14, 1985.

6. S. R. Kurtz, "Thermally Stimulated Current Characterization of the Degradation of Poly(vinyl chloride) Cable Material in Radiation and Thermal Environments," NUREG/CR-2962, SAND 82-2164, April 1983.

7. P. Maier and.A. Stolarz, "Long-Term Radiation Effects on Commercial Cable-Insulating Materials Irradiated at CERN," CERN 83-08, August 1983.

8. R. L. Clough, "Radiation Resistant Polymers," SAND 7-1, 1988, to appear as a chapter in Encyclopedia of Polymer Science and Engineering, John Wiley and Sons, Inc.

9. Ibid, p.32.

10. Ibid, pp. 30-39.

11. Rosalind Juran, editor, Modern Plastics Encyclopedia 89, McGraw-Hill, Inc., New York, pp. 143-1 $\overline{44,1988 .}$

12. J. L. Roberts, Jr. and D. T. Sawyer, "Activation of Superoxide Ion by Reactions with Protons, Electrophiles, Secondary Amines, Radicals, and Reduced Metal Ions," Israel J. Chem. 23, 430-438, 1983.

13. H. Sugimoto and D. T. Sawyer, "Iron (II) - Induced Activation of Hydrogen Peroxide to Ferryl Ion (FeO $\left.{ }^{2+}\right)$ and Singlet oxygen $\left(\mathrm{IO}_{2}\right)$ in Acetonitrile: Monoxygenations, Dehydrogenations, and Dioxygenations of Organic Substrates," JACS 106, 4283-5, 1984.

14. R. L. Clough, "Radiation Resistant Polymers," SAND 7-1, (see Ref. 8), pp. 62-63, 1988. 